University of South Florida

DIGITAL COMMONS

Digital Commons @ University of

@ UNIVERSITY OF SOUTH FLORIDA

South Florida

January 2012

\title{
Mapping and Assessing Urban Impervious Areas Using Multiple Endmember Spectral Mixture Analysis: A Case Study in the City of Tampa, Florida
}

Fenqing Weng

University of South Florida, fenqing@mail.usf.edu

Follow this and additional works at: https://digitalcommons.usf.edu/etd

Part of the American Studies Commons, Geographic Information Sciences Commons, and the Other Earth Sciences Commons

\section{Scholar Commons Citation}

Weng, Fenqing, "Mapping and Assessing Urban Impervious Areas Using Multiple Endmember Spectral Mixture Analysis: A Case Study in the City of Tampa, Florida" (2012). USF Tampa Graduate Theses and Dissertations.

https://digitalcommons.usf.edu/etd/4253

This Thesis is brought to you for free and open access by the USF Graduate Theses and Dissertations at Digital Commons @ University of South Florida. It has been accepted for inclusion in USF Tampa Graduate Theses and Dissertations by an authorized administrator of Digital Commons @ University of South Florida. For more information, please contact digitalcommons@usf.edu. 
Mapping and Assessing Urban Impervious Areas Using Multiple Endmember Spectral Mixture Analysis: A Case Study in the City of Tampa, Florida

by

Fenqing Weng

\author{
A thesis submitted in partial fulfillment \\ of the requirements for the degree of \\ Master of Arts \\ Department of Geography, Environment, and Planning \\ College of Arts and Sciences \\ University of South Florida
}

Major Professor: Ruiliang Pu, Ph.D. Jayajit Chakraborty, Ph.D.

Ambe Njoh, Ph.D.

Date of Approval:

May 29, 2012

Keywords: Impervious Surface Area, Land Use and Land Cover, Urban, Multiple Endmember Spectral Mixture Analysis, Remote Sensing

Copyright (@ 2012, Fenqing Weng 


\section{ACKNOWLEDGEMENTS}

I would like to express my sincere gratitude to my committee members, Dr. Jayajit Chakraborty, Dr. Ambe Njoh, and Dr. Ruiliang Pu for their instructive advice and useful suggestions on my thesis. Special thanks to my advisor, Dr. Ruiliang $\mathrm{Pu}$, that he has spent much time reading through each draft and provided me with inspiring advices. I would also like to thank Mr. Bruce Mitchell for his reviewing this thesis and comments at its final stage. 


\section{TABLE OF CONTENTS}

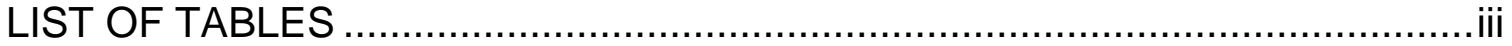

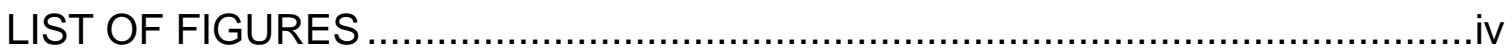

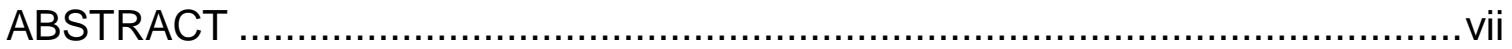

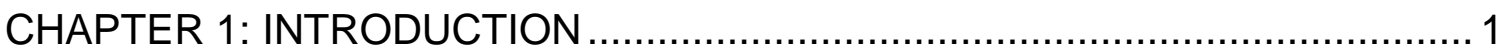

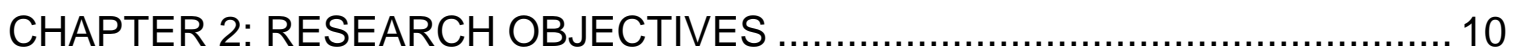

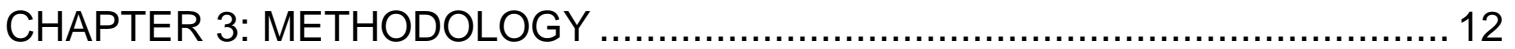

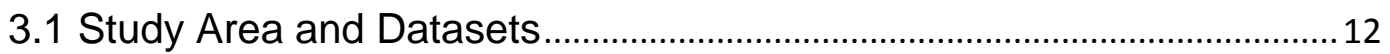

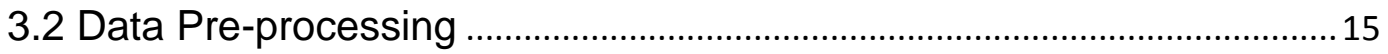

3.3 Methods for Estimating ISA …...................................................................... 16

3.3.1 Spectral mixture analysis and multiple endmember spectral mixture analysis .............................................................. 16

3.3.2 Endmember selection ............................................................. 18

3.3.3 Building the spectral library ........................................................ 21

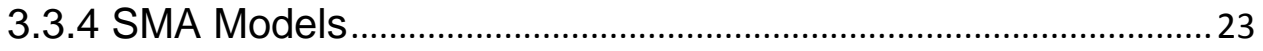

3.3.5 MESMA Models ............................................................................... 24

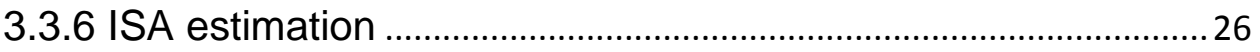

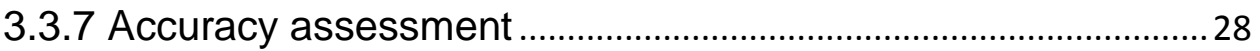

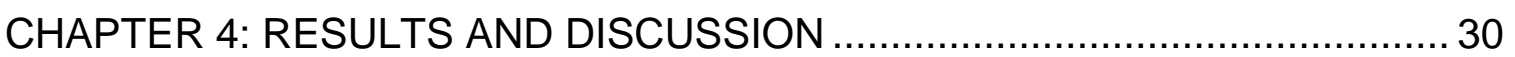

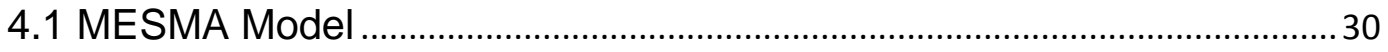

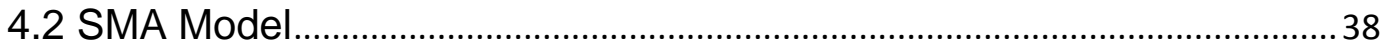

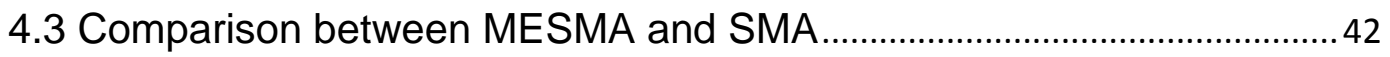

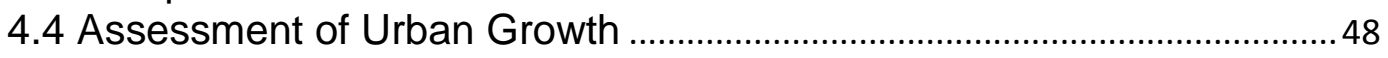

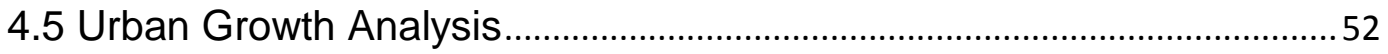

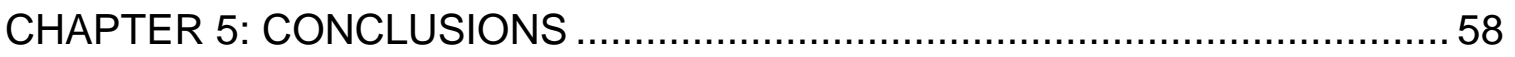

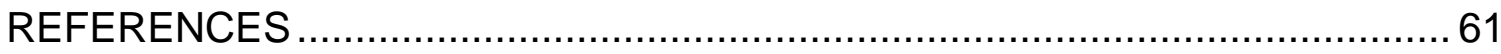

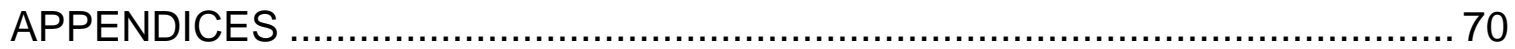


A1. Accuracy assessment

A1.1 Vegetation accuracy assessment (MESMA Vs.

Reference image)

A1.2 Vegetation accuracy assessment (SMA Vs. Reference image)

A1.3 Impervious accuracy assessment (MESMA Vs.

Reference image)

A1.4 Impervious accuracy assessment (SMA Vs. Reference image)

A1.5 Soil accuracy assessment (MESMA Vs. Reference image) .78

A1.6 Soil accuracy assessment (SMA Vs. Reference image)..........80

A2. ISA fraction distribution data

A3. Population and Population density (person/mile ${ }^{2}$ ( 94 census data by tract in the City of Tampa Florida from 1990-2010)

A4. ISA fraction changes ( 94 census data by tract in the City of Tampa Florida from 1990-2010)

A5. ISA fraction ( 94 census data by tract in the City of Tampa Florida from 1990-2010)

A6. Abbreviation

A7. Location of three high percentage of impervious surface places in the study area 


\section{LIST OF TABLES}

Table 1. Allowed models in the MESMA method............................................ 26

Table 2. Number of all combination models for the 1990, 2000, and 2010 reflectance images in the study area.

Table 3. Number of pixels successfully modeled by each level of model complexity for the 1990 TM reflectance image.

Table 4. Number of pixels successfully modeled by each level of model complexity for the 2000 TM reflectance image

Table 5. Number of pixels successfully modeled by each level of model complexity for the 2010 TM reflectance image

Table 6. Comparison of fraction estimation accuracy between MESMA and simple SMA. $(n=36)$.

Table 7. Percentage of ISA (\%ISA) and the percentage of number of pixels with ISA fraction > 0 (\%pixel-based ISA fraction > 0) in 1990, 2000, and 2010 TM images.

Table 8. Population, population density and the percentage of ISA in the 94 tracts from 1990 to 2010 . 


\section{LIST OF FIGURES}

Figure 1. Per-pixel classification and sub-pixel classification........................... 5

Figure 2. V-I-S model illustrating the characteristics of urban landscape. .......... 7

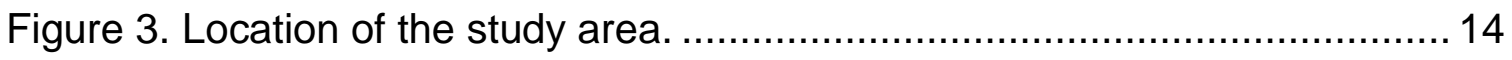

Figure 4. The flowchart of MESMA model. ................................................. 18

Figure 5. Five major endmember reflectance spectra identified by PPI

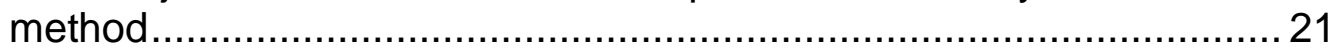

Figure 6. Flowchart of MESMA method developed in the study....................... 26

Figure 7. Flowchart of estimating ISA fraction in the study. ........................... 27

Figure 8. Fraction images generated by MESMA using Landsat- 5 TM

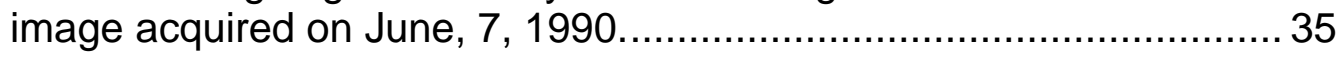

Figure 9. Fraction images generated from MESMA using Landsat-5 TM image acquired on June, 2, 2000. Vegetation fraction map (A); impervious surface fraction map (B); soil fraction map (C); and water (D).

Figure 10. Fraction images generated from MESMA using Landsat-5 TM image acquired on April, 27, 2010. Vegetation fraction map (A); impervious surface fraction map (B); soil fraction map (C); and water (D)..

Figure 11. Fraction images generated from SMA using Landsat-5 TM image acquired on June, 7, 1990. Vegetation fraction map (A); impervious surface fraction map (B); soil fraction map (C); and water (D).

Figure 12. Fraction images generated from SMA using Landsat-5 TM 
image acquired on June, 2, 2000. Vegetation fraction map (A); impervious surface fraction map (B); soil fraction map (C); and water (D).

Figure 13. Fraction images generated from SMA using Landsat-5 TM image acquired on April, 27, 2010. Vegetation fraction map (A); impervious surface fraction map (B); soil fraction map (C); and water (D).

Figure 14. Measured vegetation fraction values from aerial photographs against their modeled values by MESMA (A) and SMA (B) from the 2000 Landsat TM image.

Figure 15. Residual plots with vegetation fraction values modeled by MESMA (A) and SMA (B) from the 2000 Landsat TM image. 45

Figure 16. Measured impervious fraction values from aerial photographs against their modeled values by MESMA (A) and SMA (B) from the 2000 Landsat TM image.

Figure 17. Residual plots with impervious fraction values modeled by $\operatorname{MESMA}(\mathrm{A})$ and SMA (B) from the 2000 Landsat TM image 46

Figure 18. Measured soil fraction values from aerial photographs against their modeled values by MESMA (A) and SMA (B) from the 2000 Landsat TM image.

Figure 19. Residual plots with soil fraction values modeled by MESMA (A) and SMA (B) from the 2000 Landsat TM image.

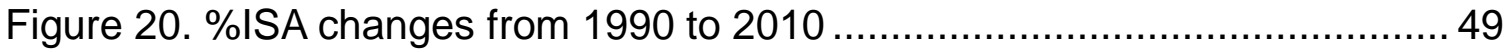

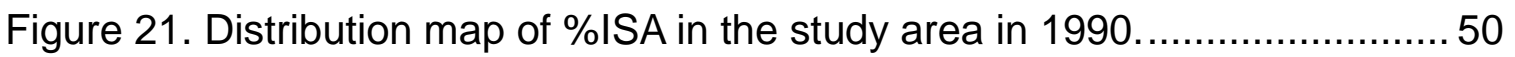

Figure 22. Distribution map of \%ISA in the study area in $2000 \ldots \ldots \ldots \ldots \ldots \ldots \ldots \ldots . . .51$

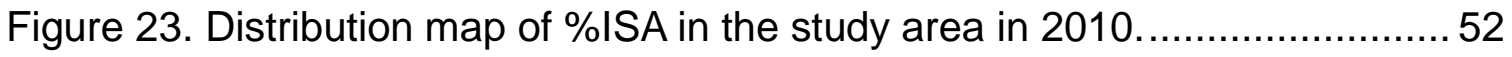

Figure 24. Ninety-four tracts in the City of Tampa covered by the study area..... 53

Figure 25. Population changes in the 94 tracts from 1990 to $2010 \ldots \ldots \ldots \ldots \ldots \ldots . . . .56$

Figure 26. Population density changes in the 94 tracts from 1990 to 2010 ....... 56 
Figure 27. \%ISA changes in the 94 tracts from 1990 to 2010.

Figure 28. \%ISA changes (per-pixel based) in the 94 tracts from 1990 to

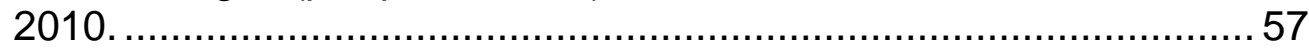

Figure A 1. \%ISA of 94 tracts covered by the study area in the City of Tampa in 1990.

Figure A 2. \%ISA of 94 tracts covered by the study area in the City of Tampa in 2000.

Figure A 3. \%ISA of 94 tracts covered by the study area in the City of Tampa in 2010 .

Figure A 4. Location of University Square (A), Downtown (B), and International Airport (C). 


\section{ABSTRACT}

The advance in remote sensing technology helps people more easily assess urban growth. In this study, the utility of multiple endmember spectral mixture analysis (MESMA) is examined in a sub-pixel analysis of Landsat Thematic Mapper (TM) imagery to map urban physical components in Tampa, FL. The three physical components of urban land cover (LC): impervious surface, vegetation and soil, were compared using the proposed MESMA with a traditional spectral mixture analysis (SMA). MESMA decomposes each pixel to address the heterogeneity of urban LC characteristic by allowing the number and types of endmembers to vary on a per pixel basis. This study generated 642 spectral mixture models of 2-, 3-, and 4-endmembers for each pixel to estimate the fractions of impervious surface, vegetation, soil, and shade in the study area with a constraint of lowest root mean square error (RMSE). A comparative analysis of the impervious surface areas (ISA) mapped with MESMA and SMA demonstrated that MESMA produced more accurate results of mapping urban physical components than those by SMA. With the multiyear Landsat TM data, we quantified sub-pixel \%ISA and the \%ISA changes to assess urban growth in the City of Tampa, Florida during the past twenty years. The experimental results 
demonstrate that the MESMA approach is effective in mapping and monitoring urban land use/land cover changes using moderate-resolution multispectral imagery at a sub-pixel level. 


\section{CHAPTER 1: INTRODUCTION}

Urbanization, a global phenomenon mainly driven by population growth and large scale rural to urban migration, is defined as outward expansion of built-up urban areas to the periphery, or the spreading of city suburbs (Black and Henderson, 1999; Herold et al., 2003; Martinuzzi et al., 2007; Burgess, 2008). Urban sprawl and expansion of suburbs results in a rapid transformation of agricultural and forested lands to urban land uses, such as residential, industrial, and commercial areas. There is no universally accepted definition to describe urbanized areas. The standards distinguishing urbanized areas from suburban areas and rural areas vary from country to country. Referring to the United States Census Bureau, an urbanized area is defined as "one or more places ('central place') and the adjacent densely settled surrounding territory ('urban fringe') that together have a minimum of 50,000 persons" (U.S. Census Bureau, 1995). Therefore, in this thesis, the urbanization process deals with the expansion of population and the transformation of land use and land cover (LULC) categories, although it also involves changes in the economic, social, and political structures of an area. This transformation of the land is often accompanied by a series of environmental and socio-economic issues, such as damage to ecological systems, regional climate alteration, over-consumption of fresh-water and energy resources, and effects to the population structure (Green et al., 1994; Kalnay and 
Cai, 2003; Xiao et al., 2006). Therefore, not all the urban growth is beneficial to social and environmental systems. How to detect and understand changes in urban areas is very significant for fostering environmental and human sustainability of cities, and also for predicting growth pattern of cities around the world, so that their present and future resource needs can be met (Weng and Quattrochi, 2007). In addition, by predicting urban growth, urban planners and policymakers can better understand why this geographic phenomenon happens, and plans for and provide the infrastructure and services required by the expanding number of new urban residents. To reduce the negative environmental impacts due to the rapid urbanization, it is necessary to quantify and categorize urban growth; especially the transformation of LULC types, in a meaningful way for land use decision-makers.

Impervious surface area (ISA) is not only a major indicator for assessing the rate of urban growth, but also a key factor in evaluating the intensity of urbanization because of its impact on habitat quality (Stankowski and Trenton, 1972; Turner and Meyer, 1991; Arnold and Gibbons, 1996; Madhavan et al., 2001; Alberti, 2005; Jat et al., 2008; Pickett et al., 2008). Impervious surfaces are mainly artificial features that do not allow water to pass through, such as parking lots, roads, sidewalks, and so on. Urban areas are composed of various materials, such as impervious surfaces, soils, vegetation (grass/turf, shrub and tree canopy), and water. In urban areas, the percentage of impervious cover varies because of different land uses. Therefore, characterization and quantification of the spatial pattern of impervious surfaces is significant when assessing urban LULC changes 
and urban growth (Daniel et al., 2002; Jarnagin, 2003; Wilson et al., 2003; Yang et al., 2003; Yuan and Bauer, 2007; Weng and Lu, 2008; Riva-Murray et al., 2010).

With the advent of remote sensing, people can easily get information regarding the structural attributes of cities with a synoptic perspective in an efficient and economical way. Remote sensing can provide a way to understand global and regional environmental changes and human-environment interactions by mapping and monitoring LULC. Much research has been done to study urban LULC aimed at monitoring urban expansion and description of why urban sprawl has taken place in particular urban areas using remote sensing data (Seto et al., 2002; Pauleit et al., 2003; Seto and Liu, 2003). This data helps researchers investigate various urban phenomena in detail, extending their understanding beyond the rather limited knowledge of urban size and shape provided by traditional paper map sources.

Remote sensing techniques more effectively monitor LULC changes by providing multi-resolution and multi-temporal information in a timely and cost-effective manner (Treitz et al., 1992; Chen et al., 2000; Weng, 2002; Xian and Crane, 2005). Many studies have demonstrated that remote sensing data are capable of estimating and mapping impervious surfaces (Ridd, 1995; Phinn et al., 2002; Small and Lu, 2006; Powell et al., 2007, Franke et al., 2009). It appears that most urban impervious land cover can be modeled using traditional classifications, which assume that the pixel size of remotely sensed data is smaller than the size of urban individual features, or that most pixels of the imagery only contain one type of urban land cover. Images with finer spatial resolution contain much more 
spectral information than those with coarser resolution. This additional spectral information can be used to extract greater detail by using endmembers. However, most urban land surfaces are spatially and spectrally heterogeneous at some scale because of the complex mixture of land cover types in urban environments (Ward et al., 2000; Small, 2002; Phinn et al., 2010; Huang et al., 2011). Using low spatial resolution images to unmix different endmembers in each pixel may be problematic due to increased spectral variances among materials and shadows (Barnsley and Barr, 1996; Dare, 2005). Per-pixel classifiers inaccurately estimate urban surface materials when using moderate to coarse spatial resolution satellite data (spatial resolution $>10$ meters), such as Landsat and SPOT imagery. This limits their capability of detecting important spectral and spatial variations in urban features (Lu and Weng, 2004; Xian and Crane, 2005) (Figure 1). Firstly, in different urban areas, the physical composition and spectral signature of land-cover classes are diverse (Ridd, 1995; Small, 2005; Song, 2005; Powell et al., 2007). Secondly, for moderate resolution remote sensing data, the percentage of mixed pixels in the imagery is very high due to complexity and heterogeneity of urban surface materials (Herold et al., 2004; Wu, 2004; Small, 2005). 


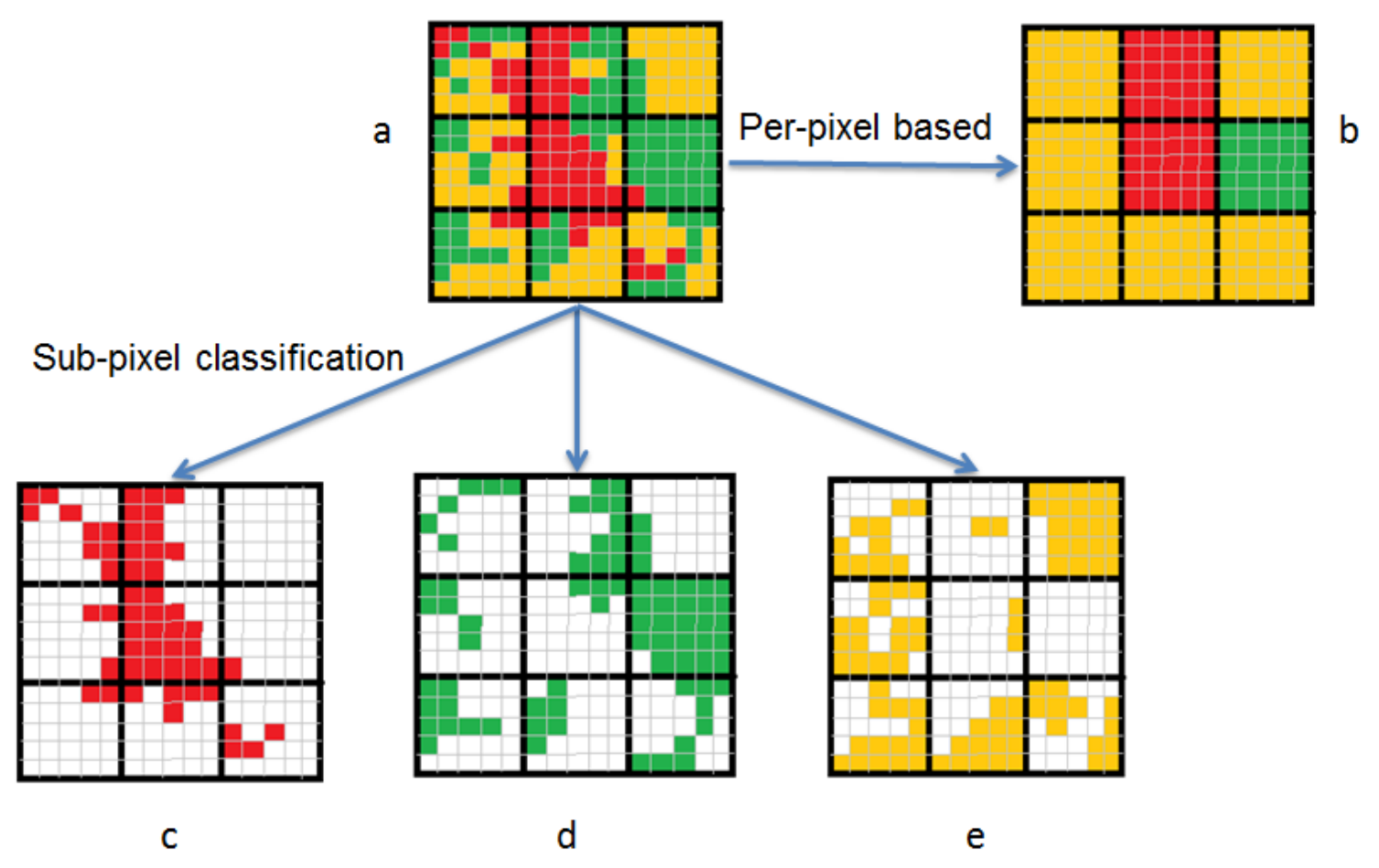

Figure 1. Per-pixel classification and sub-pixel classification. Map with high percentage of mixed pixels (there are 9 pixels in the image) (a), map by per-pixel based classification (b), fraction map of Land cover type I by sub-pixel classification (c), fraction map of Land cover type II by sub-pixel classification (d), and fraction map of Land cover type III by sub-pixel classification (e).

Ridd (1995) proposed a model for mapping the urban environment in terms of simple physical components: Vegetation, Impervious surface, Soil (V-I-S model) (Figure 2). Urban areas may be divided into these three parts, based on the percentage of the spatial unit occupied by vegetation, soil, and impervious surface, if water surfaces are ignored (or masked out). A spectral mixture analysis (SMA) technique has been developed to unmix images at sub-pixel scale to estimate the fraction abundance of these three physical components within a pixel. SMA assumes that ideally the spectral signal of a pixel can be modeled by a combination of spectra contributed by some endmembers, or components, or LULC types, or pure spectrally individual features. Mapping the urban environment 
based on spectral mixture analysis (SMA) and V-I-S model for estimating ISA fractions has been conducted in different urban areas in the world (Rogan and Chen, 2003; Lee and Lathrop, 2005; Powell et al., 2007; Pu et al., 2008; Yang et al. , 2010). For example, Ji and Jensen (1999) demonstrated that sub-pixel analysis could effectively quantify urban imperviousness using Landsat Thematic Mapper (TM) imagery. Wu (2004) applied normalized spectral mixture analysis (NSMA) method to model heterogeneous urban composition with a constraint. Lu and Weng (2009) suggested that linear spectral mixture analysis (LSMA) and the V-I-S model could be an effective method to characterize urban environments, although spectral, spatial, and temporal variability of this model should be examined in the process of application. Powell et al. (2007) used multiple endmember spectral mixture analysis (MESMA) to effectively address the problems of spatial and spectral variability of different materials using moderate spatial resolution image for the urban area of Manaus, Brazil. Yang et al. (2010) also reported a pre-screened and normalized multiple endmember spectral mixture analysis (PNMESMA), which integrated normalized spectral mixture analysis (NSMA) and MESMA, for estimating ISA fraction, and demonstrated that PNMESMA performed better in estimating ISA fraction than other SMA- or NSMAbased methods in a case study in the Lake Kasumigaura Basin, Japan. 


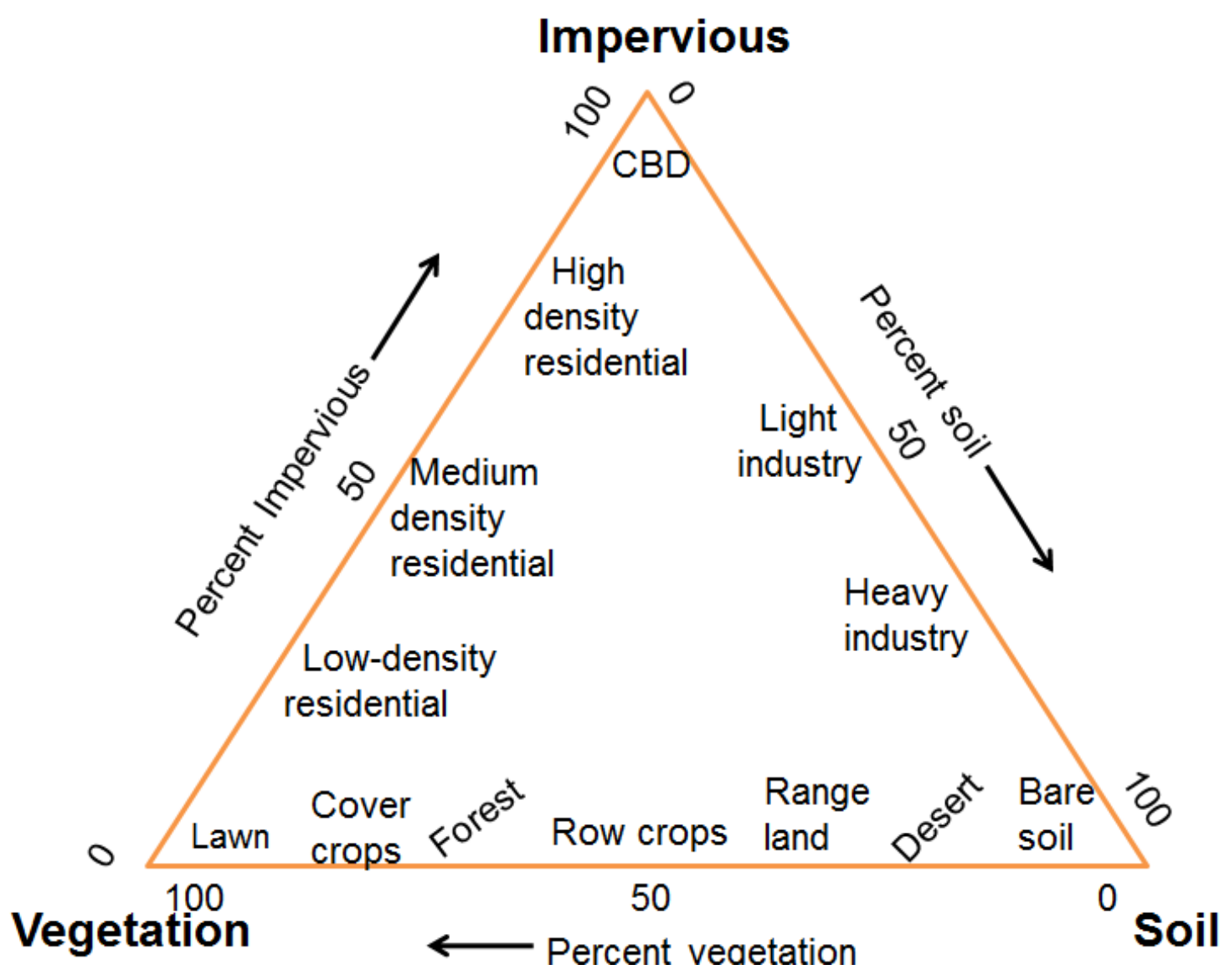

Figure 2 . V-I-S model illustrating the characteristics of urban landscape. (From Ridd, M. K., 1995)

Although simple SMA could provide a physically meaningful and plausible measure of fraction abundance for different materials on the ground in an urban environment, it cannot account for the subtle spectral variations nor can it account for differences in physical composition of materials represented in the pixels (Small, 2001; Rashed et al., 2001; Weng et al., 2004; Pu and Gong, 2011) and it is also limited by a maximum number of 6-7 endmembers within mixed pixels (Li and Mustard, 2003; Hung, 2002). Because of these issues, traditional SMA cannot account for the complexity and spectral heterogeneity of urban materials. However, the MESMA technique can overcome limitations of the 
traditional SMA by allowing the number and type of endmembers to vary for each pixel in the image. MESMA evaluates each possible model (two-, three-, or four-endmember model) based on the criteria of fraction values of each endmember, root mean square error (RMSE), and shadow fraction. Therefore, in this study, MESMA is used to unmix images with every possible combination of two, three, and four endmembers applied to every pixel in terms of the fraction abundance of the four components: vegetation, impervious surface, soil, and photometric shade (Ridd, 1995; Adams and Gillespie, 2006; Powell et al., 2007). It has advantages in modeling all the ground surface materials, comparing with the traditional SMA which assumes each endmember has a constant spectral signature and therefore uses a fixed number of endmembers to map entire areas, rather than considering the variety of number and type of land cover components in urban areas (Ridd, 1995; Song, 2005; Yang et al., 2010). This study monitors and detects land cover changes in the past two decades at the sub-pixel level, using the percentage change of impervious surface to assess the degree of urban growth, in terms of LULC changes in the City of Tampa, FL.

Many researchers have used remote sensing derived data to explain the relationships between impervious surfaces and population density. An early paper by Stankowski and Trenton (1972) suggested that there could bet a close relationship between the \%ISA and population density in an area, and that the \%ISA could be estimated by the population density. Lu et al. (2006) built a procedure of urban land-use classification based on the combination of impervious surface and population density. They also found a strong relationship 
between impervious surface and population density $\left(R^{2}=0.782\right)$. Therefore, census data can be used to explain and understand the phenomenon of urban ISA change. 


\section{CHAPTER 2: RESEARCH OBJECTIVES}

Although some studies have shown that MESMA has the capability of mapping the physical components of land cover, most of them have applied the MESMA approach in a variety of environments for vegetation mapping (e.g., Roberts et al., 1998a, 2003; Li et al., 2005; Rosso et al., 2005) using hyperspectral data and only a few (e.g., Power et al., 2007; Yang et al., 2010) have used it in an urban environment with moderate spatial resolution imagery. Because of the advantages of MESMA over SMA in mapping urban land cover at a sub-pixel level, it has great potential for use in studies which attempt to understand urban growth and LULC changes by mapping the urban environment using moderate spatial resolution satellite imagery. This study will focus on a comparative analysis between MESMA and SMA and their capability of mapping impervious surface area (ISA) using moderate spatial resolution Landsat TM imagery in the urban environment. The main goal of this study is to evaluate the performance of MESMA in mapping the physical components of urban land cover, focusing on changes in impervious surface in the City of Tampa, Florida for the years 1990,2000 , and 2010 , . By assessing changes to \%ISA, usually from natural, vegetated landscape into impervious surface, the spatial pattern and intensity of urbanization can be measured and assessed.

Specifically, four key research questions are addressed in this thesis: 
1. Does MESMA have the capability to estimate ground component fractions?

2. Does MESMA perform better in mapping physical components, compared to the traditional SMA?

3. Can urban growth in Tampa, Florida be quantified by assessing urban LULC changes, especially \%ISA change, but also including spatial pattern, density, and the rate of land cover changes?

4. Does population increase have an influence on \%ISA changes thus on urban growth in the City of Tampa, Florida? 


\section{CHAPTER 3: METHODOLOGY}

To answer the four key research questions, MESMA and SMA are respectively performed to assess urban LULC changes in the City of Tampa, Florida during the past two decades. All experimental procedures were implemented in ENVI 4.8, ArcGIS 10, SPSS 20, and VIPER Tools, a plug-in for the ENVI software package.

\subsection{Study Area and Datasets}

The region of the City of Tampa, Florida was chosen as the study area because of its rapid urbanization during the last century, particularly since World

War II (Figure 3). The City of Tampa, part of the Tampa Bay Area, is located on the west coast of Florida, with elevations ranging from sea level to as high as 48 feet (about 15 meters). Its flat topography and geographic location along the coast provide numerous possibilities of urban expansion. Tampa has a humid subtropical climate, with a rainy season extending from June to September. The population of Tampa City was approximately 300,000 in 2010 , and had an average increase rate of $0.81 \% / y e a r$ during the $1990-2010$ period (US Census Bureau, 2010).

The City of Tampa has been undergoing development since settlement in the 1800s (Xian and Crane, 2005). The recent pattern of urban LULC can be characterized as "suburban sprawl", as impervious surfaces replace natural land 
cover in peripheral areas, especially near The University of South Florida, and New Tampa. The dominant landscapes in the City of Tampa are residential and commercial areas, forest, and water. Increasing population and the development of New Tampa have caused rapid changes in the land cover structure during the past twenty years. Since the 1990s, artificial land cover, such as residential areas, commercial areas, and roads has increased quickly, replacing forests and croplands. This pattern of development changes the degree of imperviousness in the area. Therefore, ISA was chosen as the key indicator of urbanization in this study. 


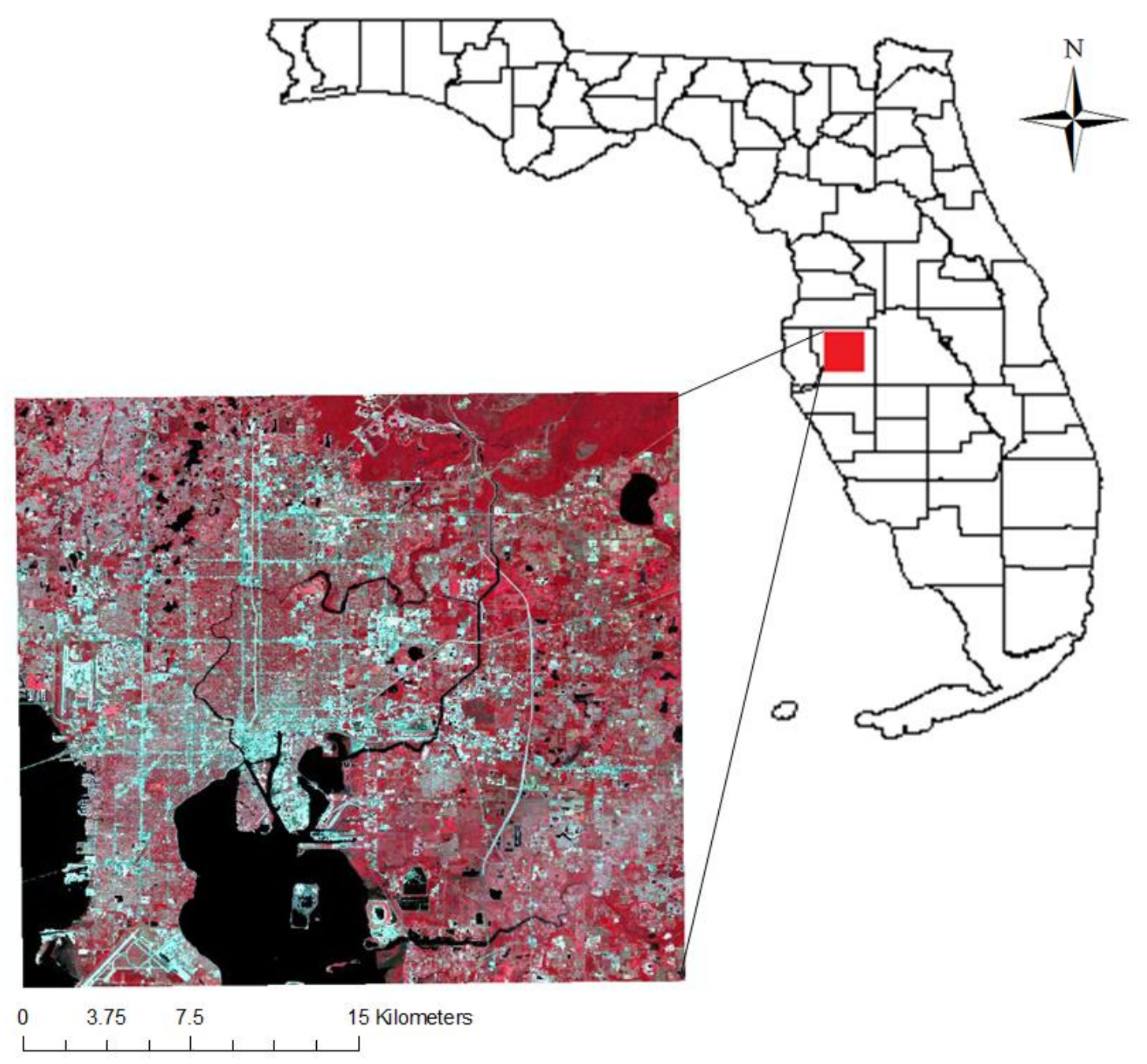

Figure 3. Location of the study area. The City of Tampa, a part of Hillsborough Country, is located on the west coast of Florida. The study area is presented in a Landsat-5 TM composite image (Bands 4, 3, 2 vs, R, G, B). The Landsat TM image was acquired on April 27, 2010.

Remotely sensed data provide a means for monitoring changes in urban land cover over time. Three scenes of the study area that were cloud-free or had low amounts of clouding were selected from Landsat-5 TM images (Path17/Row41), acquired on June, 7, 1990, June, 2, 2000, and April 27, 2010 . In order to validate the spectral unmixing results, references images comprising of 1-m spatial resolution DOQQ aerial photographs, acquired on March, 3, 2001, were selected 
as reference images to compare with the TM image acquired in 2000.

Additionally, 1990, 2000, and 2010 US Census data at the tract level and in shapefile format were collected and used to explore the relationship between urban growth and population change in the study area during the past two decades. The 1990 census data was normalized to 2000 tract boundaries allowing direct comparison between these two dates. However, because of changes in the 2000 and 2010 tract boundaries inconsistencies in the data required elimination of some of the tracts from the population analysis. In 2010 there are 143 tracts in the City of Tampa, but only 95 tracts covered by the study area could be used (see Appendix A3).

\subsection{Data Pre-processing}

Three scenes of Landsat-5 TM images were used in this study. A $900-\mathrm{km}^{2}$ region was chosen as the case study area and subset from the Landsat images. For all images, six bands (TM bands $1-5$, and 7 ) were used, and the spatial resolution of all images is $30 \mathrm{~m}$. The scenes were then geo-referenced to $7.5 \mathrm{~min}$ United States Geological Survey (USGS) topographic maps. Atmospheric correction were performed using the Fast Line-of-Sight Atmospheric Analysis of Spectral Hypercubes (FLAASH) software package in ENVI 4.8. Although water is an important component of the urban environment, it was not used as a land cover type for evaluating MEMSA and SMA, therefore water bodies in the scene were masked out by setting a threshold value in Band 7 . 


\subsection{Methods for Estimating ISA}

\subsubsection{Spectral mixture analysis and multiple endmember spectral mixture analysis}

Conventional spectral mixture analysis (SMA), a linear spectral mixture analysis, is a technique for estimating the reflectance - $R$ measured at pixel level $i$ and can be modeled as the linear sum of $n$ endmembers, or spectrally 'pure' materials, weighted by fraction $f_{k i}$ of each endmember within the field of view of pixel $i$. For a given wavelength, $\lambda$, the mixing equation for spectral images is given in equation (Adams et al., 1993):

$R_{\mathrm{i} \lambda}=\sum_{k=1}^{n} f_{k i} * R_{\mathrm{k} \lambda}+e_{i \lambda}$

while $R_{\mathrm{i} \lambda}$ is the measured value of reflectance at pixel $i ; f_{k i}$ is the fraction of endmember $k$ within pixel $i ; e_{i \lambda}$ is the residual error at pixel $i$ and represents the difference between observed and modeled spectra. The modeled fractions should be constrained by the following:

$\sum_{k=1}^{n} f_{k i}=1$, and $f_{k i} \geq 0$

In order to calculate the value of $f_{k i}$, a system of $m$ or $m+1$ equations (corresponding $m$ bands or wavelengths) is required, and the number of endmembers, $n$, should be less than the number of bands, $m$. In this study, for Landsat-5 TM image, the number of bands is 6 , therefore, the number of endmembers cannot exceed 6.

SMA assumes that all pixels in the image are modeled by a fixed number of representative endmembers. SMA is based on the following assumptions in estimating the composition of each image pixel: 
- Each pixel not only contains information about the proportion of each component but also spectrum of each component;

- Brightness of an image pixel is a linear sum of $n$ pure endmembers;

- Spectral proportions of the endmembers are equal to proportions of the area covered by endmembers on the ground;

- Most of the pixels in the image are comprised by some measurable amount of the endmembers.

SMA is limited in that it cannot account for the absence of one or more endmembers of some pixels or spectral variation within pure materials. In the multiple endmember spectral mixture analysis (MESMA), the root-mean squared error (RMSE) of the residuals for each pixel across all bands was measured to evaluate the accuracy of every model instead of the residuals in the SMA model (Roberts et al., 1998a). The RMSE for pixel $i$ can be described by the following (Adams et al., 1993, Roberts et al., 1998a):

$\operatorname{RMSE}_{\mathrm{i}}=\left(\sum_{\lambda=1}^{m}\left(e_{i \lambda}\right)^{2} / m\right)^{1 / 2}$

where $e_{i \lambda}$ is the residual error of band $\lambda$ at pixel $i$, and $m$ is the total number of bands ( 6 for Landsat- 5 TM image). MESMA has an advantage over conventional SMA when decomposing images since it allows the number and type of endmembers to vary pixel by pixel (Roberts et al., 1998a). This technique uses whichever model has the smallest RMSE, assuring that the selected endmember is representative of that class. Based on the criteria of RMSE, fraction values, and residual threshold, a series of candidate models are tested to produce fraction images with the lowest error (Roberts et al., 1998b). From Figure 4, in order to 
select appropriate endmembers for constructing a spectral library in MESMA, the Purity Pixel Index (PPI) and manual selection were used. (2) The MESMA model (based on all combinations of final library endmembers) is applied to every pixel in the image, based on a set of criteria. (3) If all the criteria are satisfied, the 'best-fit' model is selected for each pixel; if not, the remaining pixels are unclassified.

Fraction cover derived from MESMA is produced.

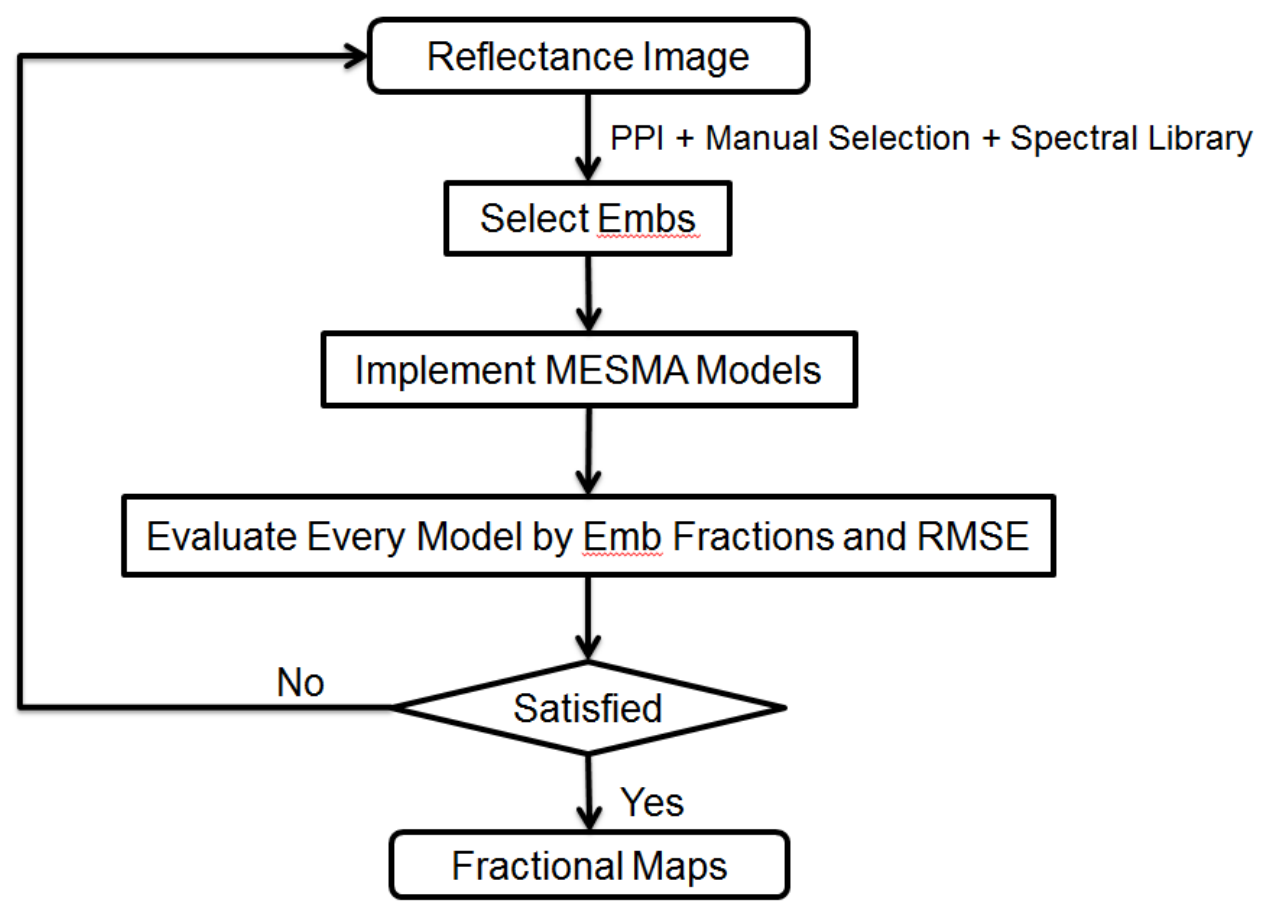

Figure 4. Flowchart of the MESMA model.

\subsubsection{Endmember selection}

The selection of appropriate endmembers is very important for SMA because of the endmembers' effects on its spectral unmixed result (Tompkins et al., 1998; Brandt et al., 2005). For standard SMA, the key to endmember selection 
is identification of extremely pure spectrum to represent each feature (i.e., endmember) on the ground (Adams et al., 1995; Powell et al., 2007). For MESMA, successful endmember selection relies on identifying a series of spectra that represent the spectral variations for each material in the scene (Roberts et al., 1998b; Okin et al., 2001). There are two sources of pure spectral signatures: (1) image endmember, selected from representative pixels from satellite sensor images (Elmore et al., 2000; Small, 2001; Song, 2005), and (2) reference endmember, collected from reference images, and measured in the laboratory or on the ground with a spectroradiometer (Smith et al., 1990; Adams et al., 1995; Roberts et al., 1998). In general, reference endmembers are of higher purity than image endmembers. Thus reference endmember spectra can be the optimal ones as the candidate endmembers for each group of interest, but they may not be appropriate for those interests within the image (Ballantine et al., 2005). This is explained by the following reasons.(1) Reference endmembers may cause uncertainty arising from radiometric calibration and geo-registration, which could affect evaluation of the performance of SMA or MESMA, while image endmembers contains the same errors caused by atmospheric effects (Song and Woodcock, 2003; Chen and Vierling, 2005). (2) Reference endmembers measured in the field or laboratory cannot provide spectra of all the ground components, but image endmember could cover all potential types of ground surface materials (e.g., all vegetation types in the City of Tampa, Florida). In this study, all representative endmembers for SMA were selected from the images.

There are a variety of methods for extracting pure pixels from the image. In 
this study, the endmembers were selected from images based on the PPI method and manual selection. Appropriate endmembers were effectively found by the PPI method, which identifies extreme pixels, or representative pure signatures, in data by searching for a set of vertices on a convex hull (Boardman et al., 1995; Chaudhry et al., 2006). Image endmembers can be collected by linking the PPI image with the image used to identify classes, avoiding the choice of edge pixels. In this study, the endmember collection was generalized into five groups: vegetation A (tree), vegetation B (shrubs and grasses), high albedo impervious surface (e.g. asphalt), low albedo impervious surface (e.g. concrete), and soil (Figure 5). In the study area, vegetation A pixels were mainly distributed in so-called urban forests, and vegetation B pixels were mainly distributed in residential areas and parks, etc. High albedo and low albedo pixels were found in the downtown, roads, and roofs. The soil pixels were found in low frequently bare lands. 


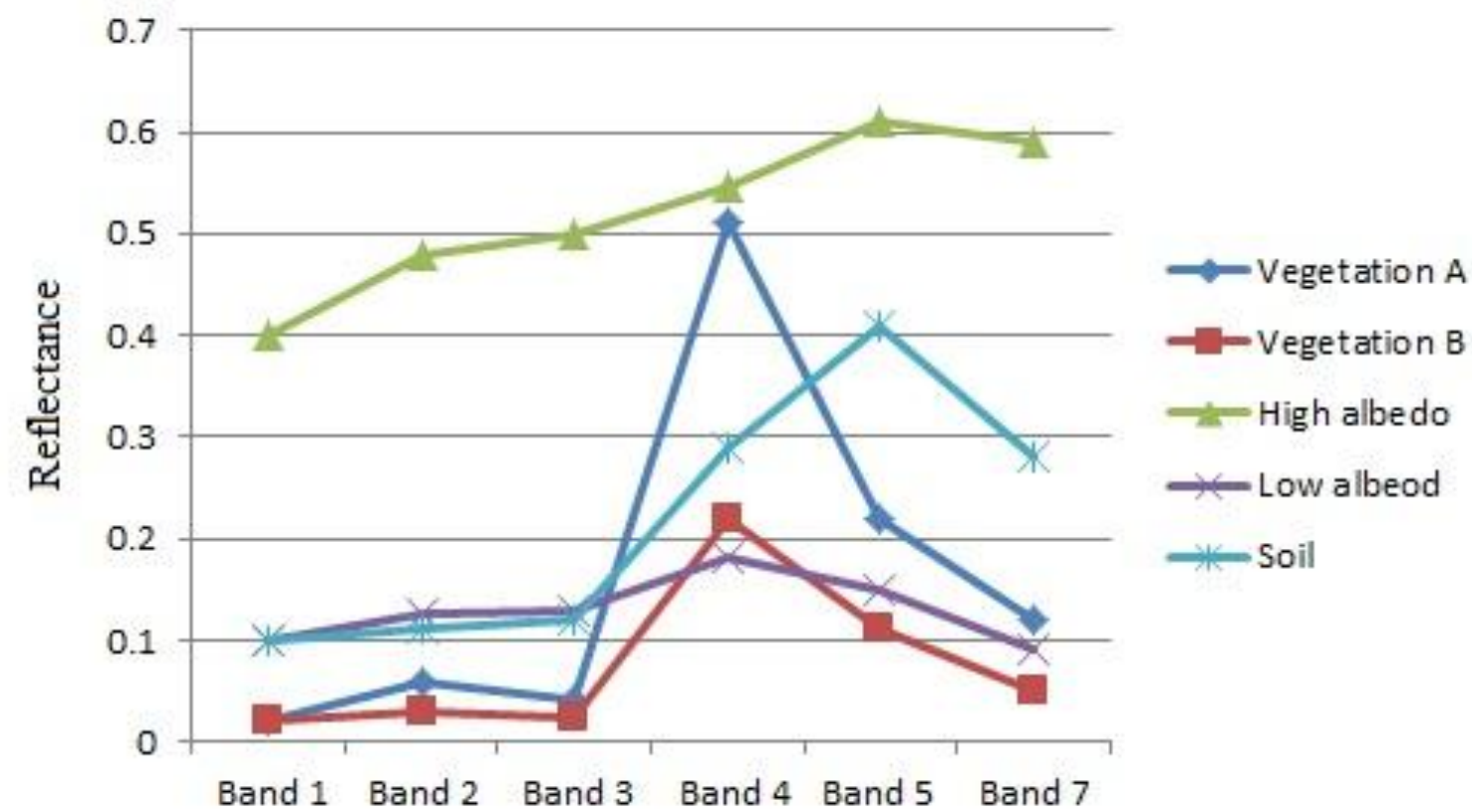

\section{Landsat- $5 \mathrm{TM}$ band}

Figure 5. Five major endmember reflectance spectra identified by PPI method

\subsubsection{Building the spectral library}

Identification of appropriate endmembers and their corresponding spectral signatures is of great importance for SMA (Sabol, 1992; Maas, 2000; Peddle and Smith, 2005; Cho et al., 2009). For MESMA, the spectral library should contain enough spectra for each class of materials to represent spectral variation of materials on the ground; however, the number of endmembers in the library cannot be too great, because the total number of endmembers in the potential models is inversely proportional to the computational efficiency and accuracy (Powell et al., 2007). Many studies show that 4-endmember models don't necessarily guarantee better performance than 3-endmember models (Fitzgerald et al., 2005; Powell et al., 2007). In order to construct a comprehensive and 
representative spectral endmember library, three steps were used in this study following a procedure developed by Dennison and Roberts (2003). (1) All possible endmembers were collected to augment the number of spectra in the library. (2) A series of representative spectra for each class of materials were selected to reduce computation errors and complexity by eliminating spectra from other material classes. (3) Endmembers that represent materials on the ground in the study area were selected for use with MESMA.

Potential image endmember pixels were identified by PPI and manual selection, resulting in five different types of candidate image endmembers, including: Vegetation A, Vegetation B, High albedo, Low albedo, and Soil. In order to construct a final endmember spectral library, the collection of endmember spectra were reduced using the product Viper Tools user manual, by Dennison and Roberts (2003). Firstly, the procedure selected representative endmembers for each material class from the library to eliminate those spectra that might be confused with other material class, based on the criteria of the value of RMSE $(<$ $2.5 \%)$. Secondly, the most representative endmembers for each material class were identified using the Endmember Average RMSE (EAR), Minimum Average Spectral Angle (MASA), In_CoB (Count based Endmember selection), and Out_CoB (Roberts, 2003). EAR is the average RMSE of a spectrum when it models all other endmembers within a material class. For each class, spectrum with the lowest EAR is considered as a possible representative endmember for the spectra within that class. The MASA is used to calculate the spectral angle between a spectrum and all other spectra within that class. The lowest MASA 
value of a candidate spectrum is usually considered as the more representative of the endmember of that class. CoB selects optimal endmembers by calculating the greatest number of spectra that candidate spectrum can be modeled within or out of their class. In this study, the final spectral library for MESMA consisted of optimal endmembers of the five classes: Vegetation A, Vegetation B, High albedo, Low albedo, and soil. Later, Vegetation A and Vegetation B were combined into a single vegetation class. High albedo and Low albedo were also combined into a single impervious surface class.

\subsubsection{SMA Models}

Spectral mixture models for simple SMA with V-I-S model could model land cover using three major physical components (vegetation, impervious surface, soil) in urban environments at the sub-pixel level. Three representative endmembers of their material classes, optimal endmembers, were used in this study. Traditional SMA model assume that the spectrum of an endmember is constant, without considering shade (i.e., shaded areas and shadow). Although shade is not a physical component, it is present in the images. For example, in highly urbanized downtown areas, tall buildings can create extensive shadows depending on solar angle and sensor position. Shadows are also a problem in forested areas because of the density of trees. Therefore, shade is a very important endmember in spectra mixture models.

Candidate endmembers by PPI and manual selection were used for SMA models. There were five different classes used in this study. For urban environments, the procedure of simple SMA was based on the following 
assumptions: (1) tree, shrubs, and grass may coexist in a pixel; (2) High albedo and low albedo may coexist in a pixel, while they are spectrally distinct; (3) the soil category is not divided into different classes because there are so few areas with a high percentage of soil. The final vegetation fraction images by SMA were calculated as the sum of vegetation A and vegetation B fractions. The final impervious surface fraction images by SMA were also calculated as the sum of High albedo impervious surface and Low albedo impervious surface fractions.

\subsubsection{MESMA Models}

The final spectral library for MESMA was used to map V-I-S fractions in the study area. MESMA differs from the traditional SMA by allowing the combination of an unfixed number of endmembers. In this study, two-, three-, four-endmember models were applied to determine the best model for each pixel by setting some constraints, including: fractions, RMSE or residuals. Shadows are not physical components, but they are spectral components that should be considered when estimating the physical proportions (Peddle et al., 1999; Fitzgerald et al., 2005; Garci'a-haro et al., 2005). Photometric shade is defined as a spectrum whose reflectance value is equal to zero for each band (Adam and Smith, 1986).

Shadows can partly account for the relationship between the endmembers that represent their class in the library collection and the endmembers that represent the materials of their class on the ground (Eddy, 2009). Therefore, the image is modeled by two endmembers, three endmembers, and four endmembers (i.e., one spectrum + photometric shade; two spectra + photometric shade; three spectra + photometric shade) for each pixel with a set of criteria (Table 1). Two 
endmember models consisted of any material class spectrum and shade, such as vegetation-shade model, impervious surface-shade model, and soil-shade model. Three endmember models consisted of two different material classes and shade, such as vegetation-impervious-shade model, vegetation-soil-shade model, and so on. The allowable endmember fraction was between - 0.05 and 1.05 (Dennison and Roberts, 2003; Hamada et al., 2011; Shahtahmassebi et al., 2011). The maximum allowable shade fraction is 0.8 (Roberts et al., 1998a). The terrain is relatively flat in the study area, hence shaded areas were relatively scarce. The RMSE was constrained to $2.5 \%$. Based on the above constraints, two-, three-, four-endmember models were applied to each pixel. If a two-endmember model could model a pixel well, then the two-endmember model was selected as the optimal one. If not, the pixels were left unclassified. For the remaining pixels, if a three-endmember model could model pixels well, the three-endmember model was selected. If not, the pixels were left unclassified. For those pixels that could not be modeled by two-, and three-endmember models, a four-endmember model was used. The results of optimal models by MESMA were to map a series of fraction abundance maps for each class of materials. Figure 6 presents a flowchart of MESMA for estimating the endmember fractions. 
Table 1. Allowed models in the MESMA method.

\begin{tabular}{|c|c|c|}
\hline 2-emb & 3-emb & 4-emb \\
\hline $\begin{array}{l}\operatorname{Veg}_{i}+\text { Shade } \\
\text { VegB }_{i}+\text { Shade } \\
\text { ImpH }_{i}+\text { Shade } \\
\text { ImpL }_{i}+\text { Shade } \\
\text { Soil } \\
+ \text { + Shade }\end{array}$ & 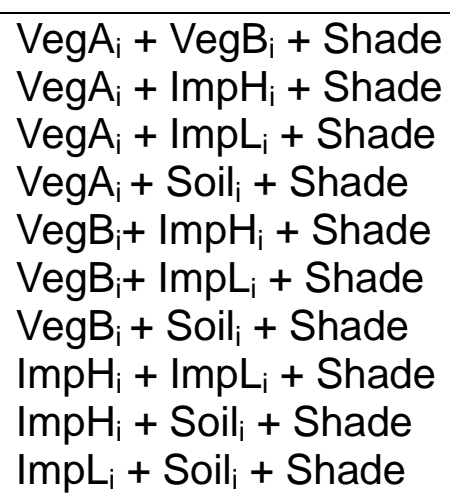 & $\begin{array}{l}\operatorname{VegA}_{i}+\operatorname{ImpH}_{i}+\operatorname{ImpL}_{i}+\text { Shade } \\
\operatorname{VegB}_{i}+\operatorname{ImpH}_{i}+\operatorname{ImpL}_{i}+\text { Shade } \\
\text { Soil }_{i}+\operatorname{ImpH}_{i}+\operatorname{ImpL}_{i}+\text { Shade }\end{array}$ \\
\hline
\end{tabular}

Note: There are five components used in the study. (1). VegA $\mathrm{A}_{\mathrm{i}}$ : Tree; (2). VegB $\mathrm{B}$ : Shrub and grass; (3). ImpH $\mathrm{Im}_{\mathrm{i}}$ : High albedo; (4). ImpL $\mathrm{L}_{\mathrm{i}}$ : Low albedo; (5).Soili:: Soil.

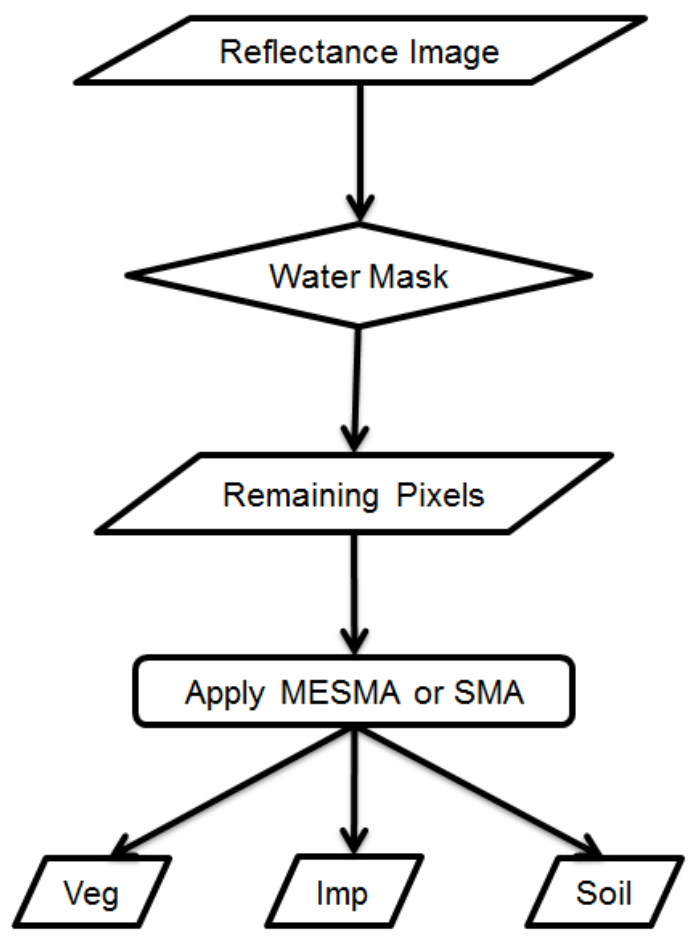

Figure 6. Flowchart of MESMA method developed in the study.

\subsubsection{ISA estimation}

Optimal results were produced by MEMSA when the fraction of shade-endmember in the model was converted to fractions that represent the 
physical composition of the materials in each pixel. After shade normalization, tree canopy, shrubs and grass were combined into one vegetation class, and then low albedo impervious surface and high albedo impervious surface were combined into one impervious surface class. The sum of the fraction values of vegetation, impervious surface, and soil were equal to 1 . The fraction value of each class within a pixel was between 0 and 1 . Water pixels, already masked out in a prior step, were assigned a fraction value representative of water. Finally, a map comprised by four classes: vegetation, impervious surface, soil, and water was finally produced. A general procedure of estimating ISA fraction in the study is shown in Figure 7. In the figure, ISA was also estimated by using SMA.
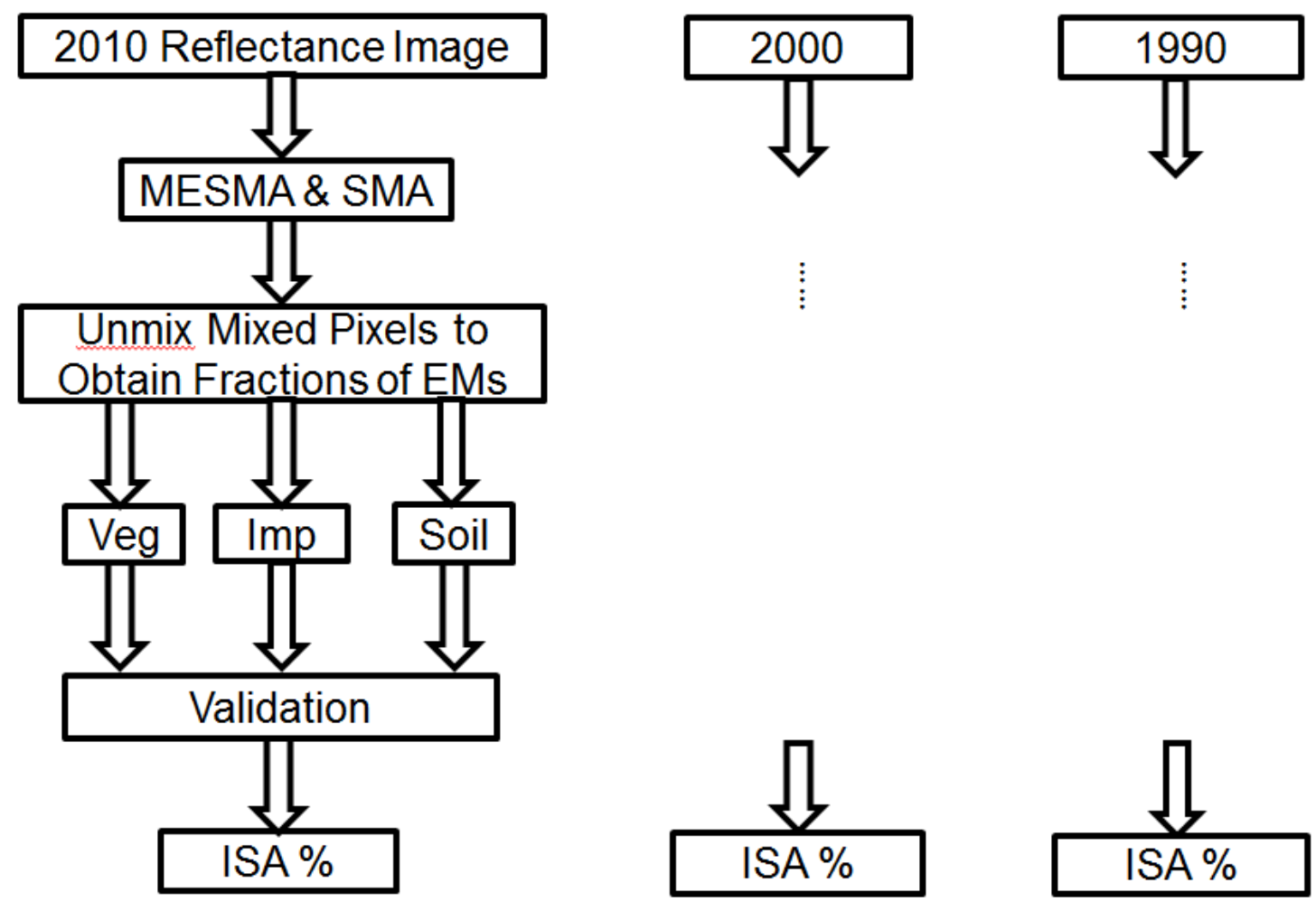

Figure 7. Flowchart of estimating ISA fraction in the study. 


\subsubsection{Accuracy assessment}

In order to evaluate whether MESMA performed better in mapping the physical components of urban land cover, the results of SMA and MESMA were both evaluated for the correlation between modeled fractions and reference fractions derived from a fine-resolution reference image (1 $\mathrm{m}$ resolution). DOQQ aerial photographs acquired in 1990, 2000, and 2011 were used as reference maps to assess accuracy. All the reference images were classified into four classes by visual interpretation: vegetation, impervious surface, soil and water. Since the spatial resolution of the aerial photograph is very high $(1 \mathrm{~m})$, the fractions of each material class interpreted from the aerial photographs corresponded with the actual fraction in the field (Anderson et al., 1996; Stehman and Czaplewski, 1998; Carpenter et al., 1999).

A random sampling technique was used to select a representative sample of the results from MEMSA and SMA images in this study. There are $>30$ samples with the same window size $(30 \mathrm{~m} \times 30 \mathrm{~m}$, which just matches the TM spatial resolution) and were randomly selected from homogenous patches on the Landsat image to eliminate errors from georeferencing process between modeled image and reference images. Within each sampled pixel/window, the fractions of materials were respectively extracted/interpreted from Landsat image and from the fine-resolution aerial photographs. The correlation between modeled fractions and reference fractions for each physical component (endmember) was calculated by the equation:

$\tilde{y}=k x+\beta$ 
Where the reference fraction $\tilde{y}$ is a dependent variable; the modeled fraction $x$ is an independent variable. For an ideal model, the slope $k=1$, and the intercept $\beta=0$. RMSE was employed to estimate the accuracy of these two models (i.e., SMA and MESMA).

RMSE $=\sqrt{\frac{\sum\left(f_{m}-f_{i}\right)^{2}}{N-1}}$

where $N$ is the number of the samples; $f_{m}$ is the fraction of each endmember modeled by SMA or MESMA; $f_{i}$ is the fraction of each endmember measured (interpreted) from the aerial photographs. 


\section{CHAPTER 4: RESULTS AND DISCUSSION}

\subsection{MESMA Model}

In MESMA, representative spectra of every material class, were chosen from the final spectral (endmember) library. For the 1990 TM image, there were a total 19 endmembers in the final spectral library, including 5 vegetation A, 3 vegetation B, 4 high albedo, 4 low albedo, and 3 soil endmembers. Therefore, there were total 338 combination models, including 19 two-endmember models, 143 three-endmember models, and 176 four-endmember models (Table 2). There were total 219 combinations of endmembers for the 2000 TM image, modeled by using 17 different endmembers (5 vegetation A, 3 vegetation B, 4 high albedo, 2 low albedo, and 3 soil endmembers). The 2010 TM image could be modeled using 18 two-endmember models, 125 three-endmember models, and 108 four-endmember models. The details that how many pixels could be estimated by these models were summarized in Tables 3-5. 
Table 2. Number of all combination models for the 1990, 2000, and 2010 reflectance images in the study area.

\begin{tabular}{|lccc|}
\hline Model & 1990 & 2000 & 2010 \\
2-endmember & 19 & 18 & 18 \\
3-endmember & 143 & 113 & 125 \\
4-endmember & 176 & 88 & 108 \\
Total & 338 & 219 & 251 \\
\hline
\end{tabular}

Table 3. Number of pixels successfully modeled by each level of model complexity for the 1990 TM reflectance image.

\begin{tabular}{|llll|}
\hline Model & Pixels modeled & \%Non-water area & \%Total area \\
Water mask & 133510 & - & 13.55 \\
2-endmember & 493880 & 57.13 & 49.39 \\
3-endmember & 366174 & 42.26 & 36.62 \\
4-endmember & 1002 & 0.12 & 0.10 \\
Total & & 99.51 & 99.66 \\
\hline
\end{tabular}


Table 4. Number of pixels successfully modeled by each level of model complexity for the 2000 TM reflectance image

\begin{tabular}{|llll|}
\hline & Pixels modeled & \%Non-water area & \%Total area \\
Water mask & 133510 & - & 13.55 \\
2-endmember & 476388 & 55.10 & 47.64 \\
3-endmember & 387703 & 44.74 & 38.77 \\
4-endmember & 98 & 0.00 & 0.00 \\
Total & & 99.84 & 99.96 \\
\hline
\end{tabular}

Table 5. Number of pixels successfully modeled by each level of model complexity for the 2010 TM reflectance image.

\begin{tabular}{|llll|}
\hline Model & Pixels modeled & \%Non-water area & \%Total area \\
Water mask & 133510 & - & 13.55 \\
2-endmember & 455104 & 52.64 & 45.51 \\
3-endmember & 402633 & 46.47 & 40.26 \\
4-endmember & 1428 & 0.16 & 0.14 \\
Total & & 99.27 & 99.46 \\
\hline
\end{tabular}

From the tables above, the two-endmember models partly explained the images, while the three-endmember models more comprehensively modeled these images, based on a series of criteria: (1) The fraction values of endmembers of major physical components were between -0.05 and 1.05 ; (2) the maximum fraction of shade was 0.8; and (3) RMS error was equal to 0.025 . However, the 
four-endmember models failed to model many pixels in the images, and also increased the cost of computation in this study. For the 1990 reflectance image, $13.55 \%$ of water areas were masked out by establishing a criterion. In non-water areas, $57.13 \%$ of the pixels were modeled by the two-endmember models, $42.26 \%$ of the pixels were modeled by the three-endmember models, but only $0.12 \%$ of the pixels were modeled by the four-endmember models. From the output of classification image, it was found that many of the pixels modeled by four-endmember models were adjacent to water. However, edge pixels with low reflectance value could be modeled by any spectra with shadows. The four-endmember models were not considered in the final MESMA results because they didn't improve the accuracy of models and increased computational cost and complexity. (Roberts et al., 1998b; Halligan, 2002). As a result both the two- and three-endmember models were chosen as the optimal ones for the purposes of this study $(57.13 \%$ of pixels modeled by two-endmember models, and additional $42.26 \%$ of pixels modeled by three-endmember models), although about $0.61 \%$ pixels in the study area remained unclassified. This number of unclassified pixels was so small that it would not greatly affect the accuracy of ISA estimation. Accordingly for the 1990 image $99.39 \%$ pixels of the land area was modeled by the MESMA method. For the 2000 image $99.84 \%$ pixels of non-water areas were modeled by the two- and three-endmember models in MESMA, and the remaining $0.16 \%$ were unclassified. A total of $99.11 \%$ of pixels were well modeled by the two- and three-endmember models for the 2010 image, leaving $0.89 \%$ of pixels in non-water areas unmodeled. 
After the shadow/shaded fraction modeled by MESMA was accounted for the physical compositions of the materials in each pixel, vegetation $A$ and vegetation B were combined into one vegetation class, and high albedo impervious surface and low albedo impervious surface were combined into one impervious surface class. Water pixels, had already been masked out, and were now assigned to a fraction value of water. The Final fraction maps of the four physical components were produced: vegetation, impervious surface, soil, and water using the 1990, 2000, and 2010 Landsat TM images (Figures 8-10). The brightness of the fraction maps for the three different years varied across the study area, with higher brightness indicating abundance of the material, and darkness a decreased amount. Comparing the images from 1990 to 2010 , the impervious surface fraction maps became brighter (Figures 8B, 9B and 10B), implying that ISA increased, while the soil fraction maps became darker. For the vegetation fraction maps, the forest area in the upper right of the maps was bright, indicating a high percentage of vegetation in that area (Figures 8A, 9A, and 10A). The appearance of downtown areas, roads, airports, and some residential areas was very bright in the impervious surface fraction maps. 
(A)

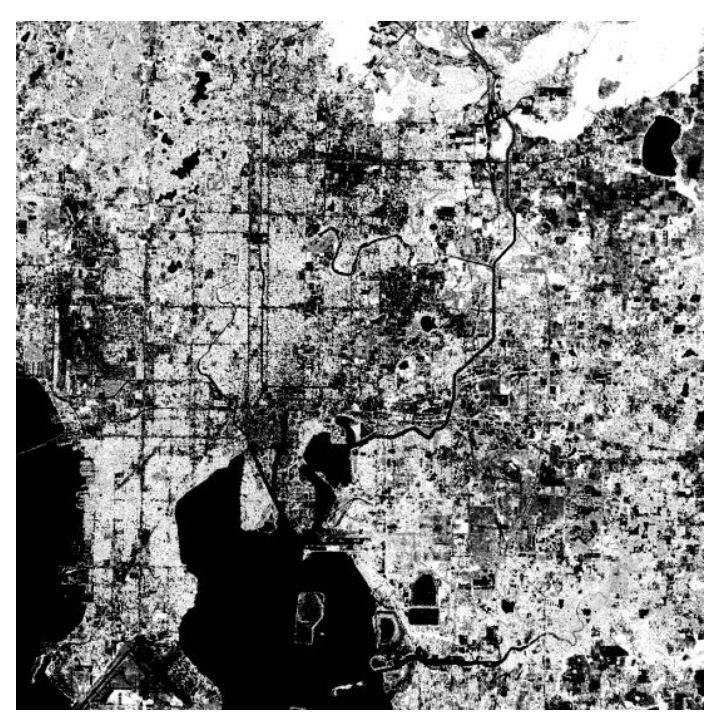

(C)

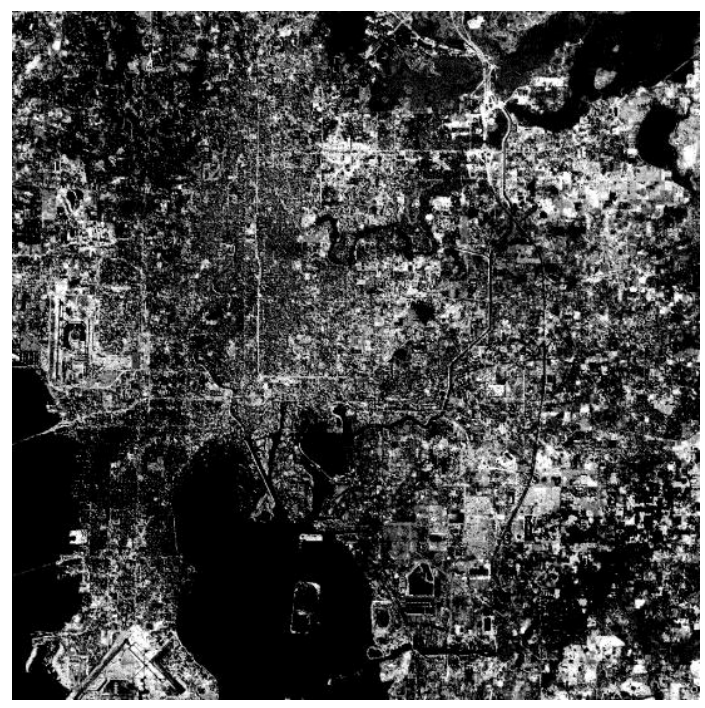

(B)

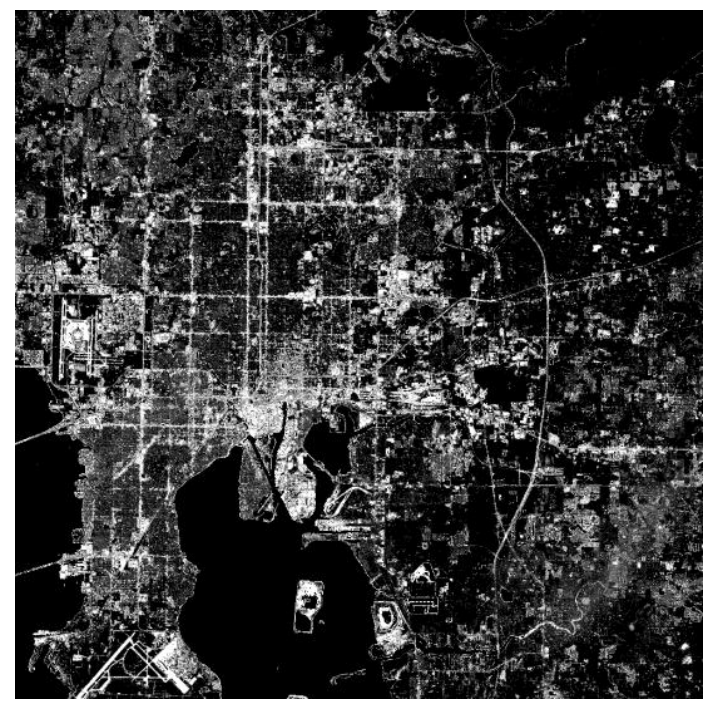

(D)

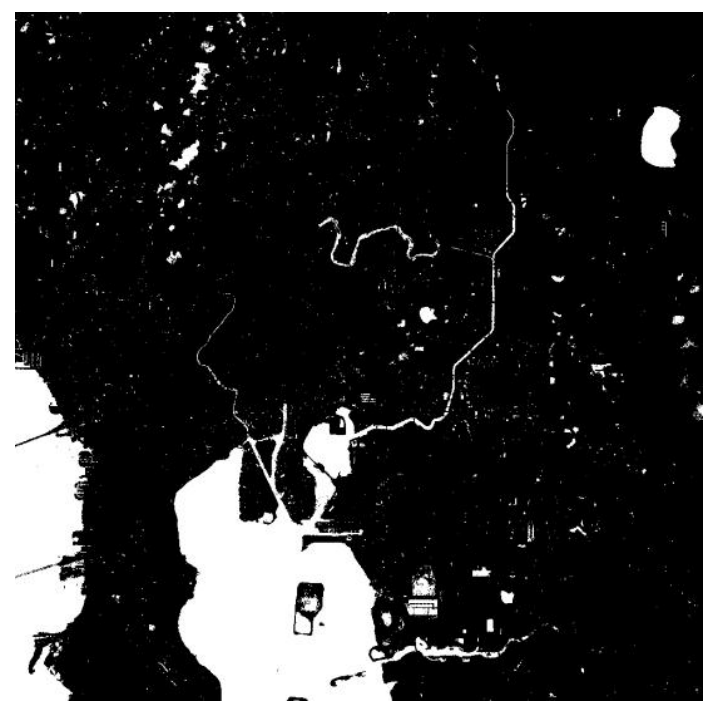

Figure 8. Fraction images generated by MESMA using Landsat-5 TM image acquired on June, 7, 1990. Vegetation fraction map (A); impervious surface fraction map (B); soil fraction map (C); and water (D). Brighter areas indicate higher fractions, while darker areas indicate lower fractions. 
(A)

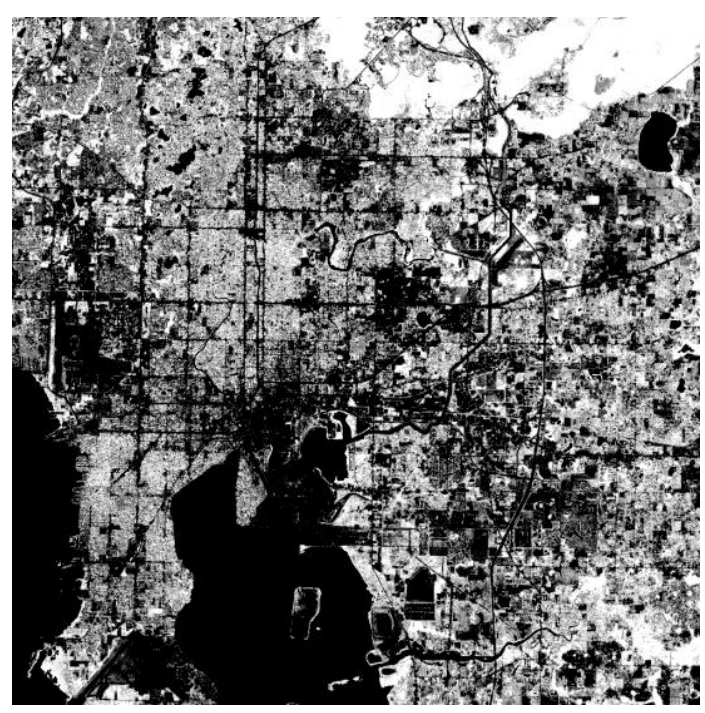

(C)

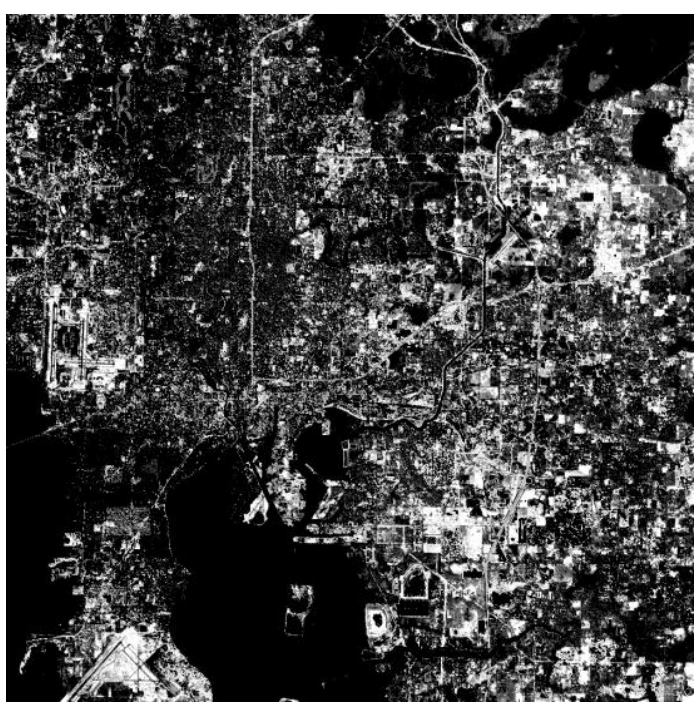

(B)

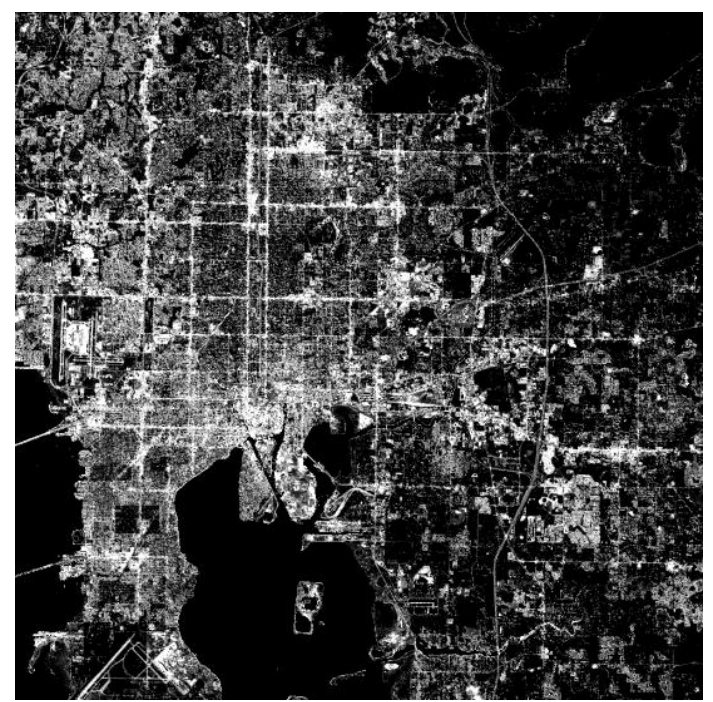

(D)

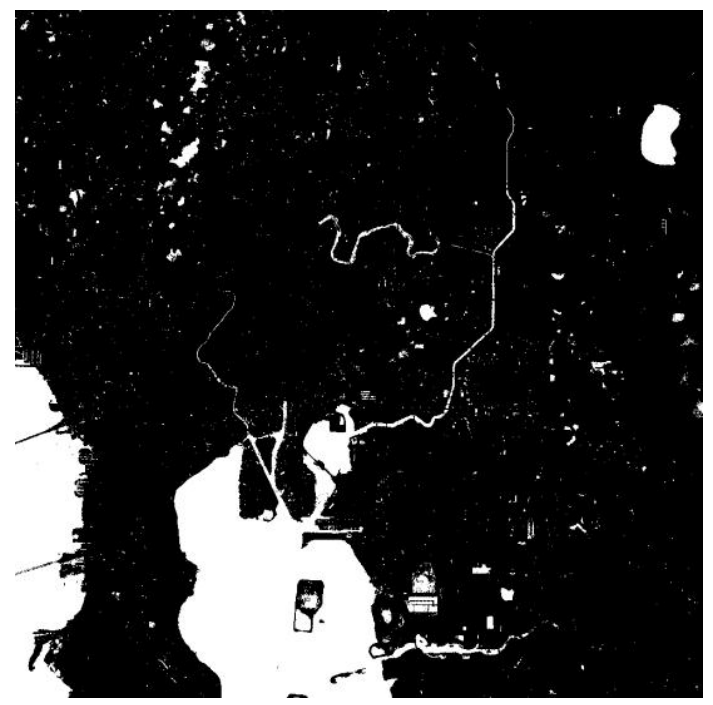

Figure 9. Fraction images generated from MESMA using Landsat-5 TM image acquired on June, 2, 2000. Vegetation fraction map (A); impervious surface fraction map (B); soil fraction map (C); and water (D). Brighter areas indicate higher fractions, while darker areas indicate lower fractions. 
(A)

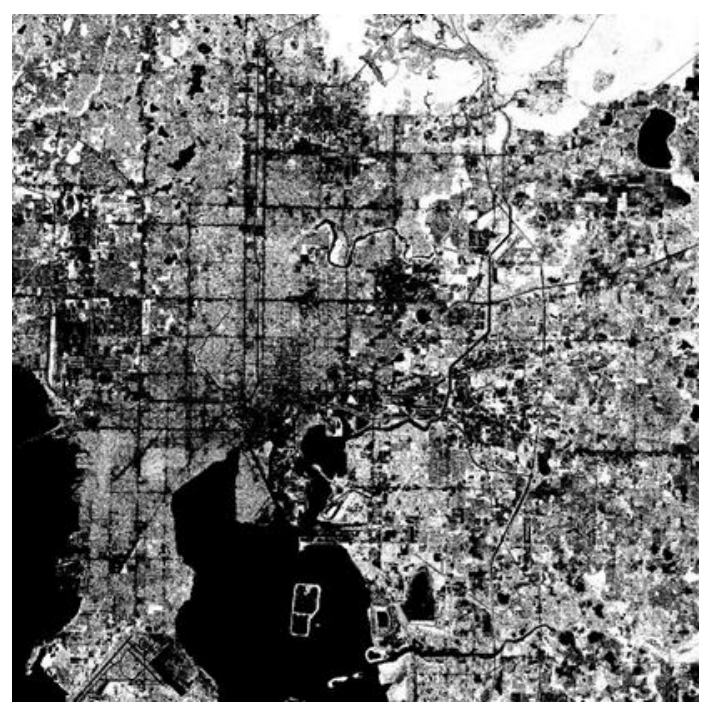

(C)

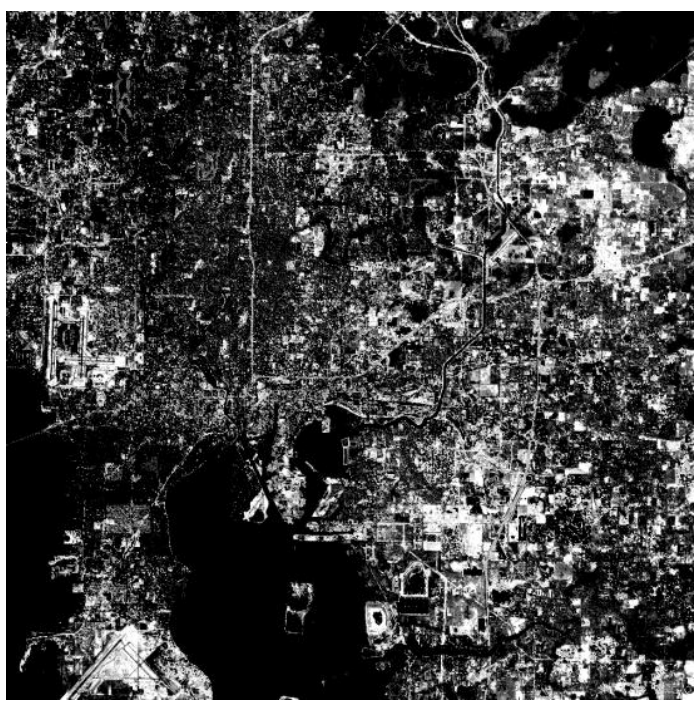

(B)

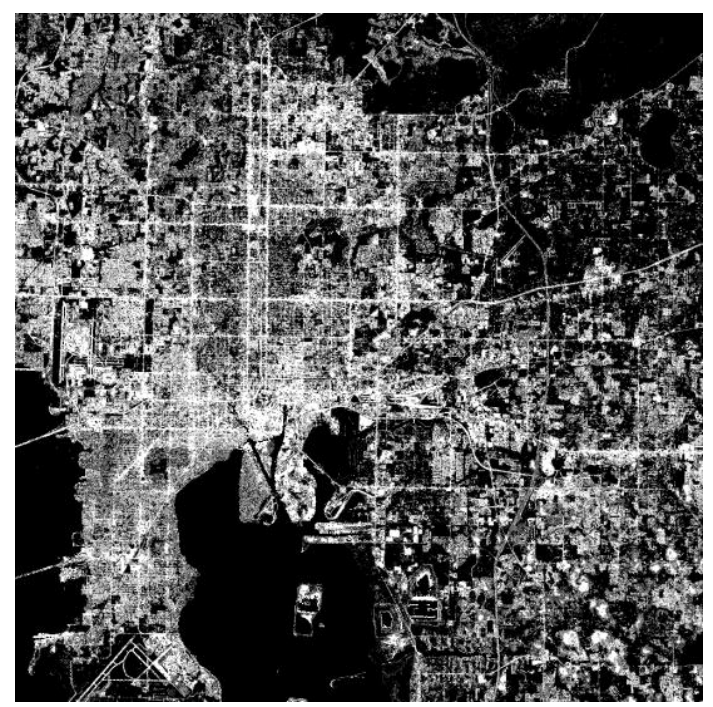

(D)

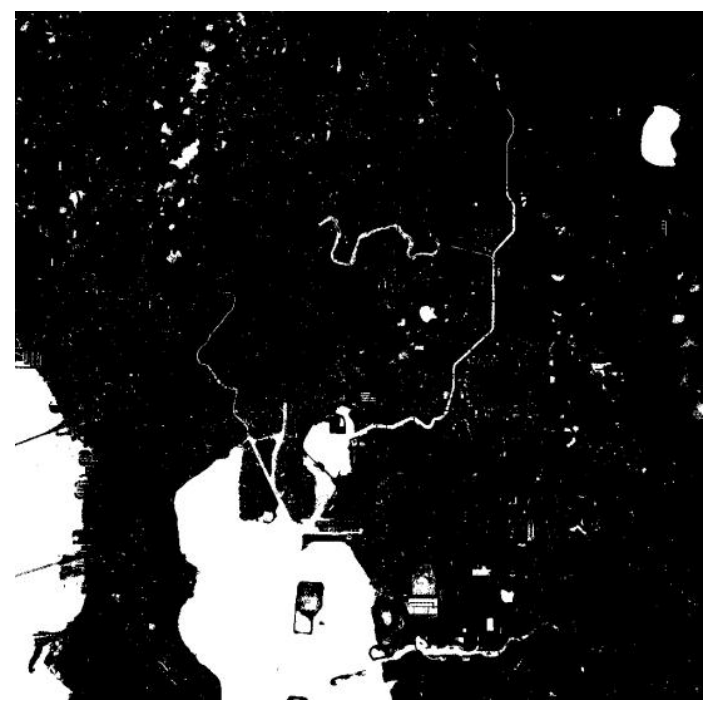

Figure 10. Fraction images generated from MESMA using Landsat-5 TM image acquired on April, 27, 2010. Vegetation fraction map (A); impervious surface fraction map (B); soil fraction map (C); and water (D). Brighter areas indicate higher fractions, while darker areas indicate lower fractions. 


\subsection{SMA Model}

In the SMA method, all training samples of endmembers (vegetation A, vegetation $\mathrm{B}$, high albedo, low albedo, and soil) were obtained by PPI and manual selection. A shadow/shaded endmember was not added in this method, since it might decrease the accuracy of the components estimation. Results of fraction maps of the four primary physical components are shown in Figures 11-13, created with corresponding Landsat TM images acquired in 1990, 2000, and 2010. The brightness in vegetation and impervious surface fraction maps modeled by SMA was very similar to that produced by MESMA, although there were some differences in the soil fraction maps. 
(A)

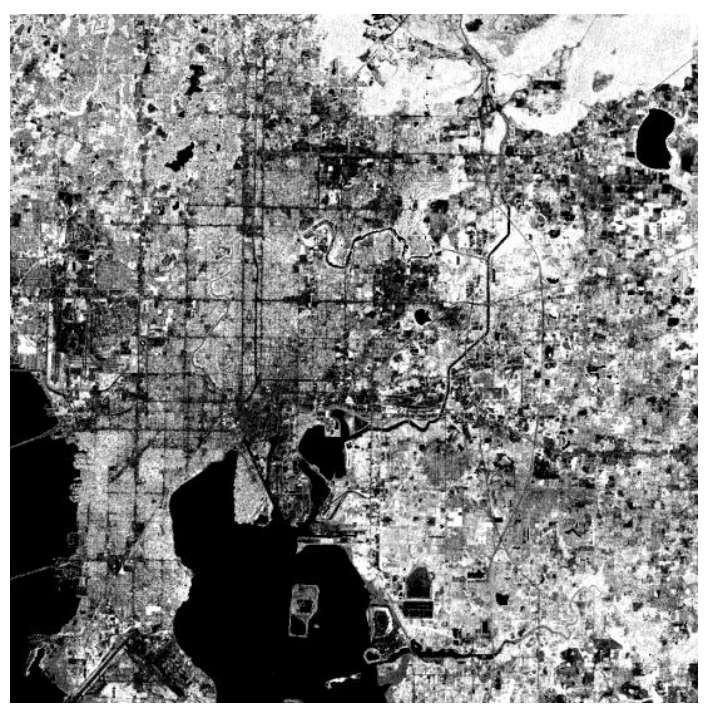

(C)

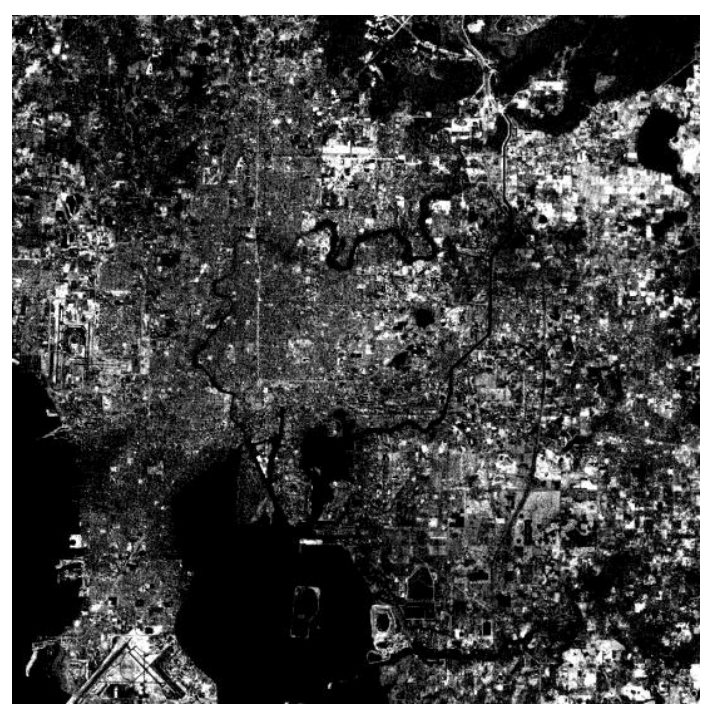

(B)

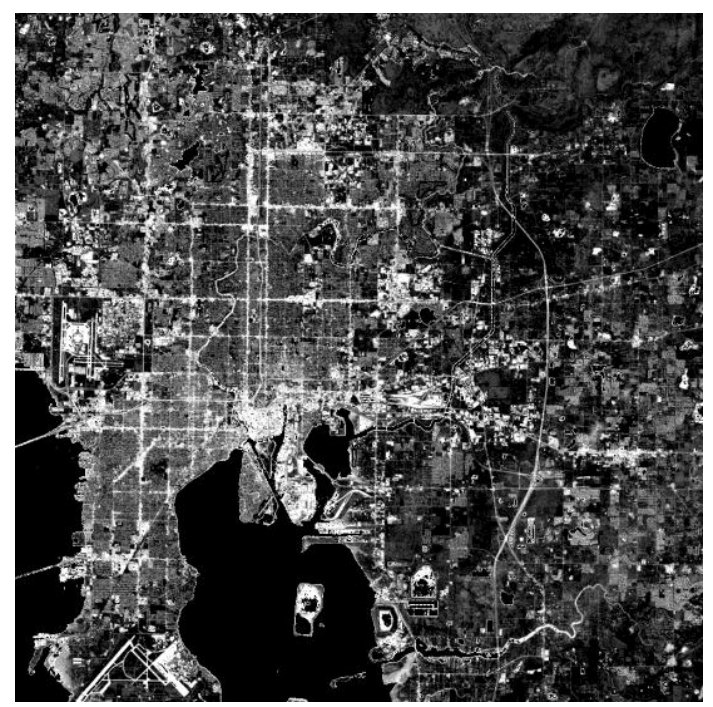

(D)

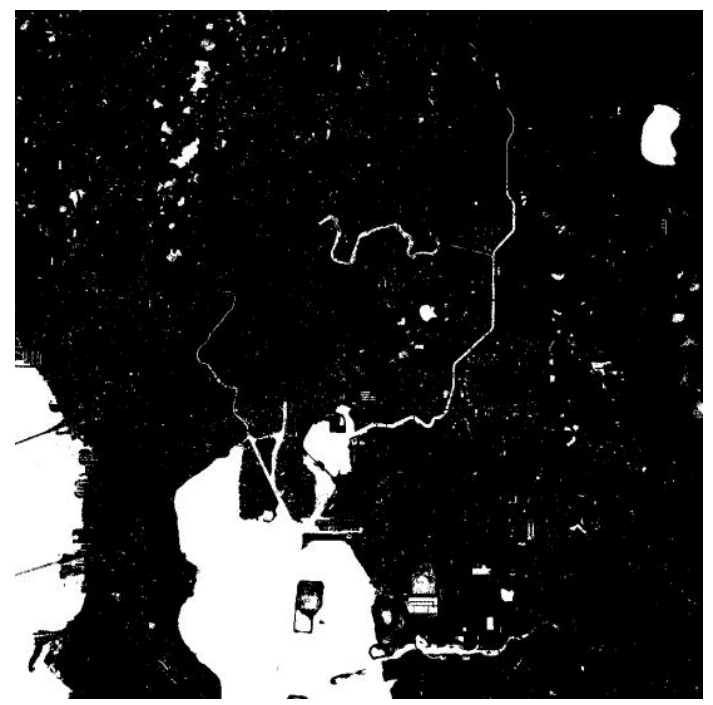

Figure 11. Fraction images generated from SMA using Landsat-5 TM image acquired on June, 7, 1990. Vegetation fraction map (A); impervious surface fraction map (B); soil fraction map (C); and water (D). Brighter areas indicate higher fractions, while darker areas indicate lower fractions. 
(A)

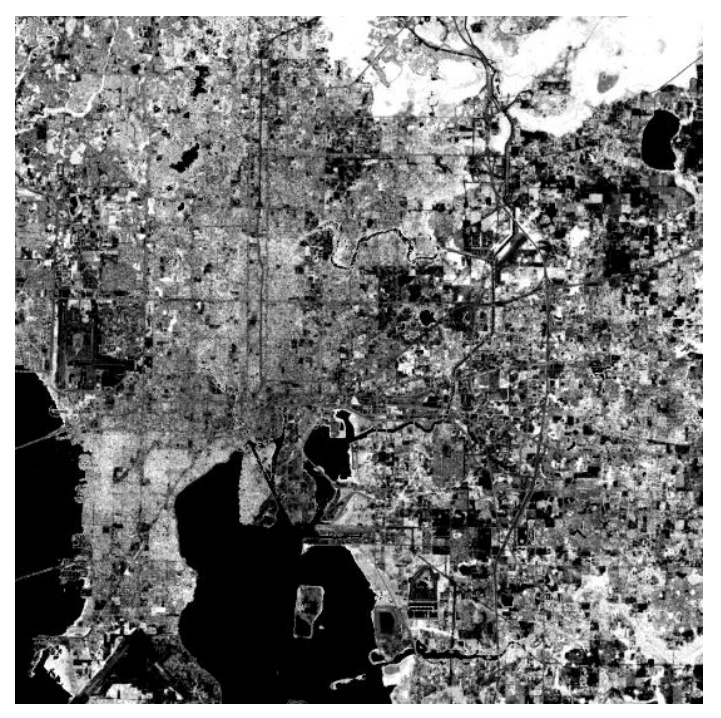

(C)

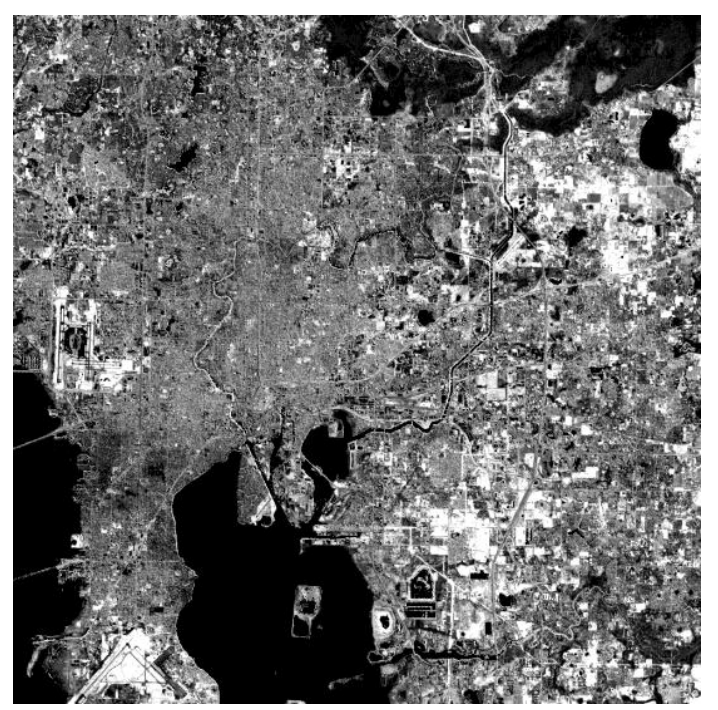

(B)

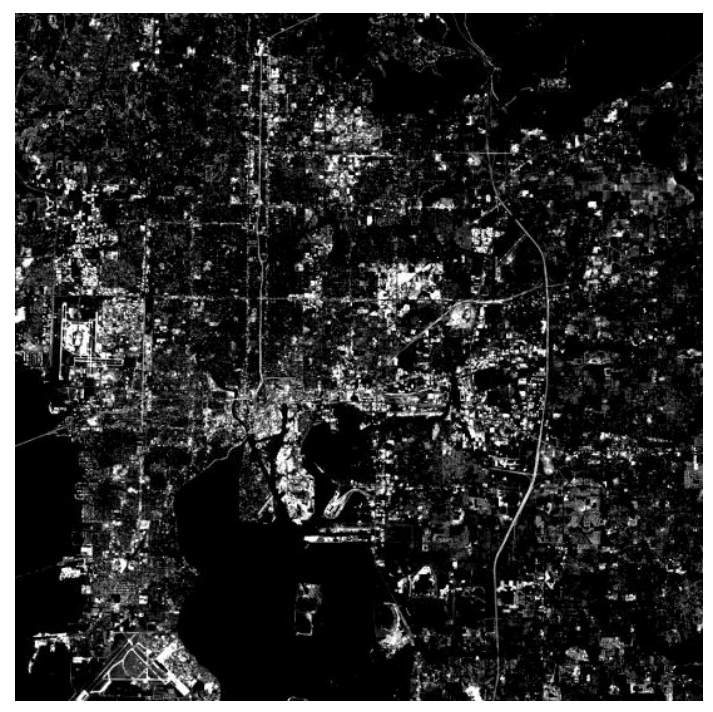

(D)

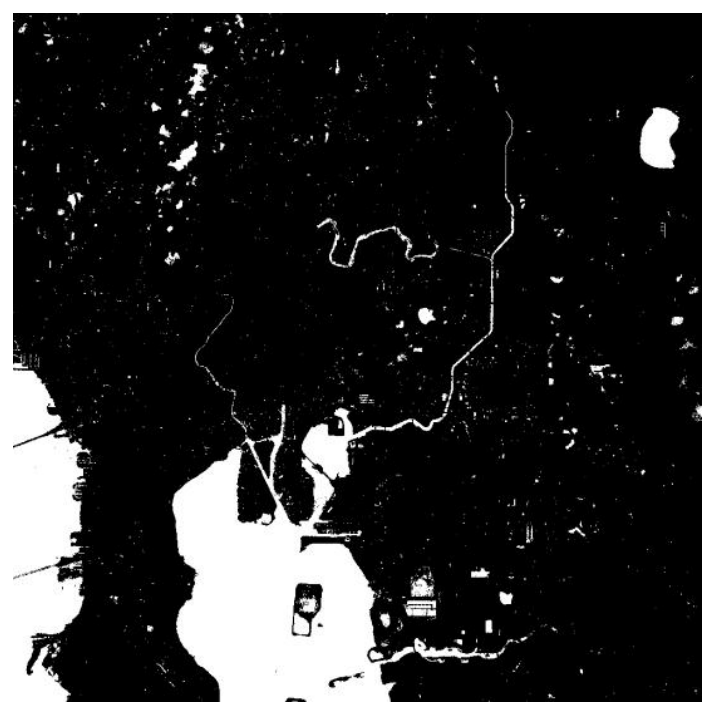

Figure 12. Fraction images generated from SMA using Landsat- 5 TM image acquired on June, 2, 2000. Vegetation fraction map (A); impervious surface fraction map (B); soil fraction map (C); and water (D). Brighter areas indicate higher fractions, while darker areas indicate lower fractions. 
(A)

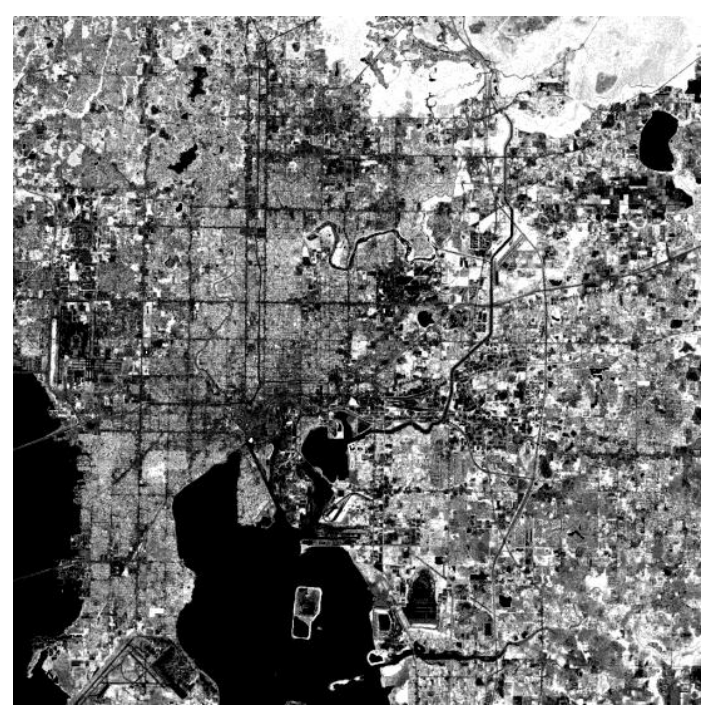

(C)

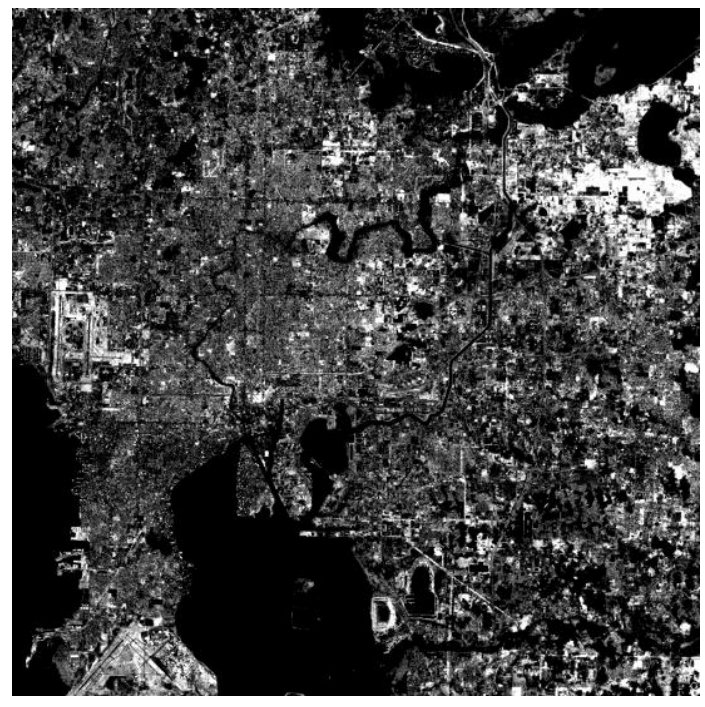

(B)

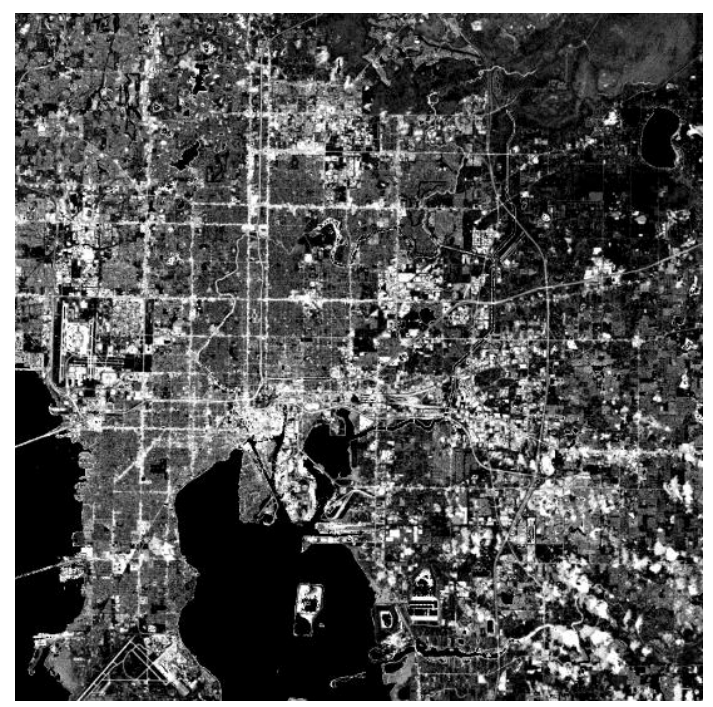

(D)

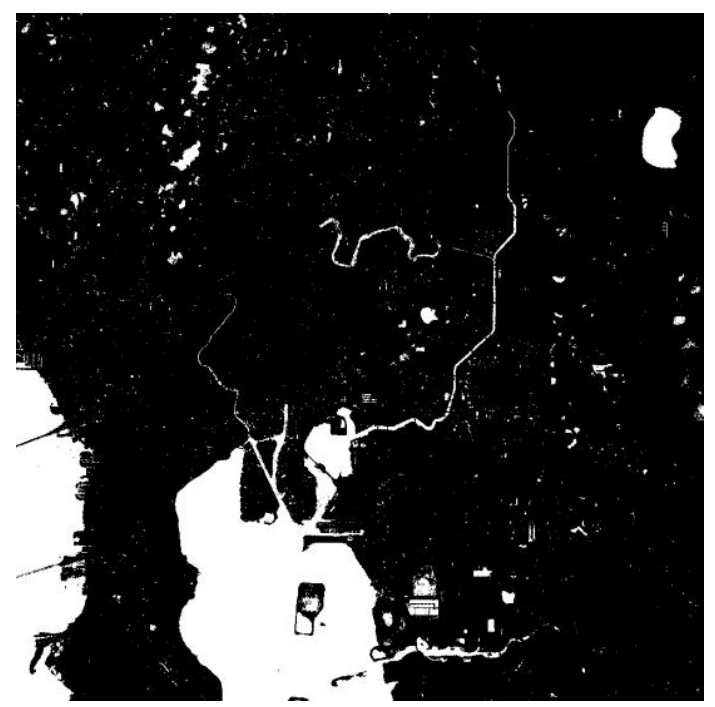

Figure 13. Fraction images generated from SMA using Landsat-5 TM image acquired on April, 27, 2010. Vegetation fraction map (A); impervious surface fraction map (B); soil fraction map (C); and water (D). Brighter areas indicate higher fractions, while darker areas indicate lower fractions. 


\subsection{Comparison between MESMA and SMA}

In order to compare the performance of mapping the physical components between MESMA and SMA, accuracy assessment analyses were done using fine-resolution aerial photographs as reference images. Reference DOQQ aerial photographs acquired on March, 13, 2001 were the only ones available for assessing the accuracy of three major physical components created from 2000 Landsat TM image. A total of 36 sample units $(30 \mathrm{~m} \times 30 \mathrm{~m})$ were utilized in the accuracy assessment which used stratified random sampling. The sample sites consisted of two subsets: one was selected from the homogenous patches in order to decrease georeferencing errors; the other subset was selected from mixed pixels in the image which had equivalent variation of the three physical materials (vegetation, impervious surface, and soil). Since the spatial resolution of the reference image was $1 \mathrm{~m}$ there were 900 small units $(1 \mathrm{~m} \times 1 \mathrm{~m})$ in the reference image of each sampled pixel from the TM image. The component fraction was visually interpreted from the reference image with the help of grid lines in ENVI. RMSE (Eq. (5)) was employed to assess the accuracy of modeled fractions with measured (interpreted) fractions. Table 6 shows the comparison results of the fraction estimations between MESMA and SMA. From the table, it is obvious from the lower RMSE that MESMA produced higher levels of accuracy than SMA when mapping the three physical components (vegetation, impervious surface and soil) at the sub-pixel level in the study area. The general conclusion that MEMSA has

higher accuracy than SMA is supported by the results displayed in Figures $14-19$ below. 
A closer examination of the results (Figures 14 - 19), indicates that MESMA has produced an overestimation in the low to medium levels $(0-68 \%)$ of vegetation areas (Figure 14A), while there is slight underestimation of the dense vegetation areas $(\mathrm{RMSE}=0.033$ for vegetation from MESMA). The overestimation is mainly due to shade effects in the vegetated areas, while the underestimation of vegetated areas is due to the complexity and diversity of vegetation spectra. The result shown in Figure 14 (B) suggest that simple SMA was also sensitive to the vegetation endmember, although some underestimation and overestimation were found for all samples $(\mathrm{RSME}=0.050)$.

Figure 16 shows that, compared to SMA (RMSE $=0.079)$, MESMA (RMSE $=$ 0.024) improved the ISA estimation accuracy through varying the number and type of endmembers from pixel to pixel. The overestimation of low ISA areas was obvious in SMA because a limited number of endmembers were available in this study. There might be some confusion between shaded non-ISA surfaces and low-albedo surfaces in the SMA process. If there were a sufficient number of representative endmembers to decrease this confusion, the accuracy of SMA in estimating ISA could be improved.

SMA was less sensitive than MESMA when modeling the soil component as shown in Figure 18(B). The overall RMSE was 0.104 in SMA, and its coefficient of determination $\left(\mathrm{R}^{2}\right)$ was 0.8260 , while for MESMA, the RMSE was reduced to 0.04 , and the corresponding coefficient of determination $\left(\mathrm{R}^{2}\right)$ was improved to 0.985 . The residual plots in the Figure 19(B) show obvious underestimation and overestimation in the samples. It is possible that due to their similar spectral 
signatures the shaded non-ISA surfaces (such as shaded soil) were confused with ISA surfaces. Photometric shade was not considered as an endmember to model material surfaces so shadow and shaded areas were difficult to accurately model in SMA. MESMA allowed the addition of a "photometric shade" endmember, improving its performance in this area.

Table 6. Comparison of fraction estimation accuracy between MESMA and simple SMA. $(n=36)$

\begin{tabular}{|llllll|}
\hline \multirow{3}{*}{ MESMA } & Components & Intercept & Slope & $\mathrm{R}^{2}$ & RMSE \\
& Vegetation & 0.032 & 0.953 & 0.986 & 0.033 \\
& Impervious & 0.015 & 0.970 & 0.992 & 0.024 \\
\multirow{3}{*}{ SMA } & Soil & -0.130 & 0.985 & 0.970 & 0.040 \\
& Vegetation & 0.035 & 0.951 & 0.970 & 0.050 \\
& Impervious & 0.030 & 0.915 & 0.918 & 0.079 \\
& Soil & -0.050 & 0.983 & 0.826 & 0.104 \\
\hline
\end{tabular}

Notes: $\mathrm{R}^{2}$ : Coefficient of Determination; RMSE: Root Mean Square Error; 
(A)

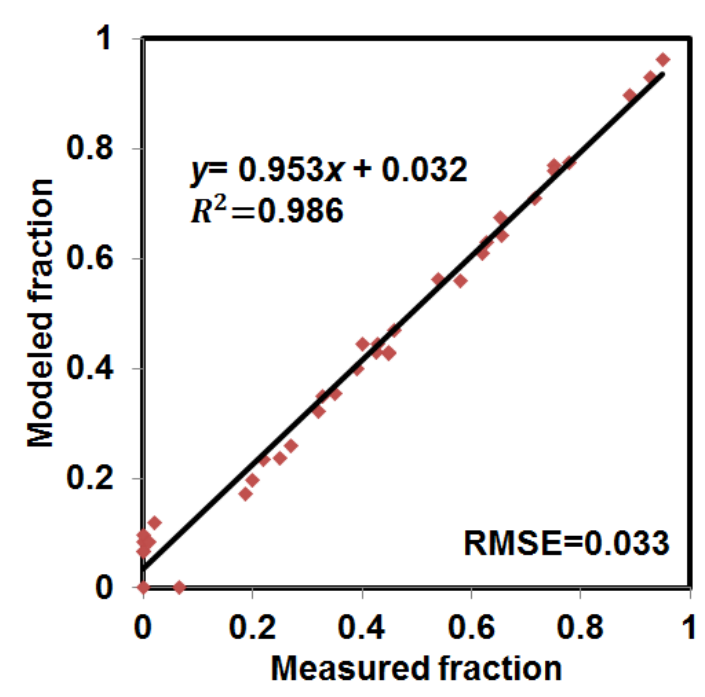

(B)

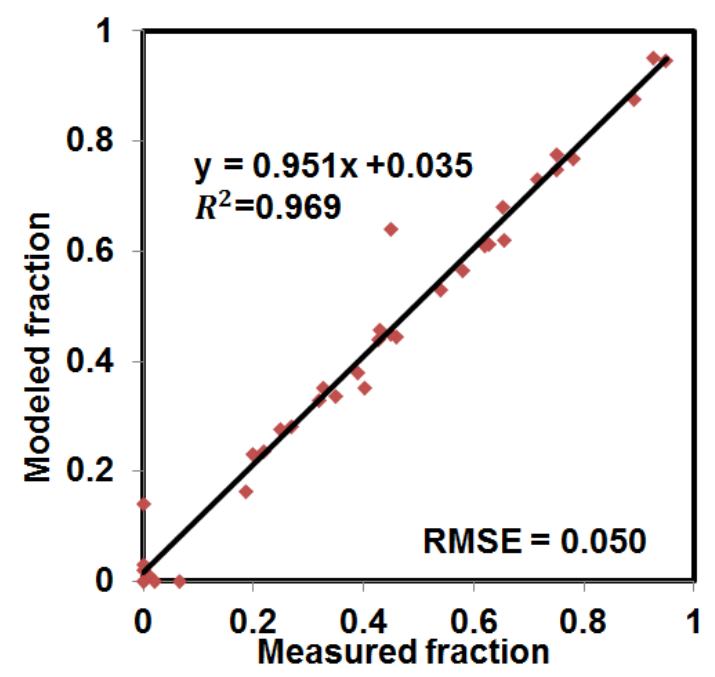

Figure 14. Measured vegetation fraction values from aerial photographs against their modeled values by MESMA (A) and SMA (B) from the 2000 Landsat TM image.

(A)

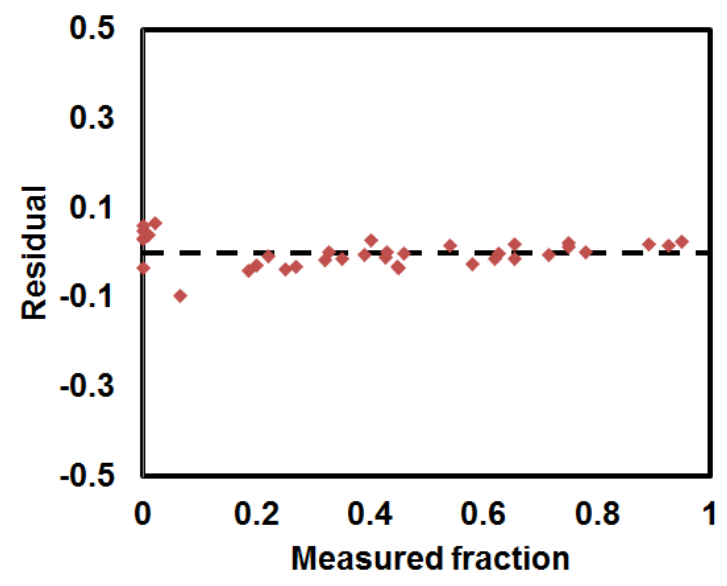

(B)

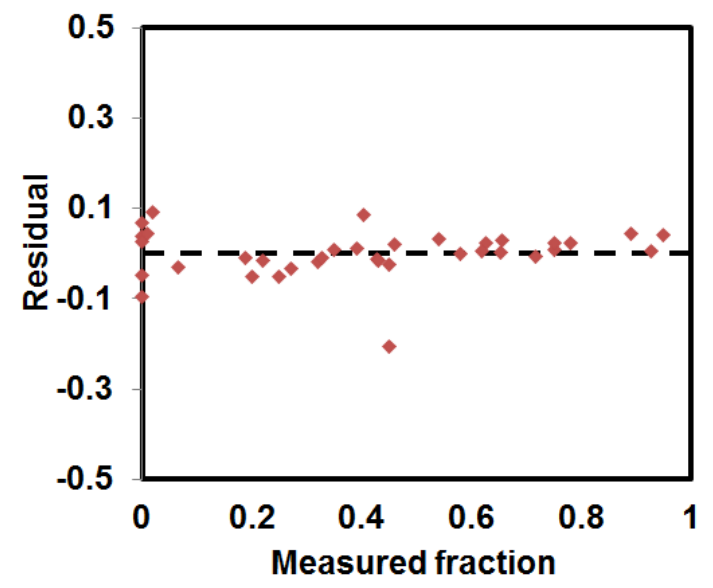

Figure 15. Residual plots with vegetation fraction values modeled by MESMA (A) and SMA (B) from the 2000 Landsat TM image. 
(A)

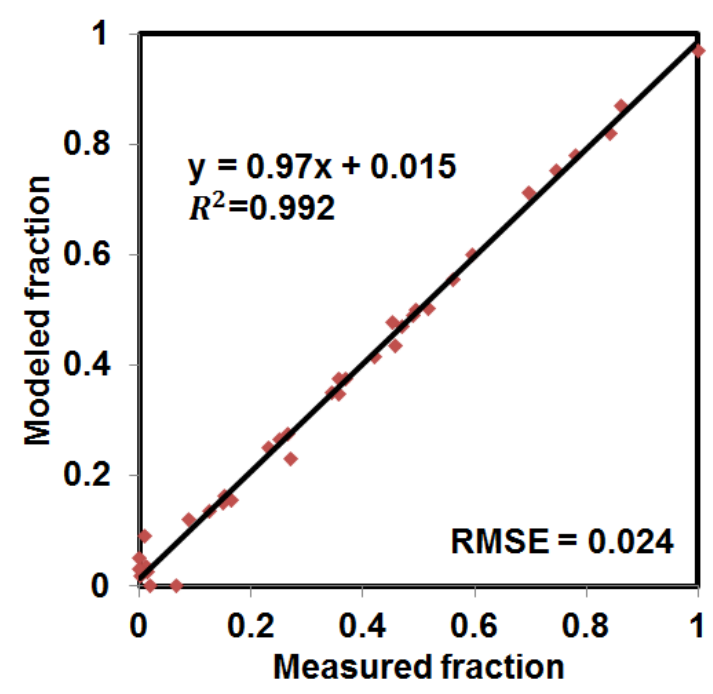

(B)

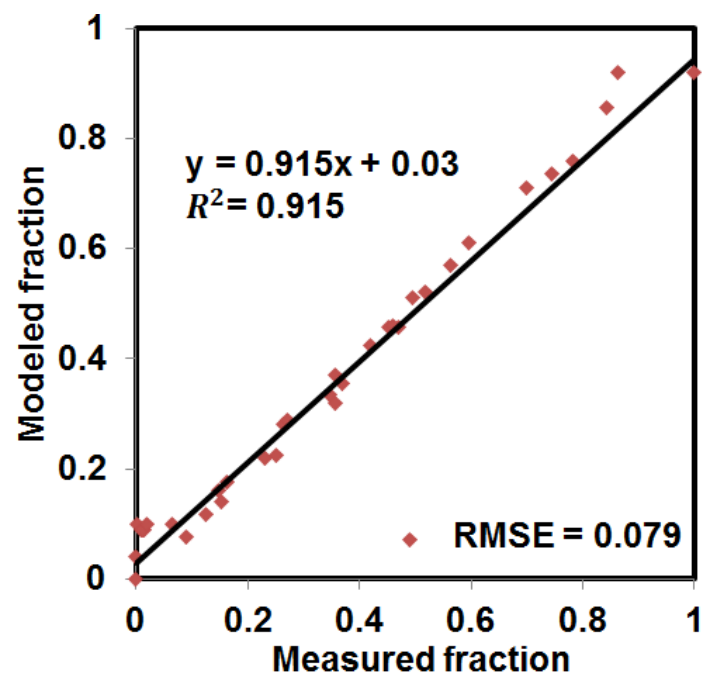

Figure 16. Measured impervious fraction values from aerial photographs against their modeled values by MESMA (A) and SMA (B) from the 2000 Landsat TM image.

(A)

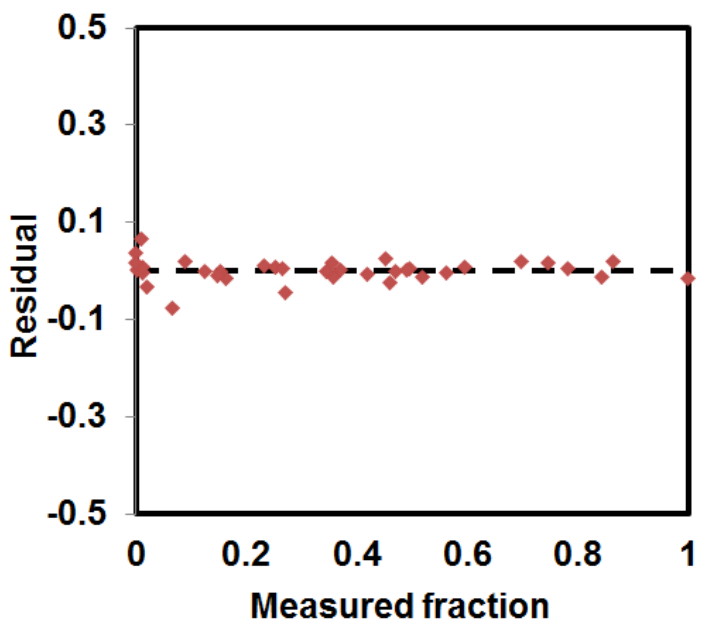

(B)

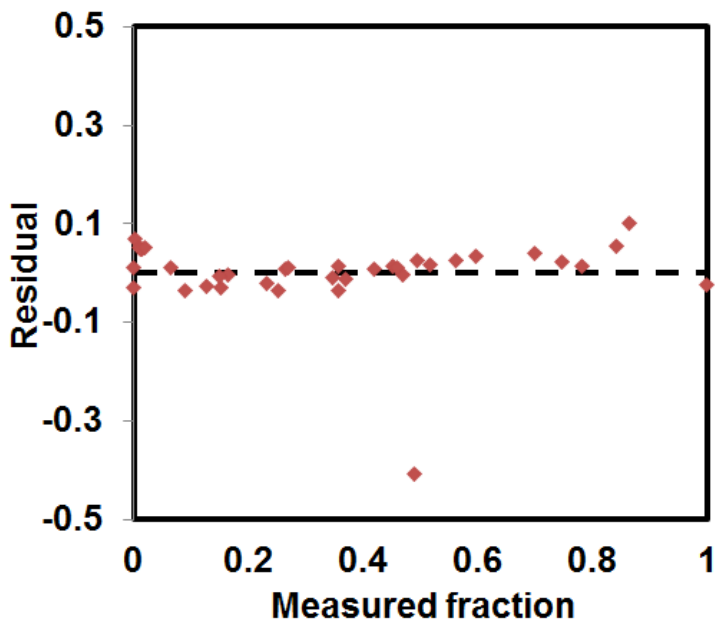

Figure 17. Residual plots with impervious fraction values modeled by MESMA (A) and SMA (B) from the 2000 Landsat TM image. 
(A)

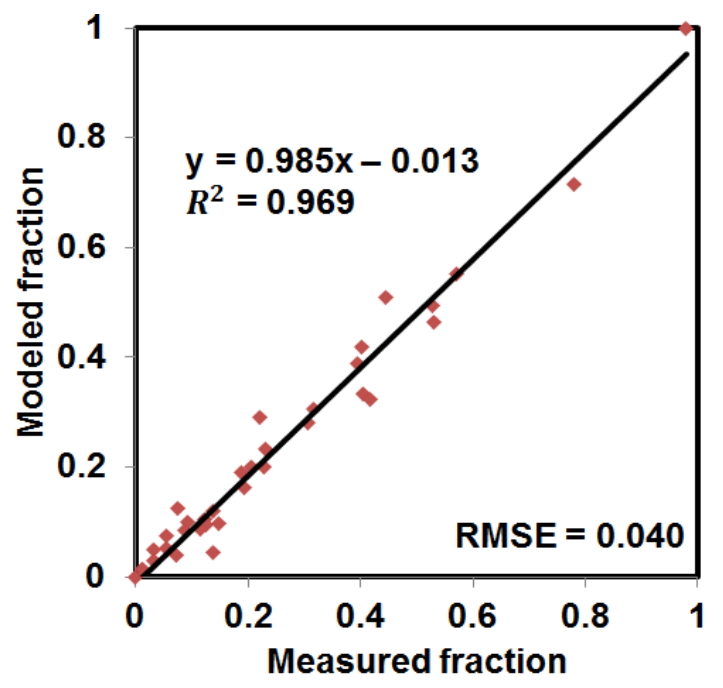

(B)

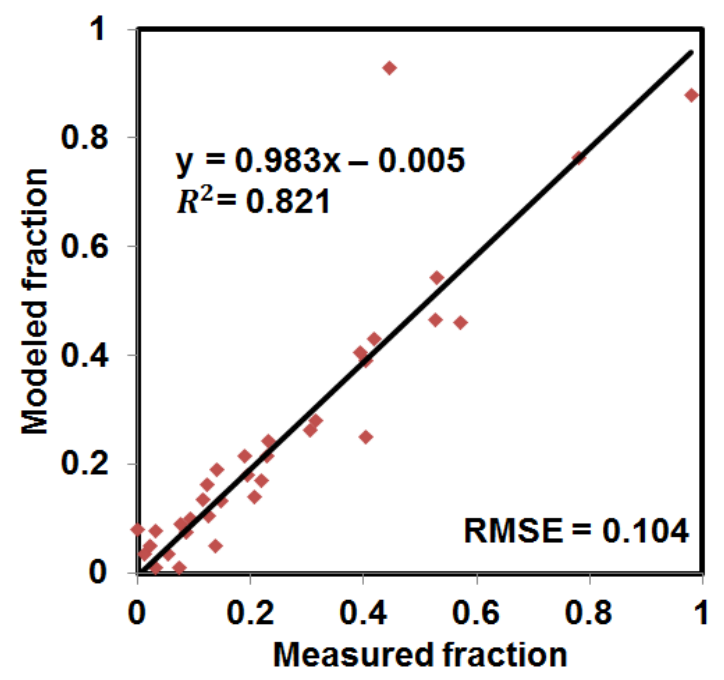

Figure 18. Measured soil fraction values from aerial photographs against their modeled values by MESMA (A) and SMA (B) from the 2000 Landsat TM image.

(A)

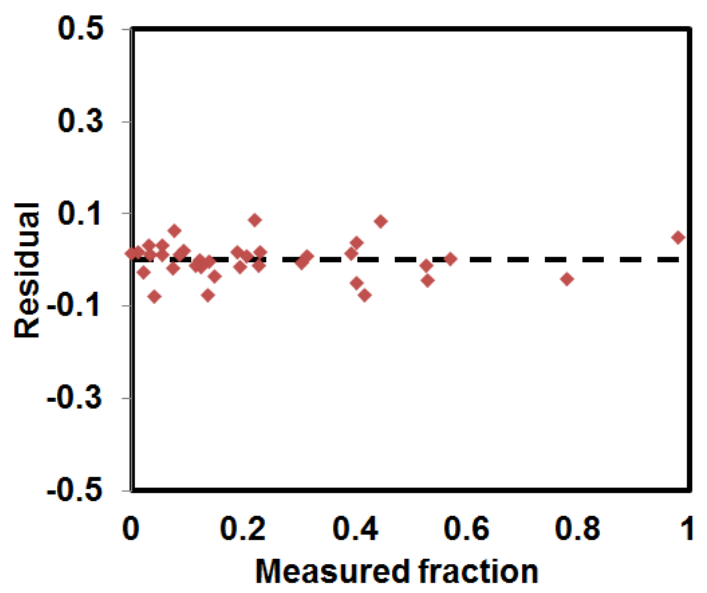

(B)

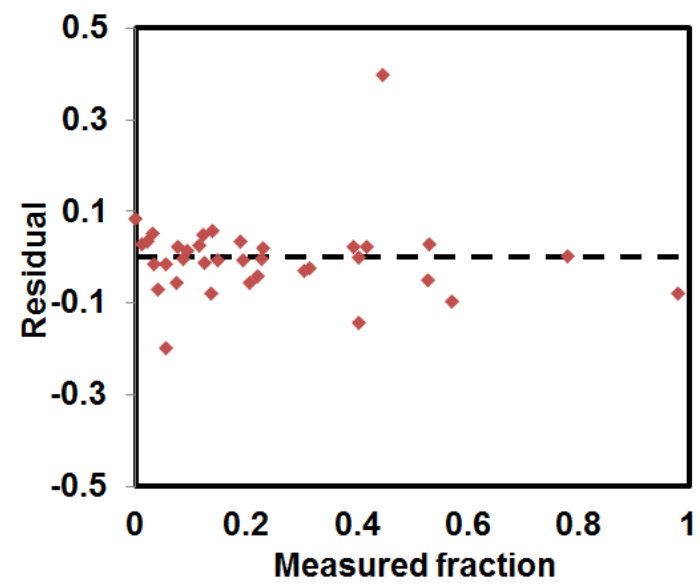

Figure 19. Residual plots with soil fraction values modeled by MESMA (A) and SMA (B) from the 2000 Landsat TM image. 


\subsection{Assessment of Urban Growth}

In order to assess the patterns and intensity of urban growth in the City of Tampa, Florida during the past twenty years, ISA distribution maps derived from the TM images acquired in 1990, 2000, and 2010 were analyzed. From these ISA fraction images it is obvious that the \%ISA in the study area consistently increased during the study period; from $14.08 \%$ in 1990 to $20.63 \%$ in 2000 , and from $20.63 \%$ in 2000 to $27.31 \%$ (Table 7 ). This result indicates great changes to the landscape in the whole study area during the past two decades, especially near the University Square area. The average rate of the ISA fraction increase was $0.655 \% /$ year in the period of $1990-2000$, and $0.668 \% /$ year in the period of 2000-2010. The consistent change rate in the study area during the two decade periods indicates a trend of steady increase. At the pixel scale of analysis, the result indicates an increase in the percentage of the number of pixels with an ISA fraction greater than 0 , which has grown from $0.83 \%$ of the whole study area in the period between $1990-2000$ to $0.71 \%$ in the period between $2000-2010$.

Table 7. Percentage of ISA (\%ISA) and the percentage of number of pixels with ISA fraction > 0 (\%pixel-based ISA fraction > 0) in 1990, 2000, and 2010 TM images.

\begin{tabular}{|cccc|}
\hline & 1990 & 2000 & 2010 \\
\% pisA & 14.08 & 20.63 & 27.31 \\
pixel-based ISA fraction $>0$ & 49.4 & 50.23 & 57.24 \\
\hline
\end{tabular}

The ISA fraction images were consistent with urban LULC distribution in the 
study area. During the past twenty years, the percentage of low percent impervious surface decreased, while the percentage of moderate to high percent impervious surface increased (Figure 20). The percentage of areas with $0-10 \%$ ISA fraction decreased from $44.38 \%$ to $34.6 \%$. The percentage of high percent impervious surface, such as $70-80 \%, 80-90 \%$, and $90-100 \%$ ISA fraction, continuously increased. By calculating the ISA change for each pixel and then visualizing the ISA fraction maps, three regions with high percentages of impervious surface were identified: Tampa International Airport, downtown Tampa, and University Square (see Figure A4 in Appendices for their locations). After checking pixel counts for these areas of increased ISA during the past two decades, University Square underwent the greatest change among the three regions. Figures 21 - 23 demonstrate the \%ISA changes in the study area from 1990 to 2010.

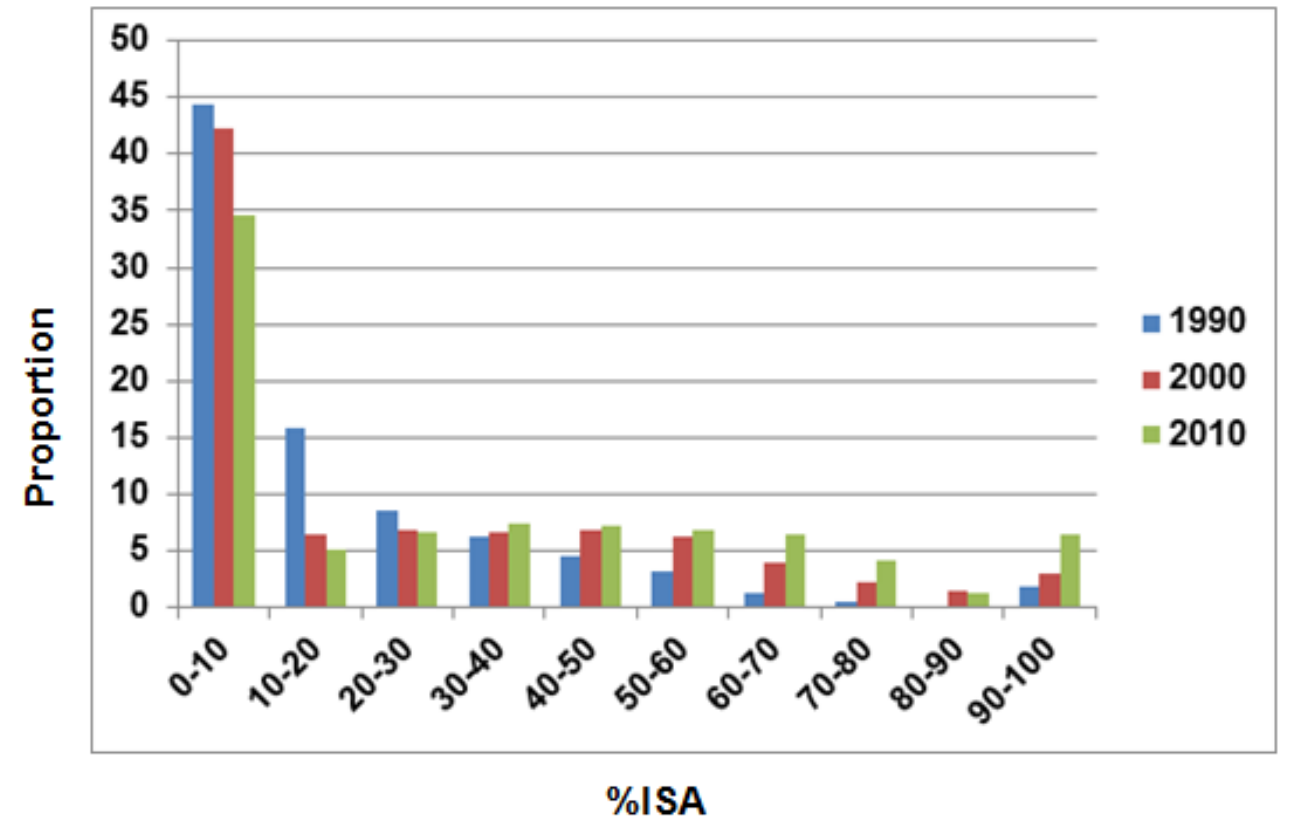

Figure 20. \%ISA changes from 1990 to 2010 


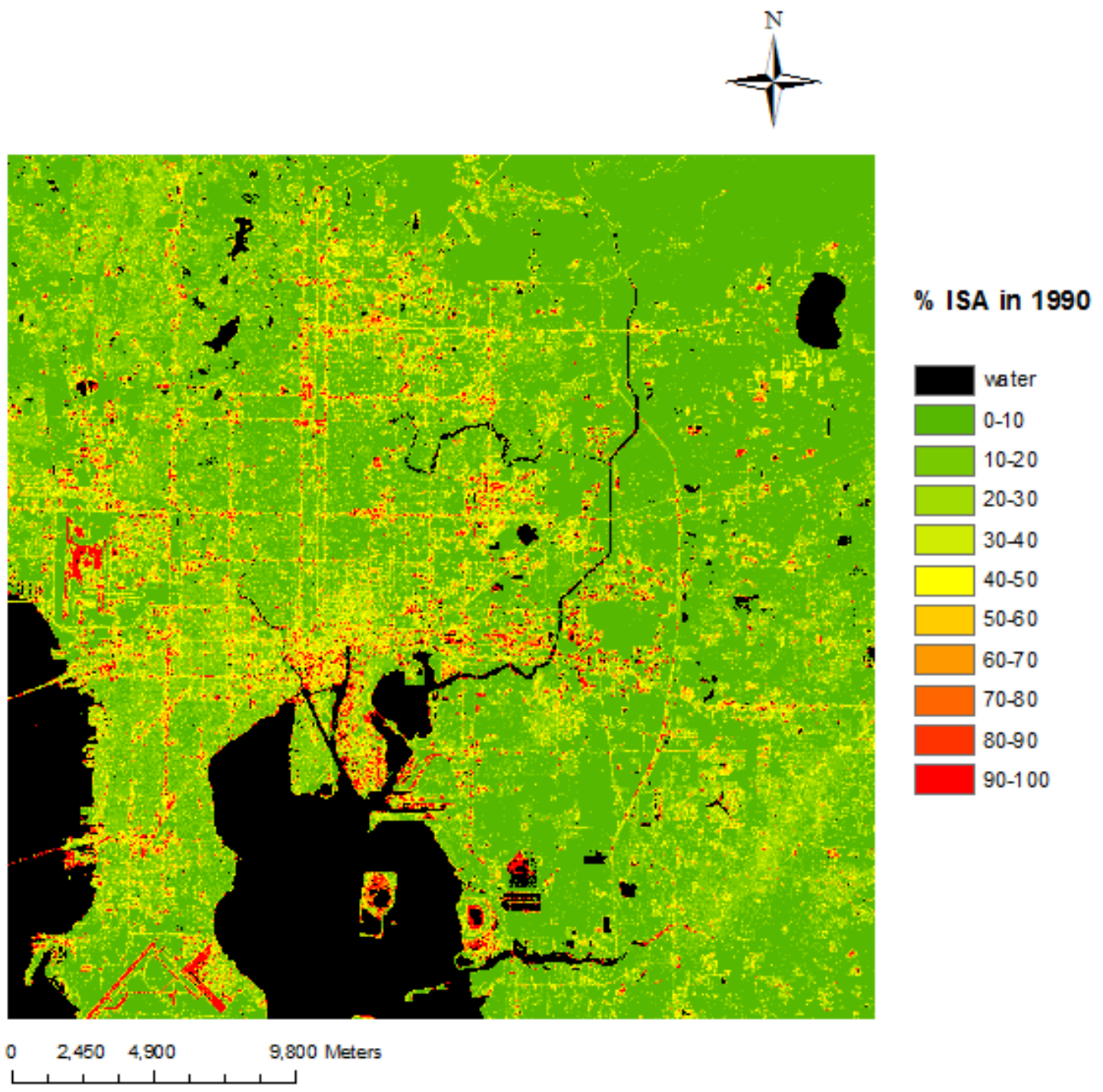

Figure 21. Distribution map of \%ISA in the study area in 1990. 


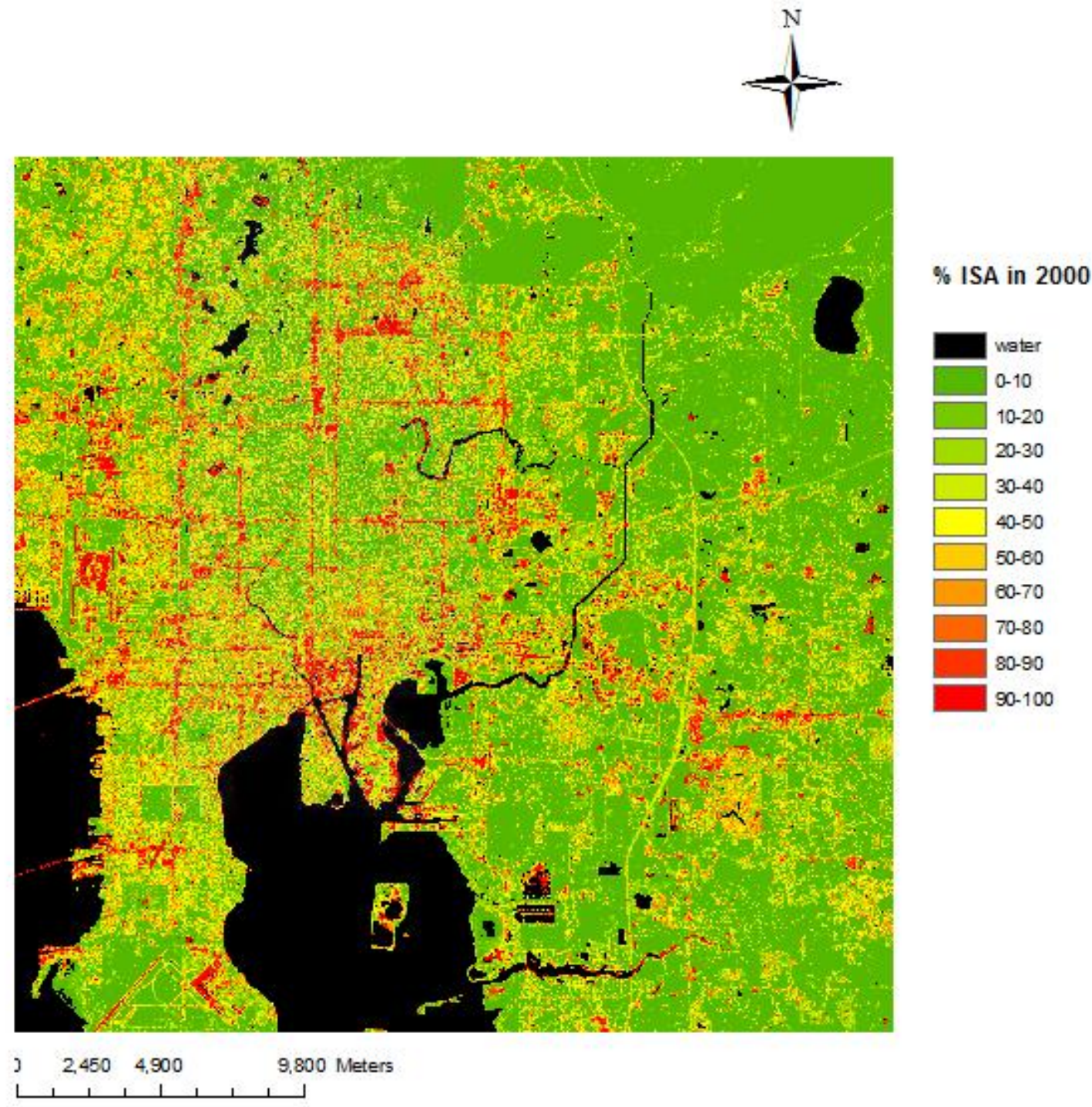

Figure 22. Distribution map of \%ISA in the study area in 2000. 


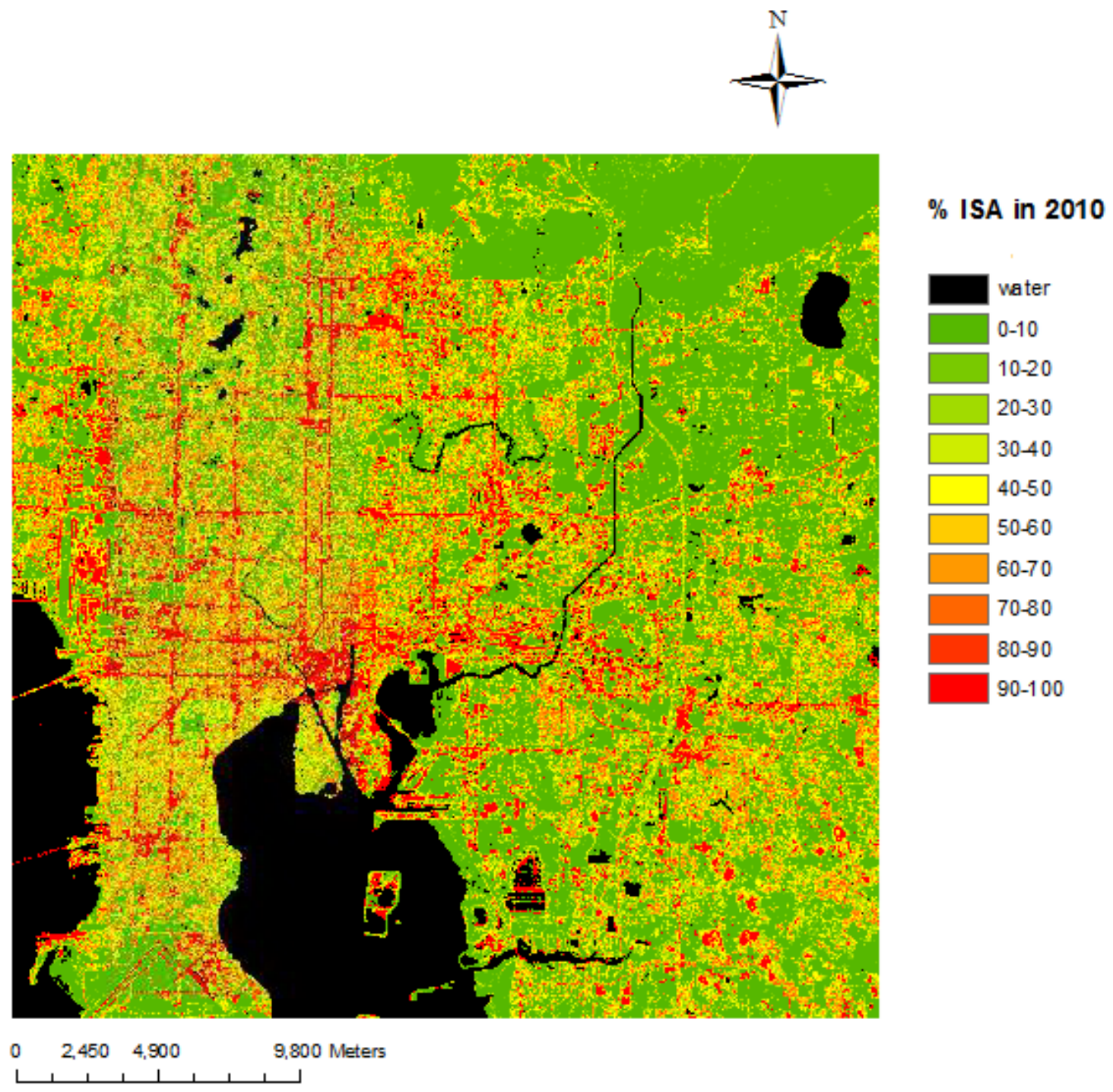

Figure 23. Distribution map of \%ISA in the study area in 2010.

\subsection{Urban Growth Analysis}

In order to understand the relationship between urban growth and population augmentation, census data were used to evaluate the impact of human activities (population increase) on urban growth. Ninety-four tracts within the City of Tampa covered by the study were selected for urban growth case analysis (Figure 24). 
Population and the \%ISA of the 94 tracts were used to test the relationship between urban landscape composition change and population change.

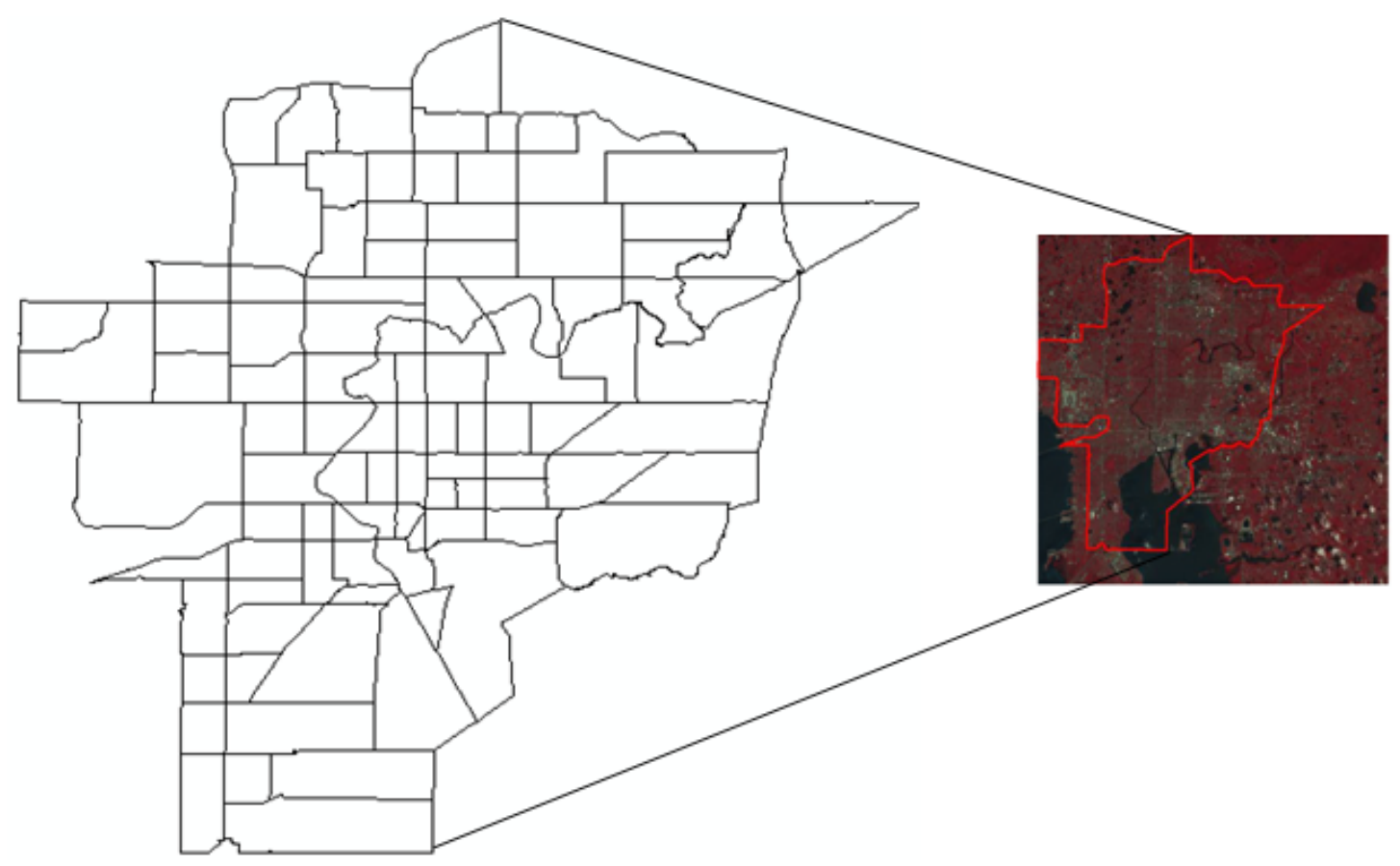

Figure 24. Ninety-four tracts in the City of Tampa covered by the study area.

Table 8 suggests that the average population, population density (person/mile ${ }^{2}$ ), and \%ISA in the 94 tracts have consistently increased from 1990 to 2010 . The population in the 94 tracts was 387,473 in 1990, increasing to 426,290 in 2010. The average population in the 94 tracts increased from 4,122.05 in 1990 to $4,535.3$ in 2010; an increase rate of $0.5 \%$ year, although population levels in some tracts did decrease (Figure 25). The rapid population increase resulted in an obvious expansion of impervious surfaces during the past two decades, especially in and surrounding the University Square area. However, it was also found that the \%ISA of some tracts increased while the population slightly 
decreased (e.g. Downtown). These decreases of population and increase of impervious surface areas occurred in areas with especially high levels of ISA. This can be explained by the conversion of downtown residential areas to commercial purposes. Although the \%ISA in these downtown areas increased greatly, the population decreased due to decreased residential space.

From Table 8 and Figure 26, it is evident that population density significantly increased from 1990 to 2010 . The average increase rate of population density was $0.15 \%$ /year from 2000 to 2010 , down slightly from $0.19 \%$ /year from 1990 to 2000. The greatest decrease of population density among the 94 tracts was tract "004000" (see A3), an area located in Downtown Tampa, where the population density declined from 11,731 (person/mile ${ }^{2}$ ) in 1990 to 875 (person/mile ${ }^{2}$ ) in 2010. In addition, the population density of some tracts in and surrounding the University Square area, such as '000100', '000300', and '010803', were very high, and consistently increased from 1990 to 2010 . According to the definition of urbanized areas by U.S. Census Bureau, these tracts can be considered as urbanized areas because the population density of the contiguous tracts is higher than 1,000 persons per square mile (see A3).

The results shown in the Figure 27 suggest that the number of tracts with relatively low \%ISA (e.g. lower than 20\%) decreased while the number of tracts with relatively high \%ISA (e.g., higher than 44\%) increased. It was also found that the \%ISA increased for every tract from 1990 to 2010 . To further demonstrate the increase of \%ISA, the results of pixel-based \%ISA of the 94 tracts are shown in Figure 28. The proportion of low to middle pixel- based \%ISA (e.g., $0-20 \%$, and 
20-40\%) went down from 1900 to 2010, while the proportion of highpixel-based \%ISA (e.g., 60-80\%, and 80-100\%) went up from 1990 to 2010. Therefore, population increases in these areas were directly associated with increased \%ISA. Also, increased population directly relates to increased \%ISA because anthropogenic activity causes increases in \%ISA unless a geological process.

Table 8. Population, population density and the percentage of ISA in the 94 tracts from 1990 to 2010.

\begin{tabular}{|r|r|r|r|r|r|r|}
\hline & \multicolumn{2}{|c|}{ POP } & \multicolumn{2}{c|}{ POPD } & \multicolumn{2}{c|}{ \%ISA } \\
\hline & Mean & Stdev & Mean & Stdev & Mean & Stdev \\
\hline 1990 & 4122.05 & 1911.42 & 4366.61 & 2093.90 & 21.21 & 7.02 \\
\hline 2000 & 4329.03 & 2207.36 & 4451.51 & 2004.86 & 33.40 & 9.92 \\
\hline 2010 & 4535.30 & 2392.90 & 4520.03 & 2077.68 & 42.39 & 11.37 \\
\hline
\end{tabular}

Note: POP: Population; POPD: Population Density; Stdev: Standard Deviation. 


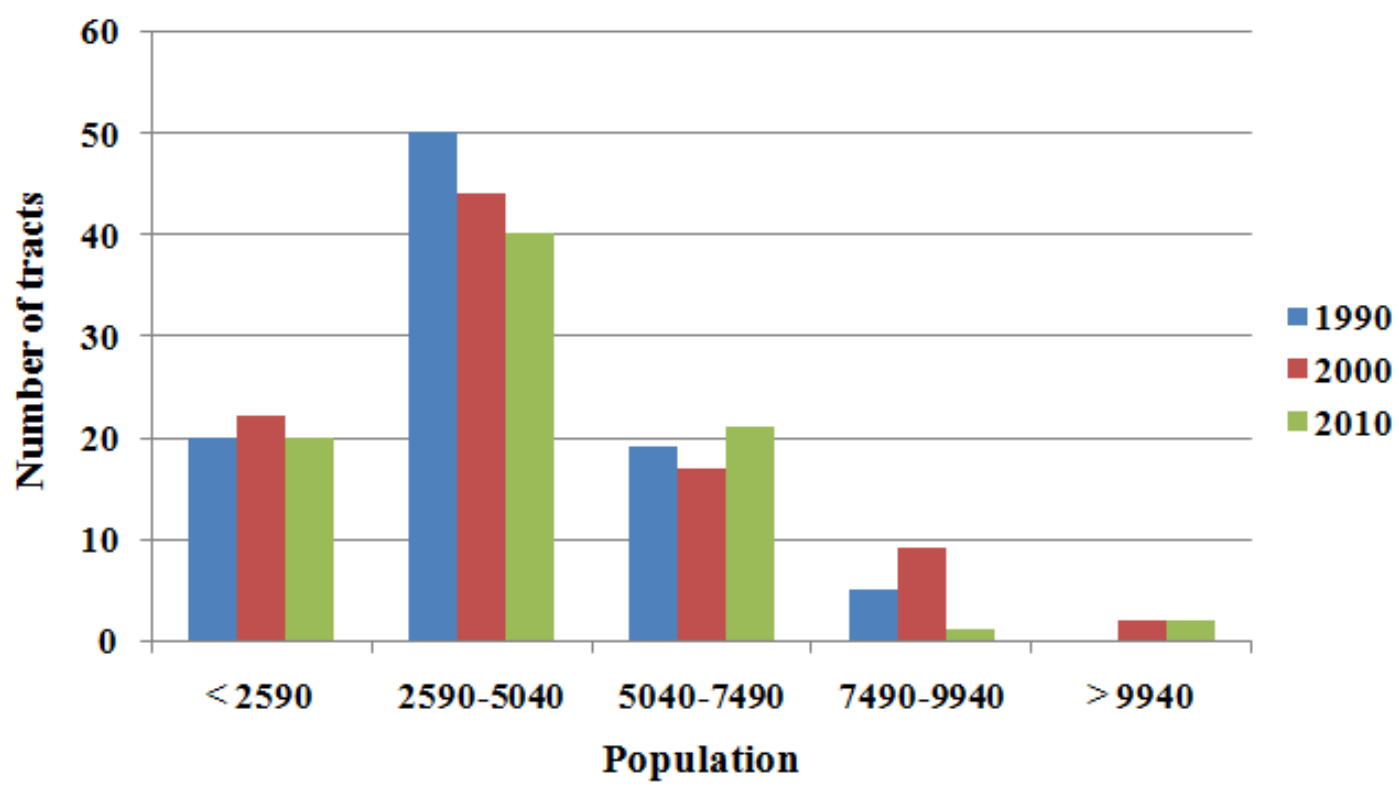

Figure 25. Population changes in the 94 tracts from 1990 to 2010.

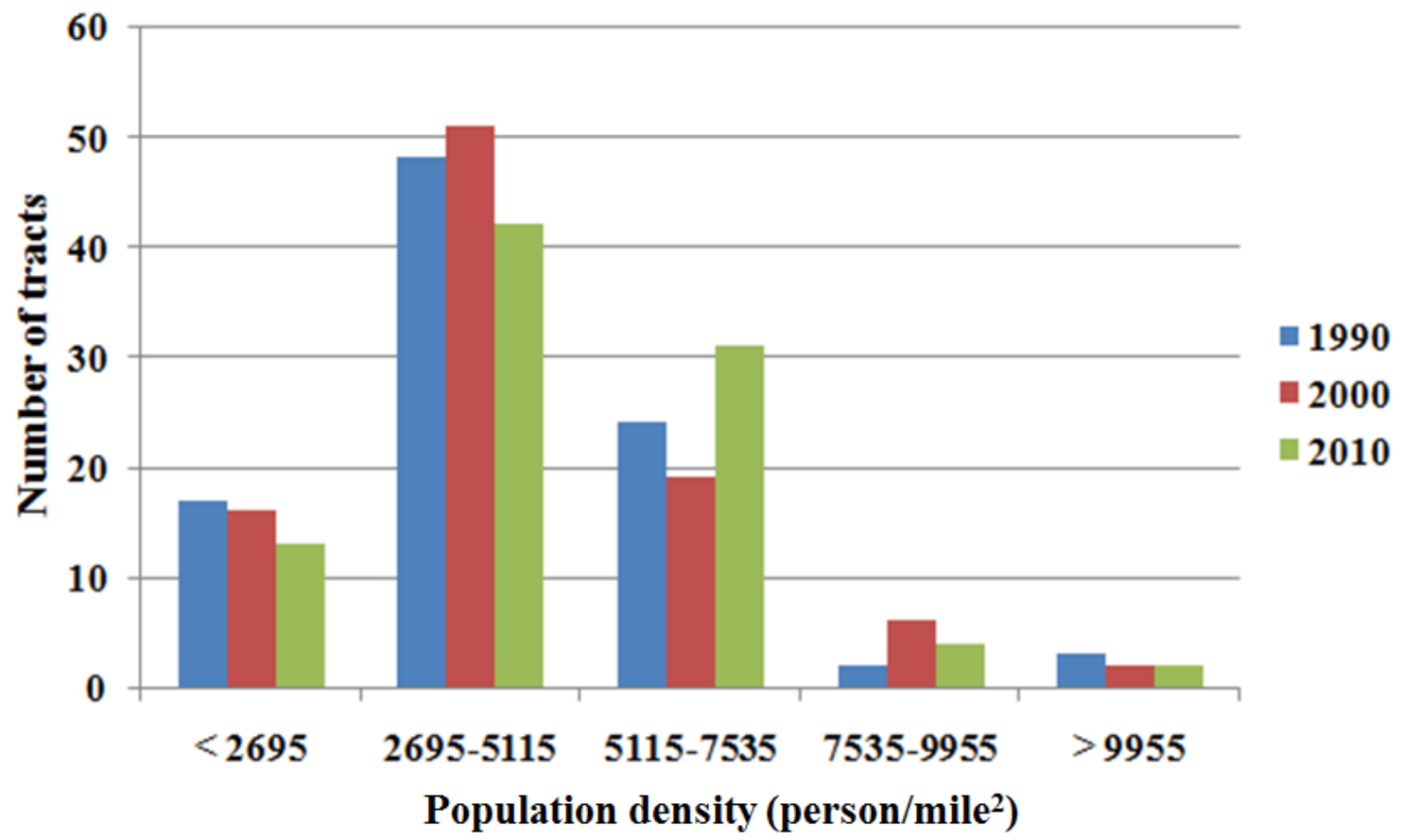

Figure 26. Population density changes in the 94 tracts from 1990 to 2010. 


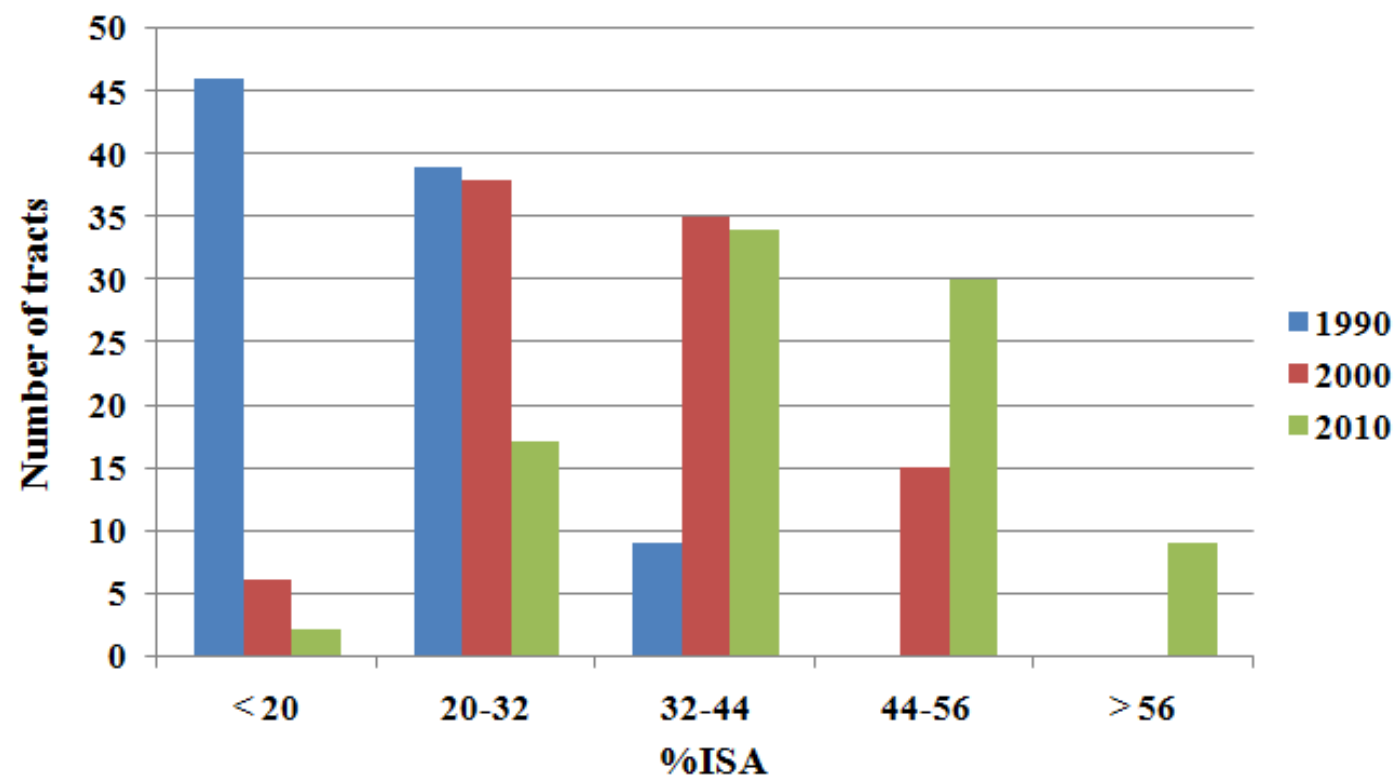

Figure 27. \%ISA changes in the 94 tracts from 1990 to 2010.

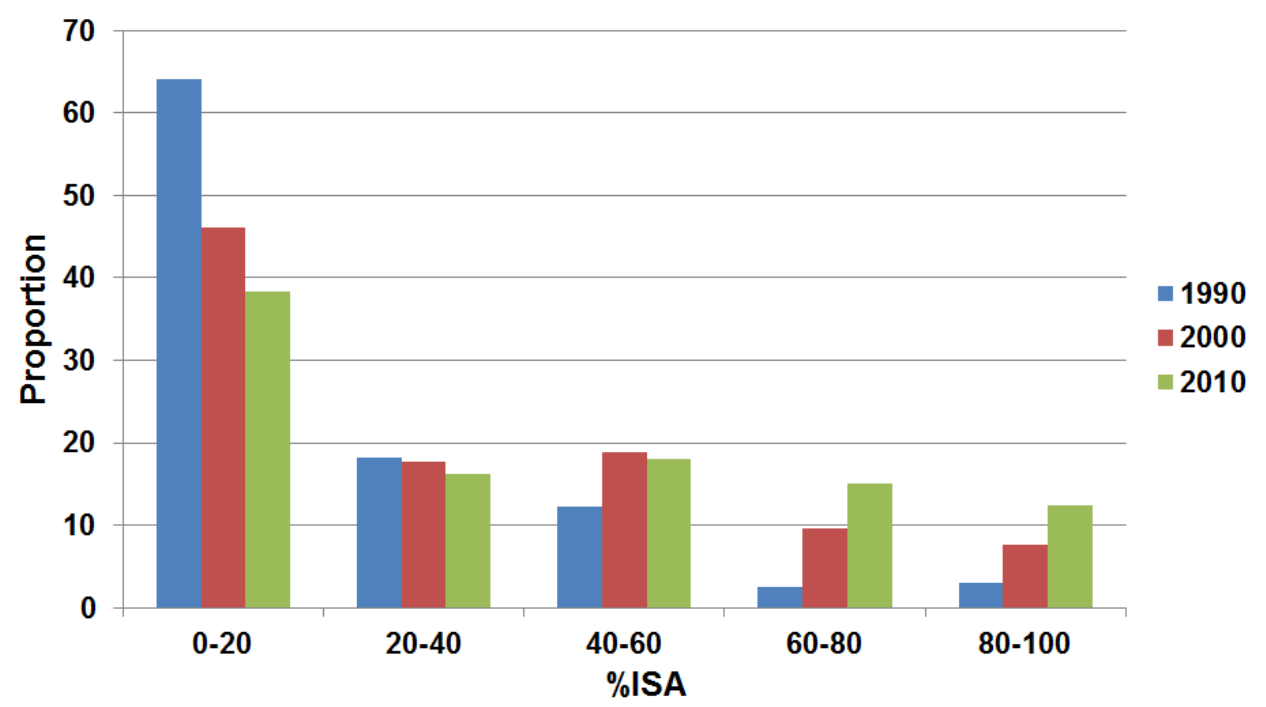

Figure 28. \%ISA changes (per-pixel based) in the 94 tracts from 1990 to 2010. 


\section{CHAPTER 5: CONCLUSIONS}

In this study, impervious surface distribution together with vegetation and soil cover, have been directly derived from Landsat TM reflectance images by applying MESMA and SMA models. The experimental results demonstrated that MESMA had a higher capability of mapping physical components for estimating impervious surface and provided better performance than the traditional SMA. This can be explained by two reasons: (1) The MESMA approach allows the number and type of endmembers to vary in each pixel of the image. This gives it an advantage over SMA when modeling urban environments, because different types of land cover occur as complex features in a small area (Powell et al., 2007; Myint and Okin, 2009). (2) Shade information and the specific information of the model can be easily traced in MESMA (Myint and Okin, 2009). In addition, MESMA was successfully applied in the study area of the City of Tampa and improved the accuracy of mapping physical components. This success was because (1) there were a sufficient number of spectra available to build a representative spectral library with the optimal number of endmembers present for each class; (2) the terrain of Tampa is relatively flat so that urban materials could be modeled with minimal shadow effects; and (3) photometric shade was

considered as a fixed endmember for every model, which effectively decreased 
the confusion between areas of low albedo and shade.

The urban environment of the City of Tampa, Florida, and its twenty-year change were assessed using ISA as an indicator. The results showed that Tampa has experienced great changes in the \%ISA during the past twenty years. From 1990 to 2010 , the $\%$ ISA expanded at an average rate of $0.66 \%$ per year. Some natural and protected landscapes were rapidly transformed into impervious surfaces. Specifically, the lower percentage of $(0-10 \%$ ISA $)$ impervious surface decreased by up to $10 \%$, while the higher percentage $(90-100 \%$ ISA) impervious surface increased by up to $5 \%$. In order to understand the relationship between human activity and the landscapes' transformation, an urban growth case study was done. It found that overall population, population density, and the \%ISA of areas within the study area all increased during the past two decades. At the tract level, every tract showed an increase of impervious surface area, and the population and population density of most tracts also increased. This underscores the linkage between increased population and the expansion of impervious surfaces, as rural and peripheral areas urbanized. However, the positive relationship between the population growth and increased \%ISA did not always occur. For example, as some already urbanized areas in downtown Tampa increased their population density without increasing the \%ISA. Therefore, human activity (notably by population increase) is the most important factor driving, the increase of the \%ISA area and urban growth outward from the city center to peripheral areas.

The findings of this study in the City of Tampa show how important increases 
in population numbers and density are in driving urban expansion into peripheral areas. In particular, the increase of population is consistent with the rapid transformation of landscapes in urban areas. Such a rapid urbanization (urban growth) in the urban environment may increase the numerous burdens on cities to provide services such as education, transportation, infrastructure, and physical security. Because of this, managed development through urban planning is essential to improve our living environment and our quality of life; promoting society's goals for a healthy and sustainable state in the economic, social, and political issues. Application of remote sensing techniques in the urban environment can provide a meaningful and efficient way of mapping and monitoring the changes in urban landscapes, especially the transformation of urban land use and land cover types. It is very significant for fostering the goals of environmental and human sustainability in cities, and can be applied in managing cities around the world. 


\section{REFERENCES}

Adams, J.B., and Gillespie, R.A., 2006. Remote sensing of landscapes with spectral images: a physical modeling approach. Cambridge University Press.

Adams, J.B., Sabol, D.E., Kapos, V., Almeida R.F., Roberts, D.A., and Smith, M.O., 1995. Classification of multispectral images based on fractions of endmembers: Application to land-cover change in the Brazilian Amazon. Remote Sensing of Environment, 52, 137-154.

Adams, J.B., and Smith, M.O., 1986. Architecture: Shade and shadow in geobotanical mapping (abs.), Fifth Thamatic Conf., Remote Sensing for Expl. Geol., Vol.111 ERIM, Houston, TX.

Adams, J.B., Smith, M.O., and Johnson, P.E., 1993. Imaging spectroscopy: Interpretation based on spectral mixing analysis. In C. M. Pieters, and P. A. J. Englert (Eds), Remote geochemical analysis: Elemental and mineralogical composition (pp. 145-164). Cambridge, England: Cambridge University Press.

Alberti, M., 2005. The effects of urban pattern on ecosystem function. International Regional Science Review, 28 (2), 168-192.

Anderson, G.L., Everitt, J.H., Escobar, D.E., Spencer, N.R., and Andrascik, R.J., 1996. Mapping leafy spurge (euphorbia esula) infestations using aerial photography and geographic information systems. Geocarto International, 11 (1), 81-89.

Arnold, C.L., and Gibbons, C.J., 1996. Impervious surface coverage: the emergence of a key environmental indicator. Journal of the American Planning Association 62 (2), 243-258.

Ballantine, J.C., Okin, G.S., Prentiss, D.E., and Roberts, D.A., 2005. Mapping North African landforms using continental scale unmixing of MODIS imagery. Remote Sensing of Environment, 97 (4), 470-483.

Barnsley, M., and Barr, S., 1996. Inferring urban land-use from satellite sensor images using kernel-based spatial reclassification. Photogrammetric Engineering and Remote Sensing, 62, 949-958.

Black, D., and Henderson, V., 1999. A theory of urban growth. Journal of Political 
Economy, 107 (2), 252-284.

Boardman, J.W., Kruse, F.A., and Green, R.O., 1995. Mapping target signatures via partial unmixing of AVIRIS data. Summaries of the Fifth Annual JPL Airborne Geoscience Workshop, Jet Propulsion Laboratory Publications, Pasadena, CA (1995), PP.23-26.

Brandt, J.S., and Townsend, P.A., 2005. Land use-land cover conversion, regeneration and degradation in the high elevation bolivian andes. Landscape Ecology, 21, 607-623.

Burgess, E.W., 2008. The growth of the city: an introduction to a research project. Urban Ecology, 71-78, DOI: 10.1007/978-0-387-73412-5_5.

Carpenter, G.A., Gopal, S., Macomber, S., Martens, S., and Woodcock, C.E., 1999. A neural network method for mixture estimation for vegetation mapping. Remote Sensing of Environment, 70 (2), 138-152.

Chaudhry, F., Wu, C., Liu, W., Chang, C., and Plaza, A., 2006. Pixel purity index-based algorithms for endmember extraction from hyperspectral imagery. Recent Advances in Hyperspectral Signal and Image Processing. ISBN: 81-7895-218-1.

Chen, S., Zeng, S., and Xie, C., 2000. Remote sensing and GIS for urban growth analysis in China. Photogrammetric Engineering and Remote Sensing, 66, 593-598.

Chen, X., and Vierling, L., 2005. Spectral mixture analyses of hyperspectral data acquired using a tethered balloon. Remote Sensing of Environment, 103, 338-350.

Cho, M., Mathieu, R., and Debba, P., 2009. Multiple endmember spectral-anagle-mapper (sam) analysis improves discrimination of savanna tree species. Hyperspectral Image and Signal Processing: Evolution in Remote Sensing, 1-4.

Daniel, C.L., James, H.D., Emily, W.H., Chester A.L., and Michael, P.P., 2002. Quantifying and describing urbanizing landscapes in the northeast United States. Photogrammetric engineering and remote sensing, 68, 1083-1090.

Dare, P.M., 2005. Shadow analysis in high-resolution satellite imagery of urban areas. Photogrammetric Engineering and Remote Sensing, 71, 169-177.

Dennison, P.E., and Roberts, D.A., 2003. Endmember selection for multiple endmember buhspectral mixture analysis using endmember average RMSE. Remote Sensing of Environment, 87, 123-135. 
Eddy, P., Staenz, K, and Zhang, J., 2009. Rangeland monitoring using hyperspectral remote sensing data and spectral mixture analysis. Hyperspectral image and signal processing: evolution in remote sensing, 1-4.

Elmore, A.J., Mustard, J.F., Manning, S.J., and Lobell, D.B., 2000. Quantifying vegetation change in semiarid environments: precision and accuracy of spectral mixture analysis and the normalized difference vegetation index. Remote Sensing of Environment, 73 (1), 87-102.

Fitzgerald, J.G., Pinter, J.P., Hunsaker, J.D., and Clarke, R.T., 2005. Multiple shadow fractions in spectral mixture analysis of a cotton canopy. Remote Sensing of Environment, 97, 526-539.

Franke, J., Roberts, D.A., Halligan, K., and Menz, G., 2009. Hierarchical multiple endmember spectral mixture analysis (MESMA) of hyperspectral imagery for urban environments. Remote Sensing of Environment, 113, 1712-1723.

Garci'a-haro, F.J., Sommer, S., and Kemper, T., 2005. A new tool for variable multiple endmember spectral mixture analysis (VMEMSA). International Journal of Remote Sensing, 26 (10), 2135-2162.

Green, K., Kempka, D., and Lackey, L., 1994. Using remote sensing to detect and monitor land-cover and land-use change. Photogrammetric Engineering and Remote Sensing, 60 (3), 331-337.

Halligan, K.Q., 2002. Multiple endmember spectral mixture analysis of vegetation in the northwest corner of Yellowstone National Park. Master's Thesis, University of California, Santa Barbara.

Hamada, Y., Stow, D.A., and Roberts, D.A., 2011. Estimating life-form cover fractions in California sage scrub communities using multispectral remote sensing. Remote Sensing of Environment, 115 (12), 3056-3068.

Herold, M., Goldstein, N.C., and Clarke, K.C., 2003. The spatiotemporal form of urban growth: measurement, analysis and modeling. Urban Remote Sensing. 86 (3), 286-302.

Herold, M., Roberts, D.A., Gardner, M.E., and Dennison, P.E., 2004. Spectrometry for urban area remote sensing-Development and analysis of a spectral library from 350 to 2400nm. Remote Sensing of Environment, 91 (3-4), 304-319.

Huang, H., Margulis, S.A., Chu, C., and Tsai, H., 2011. Investigation of the impacts of vegetation distribution and evaporative cooling on synthetic urban daytime climate using a coupled LES-LSM model. Hydrological Processes, 25, 1574-1586. 
Hung, M., 2002. Urban land cover analysis from satellite images. Pecora 15/ Land Satellite Information IV/ISPRS Commission I/FIEOS 2002 Conference Proceedings.

Jat, M.K., Garg, P.K., and Khare, D., 2008. Modelling of urban growth using spatial analysis techniques: a case study of Ajmer city (India). International Journal of Remote Sensing, 29 (2), 543-567.

Jarnagin, S., 2003. Regional and Global patterns of population, land use, and land cover change: an overview of stressors and impacts. GIScience and Remote Sensing, 41 (3), 207-227.

Ji, M., and Jensen, J., 1999. Effectiveness of subpixel analysis in detecting and quantifying urban imperviousness from Landsat Thematic Mapper Imagery. Geocarto International, 14 (4), 33-41.

Lee, S., and Lathrop, R.G., 2006. Sub-pixel estimation of urban land cover components with linear mixture model analysis and Landsat Thematic Mapper imagery. International Journal of Remote Sensing, 26 (22), 4885-4905.

Li, L., and Mustard, J., 2003. Highland contamination in lunar mare soils: Improved mapping with multiple endmember spectral mixture analysis (MESMA). Journal of Geophysical Research, 108 (E6), 5053-5066.

Li, L., Ustin, S.L., and Lay, M., 2005. Application of multiple endmember spectral mixture analysis (MESMA) to AVIRIS imagery for coastal salt marsh mapping: a case study in China Camp, CA, USA. Remote Sensing and GIS for Estimation, 26 (23), 5193-5207.

Lu, D., Batistella, M., Moran, E., and Mausel, P., 2004. Application of spectral mixture to Amazonian land-use and land-cover classification. International Journal of Remote Sensing, 25 (23), 5345-5358.

Lu, D., and Weng, Q., 2004. Spectral mixture analysis of the urban landscape in Indianapolis with Landsat ETM+ imagery. Photogrammetric Engineering and Remote Sensing, 70, 1053-1062.

Lu, D., and Weng, Q., 2005. Urban classification using full spectral information of Landsat ETM+ imagery in Marion Country, Indiana. Photogrammetric Engineering and Remote Sensing, 71, 1275-1284.

Lu, D., and Weng, Q., 2009. Extraction of urban impervious surfaces from IKONOS imagery. International Journal of Remote Sensing, 30 (5), 1297-1311.

Lu, D., Weng, Q., and Li, G., 2006. Residential population estimation using a 
remote sensing derived impervious surface approach. International Journal of Remote Sensing, 27 (16), 3353-3370.

Kalnay, E., and Cai, M., 2003. Impact of urbanization and land-use change on climate. Natural, 423 (29), 528-531.

Maas, S., 2000. Linear mixture modeling for estimating canopy cover using satellite imagery. Remote Sensing of Environment, 72, 304-308.

Madhavan, B.B., Kubo, S., Kurisaki, N., and Sivakumar, T., 2001. Appraising the anatomy and spatial growth of the Bangkok Metropolitan area using a vegetation-impervious-soil model through remote sensing. International Journal of Remote Sensing, 22 (5), 789-806.

Martinuzzi, S., Gould, W.A., and Ramos-González, O.M., 2007. Land development, land use, and urban sprawl in puertorico Puerto integrating remote sensing and population census data. Landscape and Urban Planning, 79 (3-4), 288-297.

Myint, S.W., and Okin, G.S., 2009. Modeling land-cover types using multiple endmember spectral mixture analysis in a desert city. International Journal of Remote Sensing, 30 (9), 2237-2257.

Okin, G.S., Roberts, D.A., Murray, B., and Okin, W.J., 2001. Practical limits on hyperspectral vegetation discrimination in arid and semiarid environments. Remote Sensing of Environment, 77, 212-225.

Peddle, D.R., Hall, F.G., LeDrew, E.F., 1999. Spectral mixture analysis and geometric-optical reflectance modeling of boreal forest biophysical structure. Remote Sensing of Environment, 67 (3), 288-297.

Peddle, D.R., and Smith, A.M., 2005. Spectral mixture analysis of agricultural crops: Endmember validation and biophysical estimation in potato plots. International Journal of Remote Sensing, 26 (22), 2959-4979.

Phinn, S., Stanford, M., and Scarth, P., 2002. Monitoring the composition of urban environments based on the vegetation-impervious surface-soil (VIS) model by subpixel analysis techniques. International Journal of Remote Sensing, 23, 4131-4153.

Phinn, S., Stanford, M., Scarth, P., Murray, A.T., and Shyy, P.T., 2010. Monitoring the composition of urban environments based on the vegetation-impervious surface-soil (VIS) model by subpixel analysis techniques. International Journal of Remote Sensing, 23 (20), 4131-4153.

Pickett M., Cadenasso, M.L., Grove, J.M., Nilon, C.H., Pouyat, R.V., Zipperer, W.C., and Costanza, R., 2008. Urban ecological systems: Linking terrestrial ecological, 
physical and socioeconomic components of metropolitan areas. Urban Ecology, 99-122.

Powell, R.L., Roberts, D.A., Dennison, P.E., and Hess, L.L., 2007. Sub-pixel mapping of urban land cover using multiple endmember spectral mixture analysis: Manaus, Brazil. Remote Sensing of Environment, 106, 253-267.

Pu, R., Gong, P., Michishita, R., and Sasagawa, T., 2008. Spectral Mixture Analysis for Mapping Abundance of Urban Surface Components from the Terra/ASTER Data. Remote Sensing of Environment, 112, 939-954.

Pu, R., and Gong, P., 2011. Hyperspectal Remote Sensign of Vegetation Bioparameters. In Weng, Q. (Eds.), Adances in Environmental Remote Sensing: Sensors, Algorithms, and Applications (pp. 101-142). CRC Press.

Rashed, T., Weeks, J.R., Gadalla, M.S., and Hill, A.G., 2001. Revealing the anatomy of cities through spectral mixture analysis of multispectral satellite imagery: a case study of the greater Cairo region, Egypt. Geocarto International, 16 (4), 5-15.

Ridd, M.K., 1995. Exploring a V-I-S (vegetation-impervious surface-soil) model for urban ecosystem analysis through remote sensing: comparative anatomy for cities. International Journal of Remote Sensing, 16, 2165-2185.

Riva-Murray, K., Riemann, R., Murdoch, P., Fischer, J.M., and Brightbill, R., 2010. Landscape characteristics affecting streams in urbanizing regions of the Delaware River Basin. Landscape Ecology, 25 (10), 1489-1503. DOI: 10.1007/s10980-010-9513-y.

Roberts, D. A., Batista, G.T., Pereira, L.G., Waller, E.K., and Nelson, B.W., 1998a. Change Identification Using Multitemporal Spectral Mixture Analysis: Application in Eastern Amazonia. In Lunetta, R.S., and Elvidge, C.D. (Eds.), Remote Sensing Change Detection: Environmental Monitoring Methods and Applications (pp. 137-161). Chelsea, Michigan: Ann Arbor Press.

Roberts, D.A., Gardner, M., Church, R., Ustin, S., Scheer, G., and Green, R.O., 1998b. Mapping Chaparral in the Santa Monica Mountains Using Multiple Endmember Spectral Mixture Models. Remote Sensing of Environment, 65, 267-279.

Roberts, D.A., Dennison, P.E., Gardner, M., Hetzel, Y., Ustin, S.L., and Lee, C., 2003. Evaluation of the potential of Hyperion for fire danger assessment by comparison to the Airborne Visible/Infrared Imaging Spectrometer. IEEE Transactions on Geoscience and Remote Sensing, 41 (6), 1297-1310.

Rogan, J., and Chen, D., 2003. Remote sensing technology for mapping and 
monitoring land-cover and land-use change. Progress in Planning, 61, 301-325.

Rosso, P.H., Ustin, S.L., and Hastings, A., 2005. Mapping marshland vegetation of San Francisco Bay, California, using hyperspectral data. International Journal of Remote Sensing, 26 (23), 5169-5191.

Sabol, D.E., Adams, J.B., and Smith, M.O., 1992. Quantitative subpixel spectral detection of targets in multispectral images. Journal of Geophysical Research, 97, 2659-2672.

Seto, K.C., Woodcock, C.E., Huang, X., Lu, J., and Kaufmam, R.K., 2002. Monitoring land use change in the Pearl River Delta using Landsat TM. International Journal of Remote Sensing, 23 (10), 1985-2004.

Seto, K.C., and Liu, W., 2003. Comparing ARTMAP neural network with the maximum-likelihood classifier for detecting urban change. Photogrammetric Engineering of Remote Sensing, 69 (9), 981-990.

Shahtahmassebi, A., Zhou, L., Wang, K., Xu, H., Deng, J., Li, J., Luo, R., Wu, J., and Moore, N., 2011. Monitoring rapid urban expansion using a multi-temporal RGB-impervious surface model. Environmental Engineering, 13 (2), 146-158.

Small, C., 2001. Estimation of urban vegetation abundance by spectral mixture analysis. International Journal of Remote Sensing, 22, 1305-1334.

Small, C., 2002. Multitemporal analysis of urban reflectance. Remote Sensing of Environment, 81 (2-3), 427-442.

Small, C., 2005. A global analysis of urban reflectance. International Journal of Remote Sensing, 26, 661-681.

Small, C., and Lu, J.W.T., 2006. Estimation and vicarious validation of urban vegetation abundance by spectral mixture analysis. Remote Sensing of Environment, 100 (4), 441-456.

Smith, M.O., Ustin, S.L., Adams, J.B., and Gillespie, A.R., 1990. Vegetation in deserts: I. A regional measure of abundance from multispectral images. Remote Sensing of Environment, 31, 1-26.

Song, C., 2005. Spectral mixture analysis for subpixel vegetation fractions in the urban environment: How to incorporate endmember variability? Remote Sensing of Environment, 95 (2), 248-263.

Song, C., and Woodcock, C.E., 2003. Monitoring forest succession with multitemporal Landsat images: Factors of uncertainty. IEEE Transactions on Geoscience and Remote Sensing, 41 (11), 2557-2567. 
Stankowski, S.J., and Trenton, N.J., 1972. Population density as an indirect indicator or urban and suburban land-surface modifications. U.S. Geological Survvey Professional paper, 800-B, B219-B224.

Stehman, S.V., and Czaplewski, R.L., 1998. Design and analysis for thematic map accuracy assessment: fundamental principles. Remote Sensing of Environment, 64 (3), 331-344.

Tompkins, S., Mustard, J.F., Pieters, C.M., and Forsyth, D.W., 1998. Optimization of endmembers for spectral mixture analysis. Remote Sensing of Environment, 59 (3), 472-489.

Treitz, P.M., Howard, P.J., and Gong, P., 1992. Application of satellite and GIS technologies for land-cover and land-use mapping at the rural-urban fringe: a case study. Photogrammetric Engineering and Remote Sensing, 58, 439-448.

Turner, B.L., and Meyer, W.B., 1991. Land use and land cover in global environmental change: considerations for study. International Social Science Journal, 43 (4), 669-679.

U.S. Census Bureau. Census data in the City of Tampa in 2010. (http://quickfacts.census.gov/qfd/states/12/1271000.html).

U.S. Census Bureau. Urban and rural definitions. (http://www.census.gov/population/censusdata/urdef.txt).

Ward, D., Phinn, S.R., and Murry, A.T., 2000. Monitoring growth in rapidly urbanized areas using remote sensed data. Professional Geographer, 52 (3), 371-386.

Weng, Q., 2002. Land use change analysis in the Zhujiang Delta of China using satellite remote sensing, GIS and stochastic modeling. Journal of Environmental Management, 64 (3), 293-284.

Weng, Q., 2012. Remote sensing of impervious surfaces in the urban areas: Requirements, methods, and trends. Remote Sensing of Environment, 117, 34-49.

Weng, Q., Lu, D., and Schubring, J., 2004. Estimation of land surface temperature-vegetation abundance relationship for urban heat island studies. Remote Sensing of Environment, 89, 467-483.

Weng, Q., and Lu, D., 2008. A sub-pixel analysis of urbanization effect on land surface temperature and its interplay with impervious surface and vegetation coverage in Indianapolis, United States. International Journal of Applied Earth Observation and Geoinformation, 10 (1), 68-83. 
Weng, Q., and Quattrochi, D., 2007. Urban Remote Sensing. CRC Press.

Wilson, J.S., Clay, M., Martin, E., Stuckey, D., and Vedder-Risch, K., 2003. Evaluating environmental influences of zoning in urban ecosystems with remote sensing. Remote Sensing of Environment, 86(3), 303-321.

Wu, C., 2004. Normalized spectral mixture analysis for monitoring urban composition using ETM+ imagery. Remote Sensing of Environment, 93, 480-492.

Xian, G., and Crane, M., 2005. Assessments of urban growth in the Tampa Bay watershed using remote sensing data. Remote Sensing of Environment, 97, 203215.

Xiao, J., Shen, Y., Ge, J., Tateishi, R., and Tang, C., Liang Y., and Huang, Z., 2006. Evaluating urban expansion and land use change in Shijiazhuang, China, by using GIS and remote sensing. Landscape and Urban Planning, 75 (1-2), 69-80.

Yang, F., Matsushita, B., and Fukushima, T., 2010. A pre-screened and normalized multiple endmember spectral mixture analysis for mapping impervious surface area in Lake Kasumigaura Basin, Japan. ISPRS Journal of Photogrammetry and Remote Sensing, 65, 479-490.

Yang, L., Huang, C., Homer, C.G., Wylie, B.K., and Coan, M.J., 2003. An approach for mapping large-area impervious surfaces: synergistic use of Landsat-7 ETM+ and high spatial resolution imagery. Canadian Journal of Remote Sensing, 29 (2), 230-240.

Yuan, F., and Bauer, M.E., 2007. Comparison of impervious surface area and normalized difference vegetation index as indicators of surface urban heat island effects in Landsat imagery. Remote Sensing of Environment, 106 (3), 375-386. 


\section{APPENDICES}

\section{A1. Accuracy assessment}

\section{A1.1 Vegetation accuracy assessment (MESMA Vs. Reference image)}

\begin{tabular}{|l|c|c|l|}
\multicolumn{5}{c|}{ Variables Entered/Removed $^{\mathrm{a}}$} \\
\hline $\begin{array}{l}\text { Mode } \\
1\end{array}$ & $\begin{array}{c}\text { Variables } \\
\text { Entered }\end{array}$ & $\begin{array}{c}\text { Variables } \\
\text { Removed }\end{array}$ & Method \\
\hline 1 & Actual $^{\mathrm{b}}$ & & Enter \\
\hline
\end{tabular}

a. Dependent Variable: Modeled

b. All requested variables entered.

\begin{tabular}{|l|r|r|r|r|}
\hline Model & \multicolumn{1}{|c|}{ R } & R Square & $\begin{array}{c}\text { Adjusted R } \\
\text { Square }\end{array}$ & $\begin{array}{c}\text { Std. Error of } \\
\text { the Estimate }\end{array}$ \\
\hline 1 & $.993^{\mathrm{a}}$ & .986 & .986 & .032775652 \\
\hline
\end{tabular}

a. Predictors: (Constant), Actual

b.

\begin{tabular}{|rl|r|r|r|c|c|}
\hline \multicolumn{1}{|c|}{ ANOVA $^{\mathrm{a}}$} \\
\hline & $\begin{array}{l}\text { Sum of } \\
\text { Squares }\end{array}$ & df & Mean Square & F & \multicolumn{1}{c|}{ Sig. } \\
\hline \multirow{2}{*}{1} & Regression & 2.550 & 1 & 2.550 & 2373.796 & $.000^{\mathrm{b}}$ \\
& Residual & .035 & 33 & .001 & & \\
& Total & 2.585 & 34 & & & \\
\hline
\end{tabular}

a. Dependent Variable: Modeled

b. Predictors: (Constant), Actual 


\begin{tabular}{|c|c|c|c|c|c|}
\hline \multicolumn{6}{|c|}{ Coefficients $^{\mathrm{a}}$} \\
\hline \multirow[t]{3}{*}{ Model } & \multirow{2}{*}{\multicolumn{2}{|c|}{$\begin{array}{c}\text { Unstandardized } \\
\text { Coefficients }\end{array}$}} & \multirow{3}{*}{$\begin{array}{c}\begin{array}{c}\text { Standardized } \\
\text { Coefficients }\end{array} \\
\text { Beta }\end{array}$} & \multirow[t]{3}{*}{$\mathrm{t}$} & \multirow[t]{3}{*}{ Sig. } \\
\hline & & & & & \\
\hline & B & Std. Error & & & \\
\hline (Constant) & .032 & .010 & & 3.233 & .003 \\
\hline Actual & .953 & .020 & .993 & 48.722 & .000 \\
\hline
\end{tabular}

a. Dependent Variable: Modeled 


\section{A1.2 Vegetation accuracy assessment (SMA Vs. Reference image)}

Variables Entered/Removed ${ }^{\mathrm{a}}$

\begin{tabular}{|l|l|l|l|}
\hline Model & Variables & Variables & Method \\
& Entered & Removed & \\
\hline 1 & Actual $^{\mathrm{b}}$ & & \\
\hline
\end{tabular}

a. Dependent Variable: Modeled

b. All requested variables entered.

Model Summary ${ }^{\mathrm{b}}$

\begin{tabular}{|l|r|r|r|r|}
\hline Model & \multicolumn{1}{|c|}{$\mathrm{R}$} & R Square & $\begin{array}{c}\text { Adjusted R } \\
\text { Square }\end{array}$ & $\begin{array}{r}\text { Std. Error of } \\
\text { the Estimate }\end{array}$ \\
\hline 1 & $.985^{\mathrm{a}}$ & .970 & .969 & .049905032 \\
\hline
\end{tabular}

a. Predictors: (Constant), Actual

b. Dependent Variable: Modeled

\begin{tabular}{|c|c|c|c|c|c|c|}
\hline \multicolumn{7}{|c|}{$\mathrm{ANOVA}^{\mathrm{a}}$} \\
\hline \multicolumn{2}{|c|}{ Model } & Sum of & df & Mean Square & $\mathrm{F}$ & Sig. \\
\hline \multirow{3}{*}{1} & Regression & 2.694 & 1 & 2.694 & 1081.731 & $.000^{\mathrm{b}}$ \\
\hline & Residual & .085 & 34 & .002 & & \\
\hline & Total & 2.779 & 35 & & & \\
\hline
\end{tabular}

a. Dependent Variable: Modeled

b. Predictors: (Constant), Actual

Coefficients $^{\mathrm{a}}$

\begin{tabular}{|c|c|c|c|c|c|}
\hline \multirow[t]{2}{*}{ Model } & \multicolumn{2}{|c|}{$\begin{array}{c}\text { Unstandardized } \\
\text { Coefficients }\end{array}$} & $\begin{array}{l}\text { Standardized } \\
\text { Coefficients }\end{array}$ & \multirow[t]{2}{*}{$\mathrm{t}$} & \multirow[t]{2}{*}{ Sig. } \\
\hline & $\mathrm{B}$ & Std. Error & Beta & & \\
\hline (Constant) & .035 & .014 & & 2.436 & .020 \\
\hline Actual & .951 & .029 & .985 & 32.890 & .000 \\
\hline
\end{tabular}

a. Dependent Variable: Modeled 
Residuals Statistics $^{\mathrm{a}}$

\begin{tabular}{|l|r|r|r|r|r|}
\hline & \multicolumn{1}{|c|}{ Minimum } & Maximum & \multicolumn{1}{c|}{ Mean } & Std. Deviation & \multicolumn{1}{c|}{ N } \\
\hline Predicted Value & .03512889 & .93866795 & .42254244 & .277440507 & 36 \\
Residual & -.096949980 & .176878929 & $0 \mathrm{E}-9$ & .049186936 & 36 \\
Std. Predicted & -1.396 & 1.860 & .000 & 1.000 & 36 \\
Value & -1.943 & 3.544 & .000 & .986 & 36 \\
Std. Residual & & & & \\
\hline
\end{tabular}

a. Dependent Variable: Modeled 


\section{A1.3 Impervious accuracy assessment (MESMA Vs. Reference image)}

\begin{tabular}{|l|l|l|l|}
\multicolumn{4}{c|}{ Variables Entered/Removed $^{\mathrm{a}}$} \\
\hline Model & $\begin{array}{c}\text { Variables } \\
\text { Entered }\end{array}$ & $\begin{array}{c}\text { Variables } \\
\text { Removed }\end{array}$ & Method \\
\hline 1 & Actual $^{\mathrm{b}}$ & & .Enter \\
\hline
\end{tabular}

a. Dependent Variable: Modeled

b. All requested variables entered.

\begin{tabular}{|l|r|r|r|r|}
\hline \multicolumn{5}{|c|}{ Model Summary $^{\mathrm{b}}$} \\
\hline 1 & $\mathrm{R}$ & R Square & $\begin{array}{c}\text { Adjusted R } \\
\text { Square }\end{array}$ & $\begin{array}{l}\text { Std. Error of } \\
\text { the Estimate }\end{array}$ \\
\hline 1 & $.996^{\mathrm{a}}$ & .993 & .992 & .024198452 \\
\hline
\end{tabular}
a. Predictors: (Constant), Actual
b. Dependent Variable: Modeled

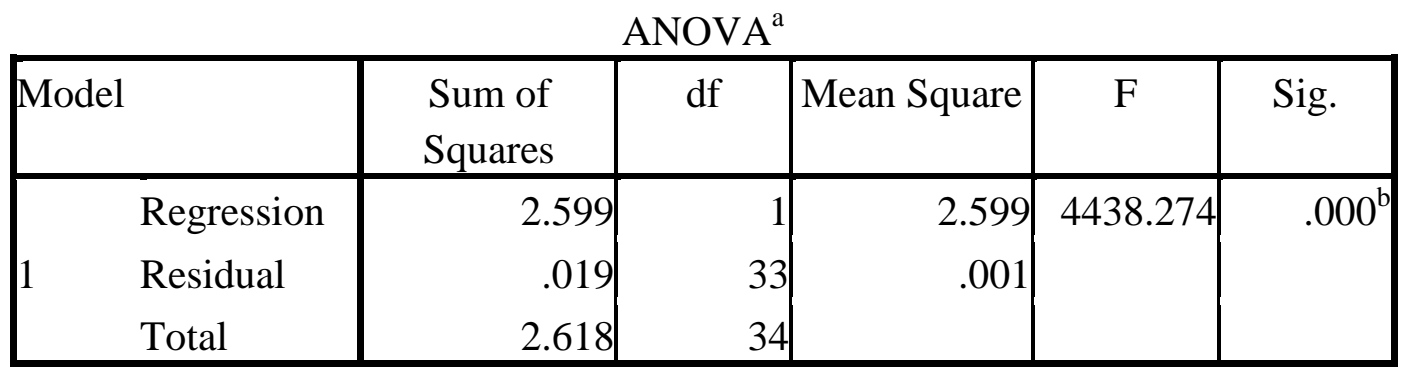

a. Dependent Variable: Modeled

b. Predictors: (Constant), Actual

\section{Coefficients $^{\mathrm{a}}$}

\begin{tabular}{|c|c|c|c|c|c|}
\hline \multirow[t]{2}{*}{ Model } & \multicolumn{2}{|c|}{$\begin{array}{c}\text { Unstandardized } \\
\text { Coefficients }\end{array}$} & $\begin{array}{l}\text { Standardized } \\
\text { Coefficients }\end{array}$ & $\mathrm{t}$ & Sig. \\
\hline & B & Std. Error & Beta & & \\
\hline (Constant) & .015 & .007 & & 2.284 & .029 \\
\hline Actual & .970 & .015 & .996 & 66.620 & .000 \\
\hline
\end{tabular}

a. Dependent Variable: Modeled

Residuals Statistics $^{\mathrm{a}}$ 


\begin{tabular}{|l|r|r|r|r|r|}
\hline & \multicolumn{1}{|c|}{ Minimum } & Maximum & \multicolumn{1}{c|}{ Mean } & Std. Deviation & \multicolumn{1}{c|}{$\mathrm{N}$} \\
\hline Predicted Value & .01486625 & .98474050 & .35211869 & .276474574 & 35 \\
Residual & -.077801391 & .065435007 & $0 \mathrm{E}-9$ & .023839937 & 35 \\
Std. Predicted & -1.220 & 2.288 & .000 & 1.000 & 35 \\
Value & -3.215 & 2.704 & .000 & .985 & 35 \\
Std. Residual & &
\end{tabular}

a. Dependent Variable: Modeled 


\section{A1.4 Impervious accuracy assessment (SMA Vs. Reference image)}

\begin{tabular}{|l|l|c|l|}
\multicolumn{4}{c|}{ Variables Entered/Removed $^{\mathrm{a}}$} \\
\hline $\begin{array}{l}\text { Mode } \\
1\end{array}$ & $\begin{array}{c}\text { Variables } \\
\text { Entered }\end{array}$ & $\begin{array}{c}\text { Variables } \\
\text { Removed }\end{array}$ & Method \\
\hline 1 & Actual $^{\mathrm{b}}$ & & Enter \\
\hline
\end{tabular}

a. Dependent Variable: Modeled

b. All requested variables entered.

\begin{tabular}{|l|r|r|r|r|}
\hline $\begin{array}{l}\text { Mode } \\
1\end{array}$ & R & R Square & $\begin{array}{c}\text { Adjusted R } \\
\text { Square }\end{array}$ & $\begin{array}{c}\text { Std. Error of } \\
\text { the Estimate }\end{array}$ \\
\hline 1 & $.958^{\mathrm{a}}$ & .918 & .915 & .079323458 \\
\hline
\end{tabular}

a. Predictors: (Constant), Actual

b. Dependent Variable: Modeled

\begin{tabular}{|c|c|c|c|c|c|c|}
\hline \multicolumn{7}{|c|}{ ANOVA $^{\mathrm{a}}$} \\
\hline & & $\begin{array}{l}\text { Sum of } \\
\text { Squares }\end{array}$ & $\mathrm{df}$ & $\begin{array}{l}\text { Mean } \\
\text { Square }\end{array}$ & $\mathrm{F}$ & Sig. \\
\hline \multirow{3}{*}{1} & Regression & 2.314 & 1 & 2.314 & 367.736 & $.000^{b}$ \\
\hline & Residual & .208 & 33 & .006 & & \\
\hline & Total & 2.522 & 34 & & & \\
\hline
\end{tabular}

a. Dependent Variable: Modeled

b. Predictors: (Constant), Actual

Coefficients $^{\mathrm{a}}$

\begin{tabular}{|rr|r|r|r|r|r|}
\hline \multicolumn{2}{|l|}{ Model } & \multicolumn{2}{|c|}{$\begin{array}{c}\text { Unstandardized } \\
\text { Coefficients }\end{array}$} & \multicolumn{1}{c|}{$\begin{array}{c}\text { Standardized } \\
\text { Coefficients }\end{array}$} & \multirow{2}{*}{ Sig. } \\
\cline { 2 - 5 } & \multicolumn{1}{|c|}{ B } & Std. Error & \multicolumn{1}{c|}{ Beta } & \\
\hline \multirow{2}{*}{1} & (Constant) & .030 & .021 & & 1.416 & .166 \\
& Actual & .915 & .048 & .958 & 19.176 & .000 \\
\hline
\end{tabular}

a. Dependent Variable: Modeled 


\begin{tabular}{|l|r|r|r|r|r|}
\hline & Minimum & Maximum & Mean & $\begin{array}{c}\text { Std. } \\
\text { Deviation }\end{array}$ & \multicolumn{1}{c|}{ N } \\
\hline Predicted Value & .03021498 & .94536179 & .34843714 & .260873835 & 35 \\
Residual & -.40781328 & .099747948 & $0 \mathrm{E}-9$ & .078148231 & 35 \\
Std. Predicted & 1 & & & & \\
Value & -1.220 & 2.288 & .000 & 1.000 & 35 \\
Std. Residual & -5.141 & 1.257 & .000 & .985 & 35 \\
\hline
\end{tabular}




\section{A1.5 Soil accuracy assessment (MESMA Vs. Reference image)}

\begin{tabular}{|l|l|l|l|}
\multicolumn{4}{c|}{ Variables Entered/Removed $^{\mathrm{a}}$} \\
\hline Model & $\begin{array}{c}\text { Variables } \\
\text { Entered }\end{array}$ & $\begin{array}{c}\text { Variables } \\
\text { Removed }\end{array}$ & Method \\
\hline 1 & Actual $^{\mathrm{b}}$ & & .Enter \\
\hline
\end{tabular}

a. Dependent Variable: Modeled

b. All requested variables entered.

Model Summary ${ }^{\mathrm{b}}$

\begin{tabular}{|l|r|r|r|r|}
\hline Model & \multicolumn{1}{|c|}{$\mathrm{R}$} & R Square & $\begin{array}{c}\text { Adjusted R } \\
\text { Square }\end{array}$ & $\begin{array}{c}\text { Std. Error of } \\
\text { the Estimate }\end{array}$ \\
\hline 1 & $.985^{\mathrm{a}}$ & .970 & .969 & .039703448 \\
\hline
\end{tabular}

a. Predictors: (Constant), Actual

b. Dependent Variable: Modeled

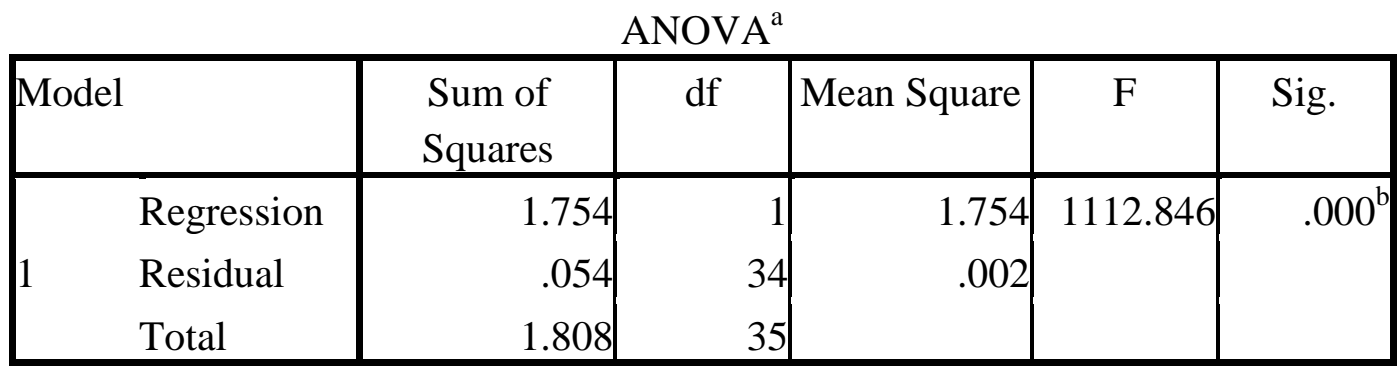

a. Dependent Variable: Modeled

b. Predictors: (Constant), Actual

Coefficients $^{\mathrm{a}}$

\begin{tabular}{|c|c|c|c|c|c|}
\hline \multirow[t]{2}{*}{ Model } & \multicolumn{2}{|c|}{$\begin{array}{c}\text { Unstandardized } \\
\text { Coefficients }\end{array}$} & $\begin{array}{l}\text { Standardized } \\
\text { Coefficients }\end{array}$ & \multirow[t]{2}{*}{$\mathrm{t}$} & \multirow[t]{2}{*}{ Sig. } \\
\hline & $\mathrm{B}$ & Std. Error & Beta & & \\
\hline (Constant) & -.013 & .010 & & -1.289 & .206 \\
\hline Actual & .985 & .030 & .985 & 33.359 & .000 \\
\hline
\end{tabular}

a. Dependent Variable: Modeled 
Residuals Statistics $^{\mathrm{a}}$

\begin{tabular}{|l|r|r|r|r|r|}
\hline & \multicolumn{1}{|c|}{ Minimum } & \multicolumn{1}{c|}{ Maximum } & \multicolumn{1}{c|}{ Mean } & Std. Deviation & \multicolumn{1}{c|}{$\mathrm{N}$} \\
\hline Predicted Value & -.01253854 & .95232528 & .22528803 & .223878171 & 36 \\
Residual & -.078043655 & .086562894 & $0 \mathrm{E}-9$ & .039132145 & 36 \\
Std. Predicted & -1.062 & 3.247 & .000 & 1.000 & 36 \\
Value & -1.966 & 2.180 & .000 & .986 & 36 \\
Std. Residual & & & & & \\
\hline
\end{tabular}




\section{A1.6 Soil accuracy assessment (SMA Vs. Reference image)}

\begin{tabular}{|l|l|c|l|}
\multicolumn{4}{c}{ Variables Entered/Removed $^{\mathrm{a}}$} \\
\hline Model & $\begin{array}{c}\text { Variables } \\
\text { Entered }\end{array}$ & $\begin{array}{c}\text { Variables } \\
\text { Removed }\end{array}$ & Method \\
\hline 1 & Actual $^{\mathrm{b}}$ & & .Enter \\
\hline
\end{tabular}

a. Dependent Variable: Modeled

b. All requested variables entered.

\begin{tabular}{|l|r|r|r|r|}
\hline \multicolumn{5}{|c|}{ Model Summary $^{\mathrm{b}}$} \\
\hline Model & \multicolumn{1}{|c|}{$\mathrm{R}$} & R Square & $\begin{array}{c}\text { Adjusted R } \\
\text { Square }\end{array}$ & $\begin{array}{c}\text { Std. Error of } \\
\text { the Estimate }\end{array}$ \\
\hline 1 & $.909^{\mathrm{a}}$ & .826 & .821 & .104081133 \\
\hline
\end{tabular}
a. Predictors: (Constant), Actual
b. Dependent Variable: Modeled

\begin{tabular}{|c|c|c|c|c|c|c|}
\hline \multicolumn{7}{|c|}{ ANOVA $^{\mathrm{a}}$} \\
\hline \multicolumn{2}{|c|}{ Model } & Sum of & df & Mean Square & $\mathrm{F}$ & Sig. \\
\hline \multirow{3}{*}{1} & Regression & 1.750 & 1 & 1.750 & 161.577 & $.000^{\mathrm{b}}$ \\
\hline & Residual & .368 & 34 & .011 & & \\
\hline & Total & 2.119 & 35 & & & \\
\hline
\end{tabular}

a. Dependent Variable: Modeled

b. Predictors: (Constant), Actual

Coefficients $^{\mathrm{a}}$

\begin{tabular}{|c|c|c|c|c|c|}
\hline \multirow[t]{2}{*}{ Model } & \multicolumn{2}{|c|}{$\begin{array}{c}\text { Unstandardized } \\
\text { Coefficients }\end{array}$} & $\begin{array}{c}\text { Standardized } \\
\text { Coefficients }\end{array}$ & \multirow[t]{2}{*}{$\mathrm{t}$} & \multirow[t]{2}{*}{ Sig. } \\
\hline & B & Std. Error & Beta & & \\
\hline (Constant) & -.005 & .025 & & -.191 & .850 \\
\hline Actual & .983 & .077 & .909 & 12.711 & .000 \\
\hline
\end{tabular}

a. Dependent Variable: Modeled 
Residuals Statistics ${ }^{\mathrm{a}}$

\begin{tabular}{|l|r|r|r|r|r|}
\hline & \multicolumn{1}{|c|}{ Minimum } & \multicolumn{1}{c|}{ Maximum } & \multicolumn{1}{c|}{ Mean } & Std. Deviation & \multicolumn{1}{c|}{$\mathrm{N}$} \\
\hline Predicted Value & -.00486249 & .95892680 & .23269922 & .223628843 & 36 \\
Residual & -.198932692 & .496338367 & $0 \mathrm{E}-9$ & .102583485 & 36 \\
Std. Predicted & -1.062 & 3.247 & .000 & 1.000 & 36 \\
Value & -1.911 & 4.769 & .000 & .986 & 36 \\
Std. Residual & &
\end{tabular}

a. Dependent Variable: Modeled 


\section{A2. ISA fraction distribution data}

Table A 1. ISA fraction distribution data in the study area from 1990 to 2010

$\begin{array}{llll}\text { \% ISA } & 1990 & 2000 & 2010 \\ 0-10 & 44.379 & 42.198 & 34.599 \\ 10-20 & 15.842 & 6.412 & 5.047 \\ 20-30 & 8.544 & 6.916 & 6.645 \\ 30-40 & 6.199 & 6.693 & 7.507 \\ 40-50 & 4.496 & 6.901 & 7.314 \\ 50-60 & 3.167 & 6.370 & 6.842 \\ 60-70 & 1.228 & 4.035 & 6.415 \\ 70-80 & 0.55 & 2.310 & 4.273 \\ 80-90 & 0.228 & 1.524 & 1.282 \\ 90-100 & 1.818 & 3.089 & 6.526\end{array}$




\section{A3. Population and Population density (person/mile ${ }^{2}$ ) (94 census data by tract in the City of Tampa Florida from 1990-2010)}

\begin{tabular}{lrrrrrrr} 
Tract & POP90 & POP00 & POP10 & \multicolumn{1}{l}{ Area } & POPD90 & POPD00 & POPD10 \\
000100 & 6546 & 7754 & 9401 & 2.63 & 2488.97 & 2948.29 & 3574.52 \\
000200 & 7118 & 8074 & 7621 & 1.15 & 6189.57 & 7020.87 & 6626.96 \\
000300 & 6444 & 7228 & 8376 & 1.13 & 5702.65 & 6396.46 & 7412.39 \\
000400 & 4562 & 4772 & 4793 & 1.52 & 3001.32 & 3139.47 & 3153.29 \\
000500 & 3906 & 3859 & 3779 & 1.15 & 3396.52 & 3355.65 & 3286.09 \\
000600 & 5821 & 6712 & 6547 & 1.03 & 5651.46 & 6516.50 & 6356.31 \\
000700 & 6223 & 6308 & 5724 & 0.82 & 7589.02 & 7692.68 & 6980.49 \\
000800 & 3135 & 3675 & 3264 & 1.02 & 3073.53 & 3602.94 & 3200.00 \\
000900 & 5011 & 6614 & 7024 & 0.87 & 5759.77 & 7602.30 & 8073.56 \\
001000 & 7408 & 7372 & 8457 & 2.20 & 3367.27 & 3350.91 & 3844.09 \\
001100 & 2345 & 2345 & 2166 & 0.65 & 3607.69 & 3607.69 & 3332.31 \\
001200 & 3269 & 2798 & 2879 & 0.54 & 6053.70 & 5181.48 & 5331.48 \\
001300 & 5023 & 5440 & 5706 & 1.51 & 3326.49 & 3602.65 & 3778.81 \\
001400 & 3790 & 4187 & 4462 & 0.93 & 4075.27 & 4502.15 & 4797.85 \\
001500 & 2542 & 2554 & 2412 & 0.58 & 4382.76 & 4403.45 & 4158.62 \\
001600 & 2141 & 1991 & 1923 & 0.51 & 4198.04 & 3903.92 & 3770.59 \\
001700 & 4177 & 4272 & 4187 & 1.02 & 4095.10 & 4188.24 & 4104.90 \\
001800 & 3521 & 3334 & 4129 & 0.93 & 3786.02 & 3584.95 & 4439.78 \\
001900 & 3024 & 2647 & 2831 & 0.76 & 3978.95 & 3482.89 & 3725.00 \\
002000 & 2532 & 2638 & 2729 & 0.50 & 5064.00 & 5276.00 & 5458.00 \\
002100 & 2820 & 2939 & 2701 & 0.51 & 5529.41 & 5762.75 & 5296.08 \\
002200 & 1800 & 1870 & 1580 & 0.50 & 3600.00 & 3740.00 & 3160.00 \\
002300 & 2972 & 3160 & 3057 & 0.56 & 5307.14 & 5642.86 & 5458.93 \\
002400 & 3821 & 4066 & 3792 & 0.93 & 4108.60 & 4372.04 & 4077.42 \\
002500 & 5371 & 6293 & 6637 & 1.02 & 5265.69 & 6169.61 & 6506.86 \\
002600 & 2426 & 2091 & 1784 & 6.52 & 372.09 & 320.71 & 273.62 \\
002700 & 5984 & 6592 & 6888 & 1.36 & 4400.00 & 4847.06 & 5064.71 \\
002800 & 2927 & 2913 & 2792 & 0.66 & 4434.85 & 4413.64 & 4230.30
\end{tabular}




\begin{tabular}{|c|c|c|c|c|c|c|c|}
\hline 002900 & 2308 & 2218 & 1922 & 0.51 & 4525.49 & 4349.02 & 3768.63 \\
\hline 003000 & 3525 & 3526 & 2914 & 0.52 & 6778.85 & 6780.77 & 5603.85 \\
\hline 003100 & 3631 & 2498 & 2673 & 0.51 & 7119.61 & 4898.04 & 5241.18 \\
\hline 003200 & 2317 & 2569 & 2463 & 0.32 & 7240.63 & 8028.13 & 7696.88 \\
\hline 003300 & 3400 & 1987 & 2063 & 0.32 & 10625.00 & 6209.38 & 6446.88 \\
\hline 003400 & 3048 & 2388 & 3009 & 0.52 & 5861.54 & 4592.31 & 5786.54 \\
\hline 003500 & 2722 & 2398 & 2416 & 0.63 & 4320.63 & 3806.35 & 3834.92 \\
\hline 003600 & 3725 & 3753 & 4333 & 1.59 & 2342.77 & 2360.38 & 2725.16 \\
\hline 003700 & 1842 & 3137 & 2014 & 3.56 & 517.42 & 881.18 & 565.73 \\
\hline 003800 & 1370 & 1411 & 1047 & 0.83 & 1650.60 & 1700.00 & 1261.45 \\
\hline 003900 & 1842 & 1660 & 1975 & 0.67 & 2749.25 & 2477.61 & 2947.76 \\
\hline 004000 & 1877 & 1479 & 140 & 0.16 & 11731.25 & 9243.75 & 875.00 \\
\hline 004100 & 1312 & 1176 & 1835 & 0.25 & 5248.00 & 4704.00 & 7340.00 \\
\hline 004200 & 1499 & 1530 & 1055 & 0.40 & 3747.50 & 3825.00 & 2637.50 \\
\hline 004300 & 3437 & 2988 & 3052 & 0.29 & 11851.72 & 10303.45 & 10524.14 \\
\hline 004400 & 2266 & 2261 & 2071 & 0.37 & 6124.32 & 6110.81 & 5597.30 \\
\hline 004500 & 3800 & 4076 & 4244 & 0.73 & 5205.48 & 5583.56 & 5813.70 \\
\hline 004700 & 2609 & 2676 & 2245 & 0.71 & 3674.65 & 3769.01 & 3161.97 \\
\hline 004800 & 4201 & 4300 & 3886 & 0.99 & 4243.43 & 4343.43 & 3925.25 \\
\hline 004900 & 3158 & 3438 & 3982 & 0.70 & 4511.43 & 4911.43 & 5688.57 \\
\hline 005000 & 3357 & 3184 & 5505 & 0.72 & 4662.50 & 4422.22 & 7645.83 \\
\hline 005100 & 1454 & 2420 & 4667 & 1.05 & 1384.76 & 2304.76 & 4444.76 \\
\hline 005300 & 2297 & 2203 & 3809 & 3.37 & 681.60 & 653.71 & 1130.27 \\
\hline 005400 & 5634 & 5436 & 5465 & 1.36 & 4142.65 & 3997.06 & 4018.38 \\
\hline 005500 & 1436 & 1597 & 1931 & 0.37 & 3881.08 & 4316.22 & 5218.92 \\
\hline 005700 & 3792 & 4220 & 3670 & 0.68 & 5576.47 & 6205.88 & 5397.06 \\
\hline 005800 & 4263 & 4356 & 4363 & 1.14 & 3739.47 & 3821.05 & 3827.19 \\
\hline 006000 & 4609 & 4959 & 5271 & 1.27 & 3629.13 & 3904.72 & 4150.39 \\
\hline 006100 & 6165 & 6652 & 6612 & 0.99 & 6227.27 & 6719.19 & 6678.79 \\
\hline 006200 & 3373 & 3268 & 3526 & 0.66 & 5110.61 & 4951.52 & 5342.42 \\
\hline 006300 & 3432 & 3531 & 3733 & 0.74 & 4637.84 & 4771.62 & 5044.59 \\
\hline
\end{tabular}




$\begin{array}{rrrrrrrr}006600 & 3796 & 3647 & 3736 & 0.78 & 4866.67 & 4675.64 & 4789.74 \\ 006700 & 4577 & 4903 & 5381 & 1.13 & 4050.44 & 4338.94 & 4761.95 \\ 006800 & 7296 & 7284 & 7503 & 1.40 & 5211.43 & 5202.86 & 5359.29 \\ 006985 & 4916 & 4999 & 5214 & 1.21 & 4062.81 & 4131.40 & 4309.09 \\ 007085 & 9903 & 6142 & 6656 & 1.38 & 7176.09 & 4450.72 & 4823.19 \\ 010203 & 2218 & 2019 & 1977 & 1.64 & 1352.44 & 1231.10 & 1205.49 \\ 010204 & 3625 & 3853 & 5024 & 1.71 & 2119.88 & 2253.22 & 2938.01 \\ 010401 & 4352 & 5206 & 5350 & 1.03 & 4225.24 & 5054.37 & 5194.17 \\ 010402 & 3091 & 4291 & 5094 & 4.07 & 759.46 & 1054.30 & 1251.60 \\ 010500 & 7744 & 7578 & 7152 & 1.68 & 4609.52 & 4510.71 & 4257.14 \\ 010600 & 3241 & 2666 & 3231 & 1.04 & 3116.35 & 2563.46 & 3106.73 \\ 010700 & 9322 & 9611 & 8831 & 2.43 & 3836.21 & 3955.14 & 3634.16 \\ 010803 & 4785 & 7775 & 9402 & 0.76 & 6296.05 & 10230.26 & 12371.05 \\ 010804 & 7835 & 10054 & 11651 & 2.97 & 2638.05 & 3385.19 & 3922.90 \\ 010805 & 2627 & 3643 & 4943 & 0.74 & 3550.00 & 4922.97 & 6679.73 \\ 010806 & 6095 & 8554 & 7506 & 1.03 & 5917.48 & 8304.85 & 7287.38 \\ 010807 & 7483 & 7741 & 8202 & 0.99 & 7558.59 & 7819.19 & 8284.85 \\ 010808 & 2786 & 3023 & 2956 & 0.41 & 6795.12 & 7373.17 & 7209.76 \\ 010900 & 3062 & 2541 & 5160 & 2.42 & 1265.29 & 1050.00 & 2132.23 \\ 011003 & 3643 & 4537 & 4520 & 2.03 & 1794.58 & 2234.98 & 2226.60 \\ 011203 & 3612 & 3420 & 3008 & 0.84 & 4300.00 & 4071.43 & 3580.95 \\ 011204 & 6252 & 6194 & 6029 & 1.60 & 3907.50 & 3871.25 & 3768.13 \\ 011205 & 2391 & 2666 & 2697 & 0.91 & 2627.47 & 2929.67 & 2963.74 \\ 011206 & 2802 & 2798 & 2852 & 0.78 & 3592.31 & 3587.18 & 3656.41 \\ 011301 & 3529 & 3108 & 3041 & 1.12 & 3150.89 & 2775.00 & 2715.18 \\ 011302 & 7475 & 8262 & 8061 & 2.36 & 3167.37 & 3500.85 & 3415.68 \\ 011603 & 3995 & 3911 & 4107 & 1.25 & 3196.00 & 3128.80 & 3285.60 \\ 011605 & 6123 & 6043 & 6748 & 3.21 & 1907.48 & 1882.55 & 2102.18 \\ 011801 & 7808 & 11277 & 12387 & 2.23 & 3501.35 & 5056.95 & 5554.71 \\ 011802 & 6528 & 6734 & 6670 & 1.27 & 5140.16 & 5302.36 & 5251.97 \\ 011901 & 3971 & 4224 & 4746 & 0.82 & 4842.68 & 5151.22 & 5787.80\end{array}$




$\begin{array}{rrrrrrrr}011902 & 6544 & 6482 & 7183 & 1.36 & 4811.76 & 4766.18 & 5281.62 \\ 011903 & 6833 & 7625 & 7604 & 1.05 & 6507.62 & 7261.90 & 7241.90 \\ 012001 & 3031 & 2692 & 2511 & 2.84 & 1067.25 & 947.89 & 884.15 \\ 012002 & 3822 & 3633 & 3652 & 1.92 & 1990.63 & 1892.19 & 1902.08 \\ \text { SUM } & 392767 & 412436 & 432180 & 116.28 & 3377.77 & 3546.92 & 3716.72\end{array}$

Census data sources (All the tract number based on the criteria of tracts in 1990): 1990 census data :

(http://www.census.gov/geo/www/ezstate/FL.pdf)

2000 census data :

(http://www.census.gov/geo/www/cenpop/tract/tract_pop.txt)

2010 census data :

(http://www.census.gov/geo/www/2010census/centerpop2010/tract/

CenPop2010_Mean_TR12.txt) 


\section{A4. ISA fraction changes ( 94 census data by tract in the City of Tampa}

Florida from 1990-2010)

\begin{tabular}{|c|c|c|c|c|c|}
\hline Tract & $\%$ ISA-90 & $\%$ ISA-00 & $\%$ ISA-10 & $\%$ ISAC (90-00) & $\%$ ISAC (00-10) \\
\hline 000100 & 24.21 & 35.50 & 44.62 & 11.29 & 9.12 \\
\hline 000200 & 26.13 & 42.93 & 54.03 & 16.80 & 11.10 \\
\hline 000300 & 16.21 & 28.66 & 42.04 & 12.45 & 13.38 \\
\hline 000400 & 28.60 & 39.98 & 50.47 & 11.38 & 10.49 \\
\hline 000500 & 10.87 & 22.18 & 31.33 & 11.31 & 9.15 \\
\hline 000600 & 19.79 & 33.11 & 43.74 & 13.32 & 10.63 \\
\hline 000700 & 15.15 & 24.01 & 36.19 & 8.86 & 12.18 \\
\hline 000800 & 14.69 & 23.12 & 27.83 & 8.43 & 4.71 \\
\hline 000900 & 17.27 & 26.83 & 35.77 & 9.56 & 8.94 \\
\hline 001000 & 14.92 & 24.12 & 30.25 & 9.20 & 6.13 \\
\hline 001100 & 11.34 & 17.04 & 25.10 & 5.70 & 8.06 \\
\hline 001200 & 17.82 & 25.14 & 39.19 & 7.32 & 14.05 \\
\hline 001300 & 18.49 & 27.90 & 39.26 & 9.41 & 11.36 \\
\hline 001400 & 13.64 & 25.05 & 34.74 & 11.41 & 9.69 \\
\hline 001500 & 12.55 & 24.43 & 33.23 & 11.88 & 8.80 \\
\hline 001600 & 21.36 & 33.11 & 50.46 & 11.75 & 17.35 \\
\hline 001700 & 14.82 & 24.03 & 32.90 & 9.21 & 8.87 \\
\hline 001800 & 20.11 & 28.00 & 40.13 & 7.89 & 12.13 \\
\hline 001900 & 21.83 & 32.97 & 46.71 & 11.14 & 13.74 \\
\hline 002000 & 14.08 & 26.52 & 37.58 & 12.44 & 11.06 \\
\hline 002100 & 13.71 & 27.13 & 38.38 & 13.42 & 11.25 \\
\hline 002200 & 24.91 & 35.61 & 53.90 & 10.70 & 18.29 \\
\hline 002300 & 18.21 & 29.99 & 37.44 & 11.78 & 7.45 \\
\hline 002400 & 19.82 & 33.12 & 39.93 & 13.30 & 6.81 \\
\hline 002500 & 23.12 & 42.79 & 48.43 & 19.67 & 5.64 \\
\hline 002600 & 26.38 & 39.89 & 46.17 & 13.51 & 6.28 \\
\hline 002700 & 23.80 & 41.55 & 51.44 & 17.75 & 9.89 \\
\hline 002800 & 15.52 & 28.09 & 35.36 & 12.57 & 7.27 \\
\hline 002900 & 17.91 & 29.93 & 41.88 & 12.02 & 11.95 \\
\hline 003000 & 26.20 & 39.27 & 49.45 & 13.07 & 10.18 \\
\hline 003100 & 22.94 & 37.02 & 51.85 & 14.08 & 14.83 \\
\hline 003200 & 27.77 & 44.46 & 57.32 & 16.69 & 12.86 \\
\hline 003300 & 33.09 & 48.26 & 66.44 & 15.17 & 18.18 \\
\hline 003400 & 21.30 & 32.82 & 43.90 & 11.52 & 11.08 \\
\hline 003500 & 24.12 & 36.14 & 45.08 & 12.02 & 8.94 \\
\hline 003600 & 20.94 & 31.56 & 40.79 & 10.62 & 9.23 \\
\hline 003700 & 26.18 & 34.92 & 41.12 & 8.74 & 6.20 \\
\hline 003800 & 35.14 & 49.01 & 59.14 & 13.87 & 10.13 \\
\hline
\end{tabular}




\begin{tabular}{|c|c|c|c|c|c|}
\hline 003900 & 40.79 & 54.14 & 68.74 & 13.35 & 14.60 \\
\hline 004000 & 34.15 & 45.68 & 52.87 & 11.53 & 7.19 \\
\hline 004100 & 30.30 & 44.16 & 55.55 & 13.86 & 11.39 \\
\hline 004200 & 26.97 & 41.89 & 49.95 & 14.92 & 8.06 \\
\hline 004300 & 25.18 & 40.21 & 49.37 & 15.03 & 9.16 \\
\hline 004400 & 29.51 & 47.85 & 61.28 & 18.34 & 13.43 \\
\hline 004500 & 25.60 & 42.14 & 56.43 & 16.54 & 14.29 \\
\hline 004700 & 35.00 & 51.91 & 57.56 & 16.91 & 5.65 \\
\hline 004800 & 27.53 & 43.27 & 55.59 & 15.74 & 12.32 \\
\hline 004900 & 34.48 & 53.47 & 65.71 & 18.99 & 12.24 \\
\hline 005000 & 37.04 & 53.93 & 61.47 & 16.89 & 7.54 \\
\hline 005100 & 34.32 & 50.03 & 52.01 & 15.71 & 1.98 \\
\hline 005300 & 25.68 & 31.12 & 34.90 & 5.44 & 3.78 \\
\hline 005400 & 18.27 & 30.74 & 32.02 & 12.47 & 1.28 \\
\hline 005500 & 33.14 & 55.38 & 59.95 & 22.24 & 4.57 \\
\hline 005700 & 27.49 & 44.68 & 52.01 & 17.19 & 7.33 \\
\hline 005800 & 27.24 & 36.77 & 48.73 & 9.53 & 11.96 \\
\hline 006000 & 19.52 & 33.43 & 38.39 & 13.91 & 4.96 \\
\hline 006100 & 10.41 & 17.81 & 19.88 & 7.40 & 2.07 \\
\hline 006200 & 22.37 & 35.76 & 48.95 & 13.39 & 13.19 \\
\hline 006300 & 18.85 & 32.26 & 47.16 & 13.41 & 14.90 \\
\hline 006600 & 27.67 & 34.21 & 52.16 & 6.54 & 17.95 \\
\hline 006700 & 17.91 & 27.08 & 36.31 & 9.17 & 9.23 \\
\hline 006800 & 16.72 & 28.89 & 35.65 & 12.17 & 6.76 \\
\hline 006985 & 11.54 & 21.33 & 25.23 & 9.79 & 3.90 \\
\hline 007085 & 26.71 & 33.19 & 47.41 & 6.48 & 14.22 \\
\hline 010203 & 7.54 & 8.86 & 15.98 & 1.32 & 7.12 \\
\hline 010204 & 11.27 & 16.68 & 24.29 & 5.41 & 7.61 \\
\hline 010401 & 15.02 & 21.65 & 29.91 & 6.63 & 8.26 \\
\hline 010402 & 15.92 & 23.72 & 30.20 & 7.80 & 6.48 \\
\hline 010500 & 20.25 & 29.04 & 36.55 & 8.79 & 7.51 \\
\hline 010600 & 13.64 & 22.49 & 25.93 & 8.85 & 3.44 \\
\hline 010700 & 16.28 & 24.09 & 31.69 & 7.81 & 7.60 \\
\hline 010803 & 22.88 & 43.07 & 49.77 & 20.19 & 6.70 \\
\hline 010804 & 10.96 & 20.07 & 29.69 & 9.11 & 9.62 \\
\hline 010805 & 27.07 & 38.94 & 52.46 & 11.87 & 13.52 \\
\hline 010806 & 28.68 & 51.90 & 58.56 & 23.22 & 6.66 \\
\hline 010807 & 24.75 & 37.53 & 47.85 & 12.78 & 10.32 \\
\hline 010808 & 22.56 & 46.92 & 54.65 & 24.36 & 7.73 \\
\hline 010900 & 13.90 & 23.60 & 29.97 & 9.70 & 6.37 \\
\hline 011003 & 12.28 & 16.89 & 23.97 & 4.61 & 7.08 \\
\hline
\end{tabular}




$\begin{array}{lrrrrr}011203 & 12.43 & 19.69 & 22.92 & 7.26 & 3.23 \\ 011204 & 17.65 & 27.15 & 34.24 & 9.50 & 7.09 \\ 011205 & 12.21 & 22.15 & 28.06 & 9.94 & 5.91 \\ 011206 & 18.53 & 29.54 & 38.09 & 11.01 & 8.55 \\ 011301 & 15.45 & 28.14 & 29.95 & 12.69 & 1.81 \\ 011302 & 15.64 & 28.95 & 31.33 & 13.31 & 2.38 \\ 011603 & 14.76 & 28.16 & 33.16 & 13.40 & 5.00 \\ 011605 & 24.65 & 39.89 & 45.21 & 15.24 & 5.32 \\ 011801 & 19.13 & 32.97 & 36.98 & 13.84 & 4.01 \\ 011802 & 23.69 & 41.64 & 51.28 & 17.95 & 9.64 \\ 011901 & 21.18 & 33.51 & 36.74 & 12.33 & 3.23 \\ 011902 & 18.29 & 35.98 & 41.42 & 17.69 & 5.44 \\ 011903 & 18.39 & 33.82 & 41.95 & 15.43 & 8.13 \\ 012001 & 21.89 & 29.72 & 39.67 & 7.83 & 9.95 \\ 012002 & 17.26 & 25.69 & 33.47 & 8.43 & 7.78 \\ \text { SUM } & 15.57 & 23.87 & 30.11 & 8.30 & 6.24\end{array}$


A5. ISA fraction ( 94 census data by tract in the City of Tampa Florida from 1990-2010)

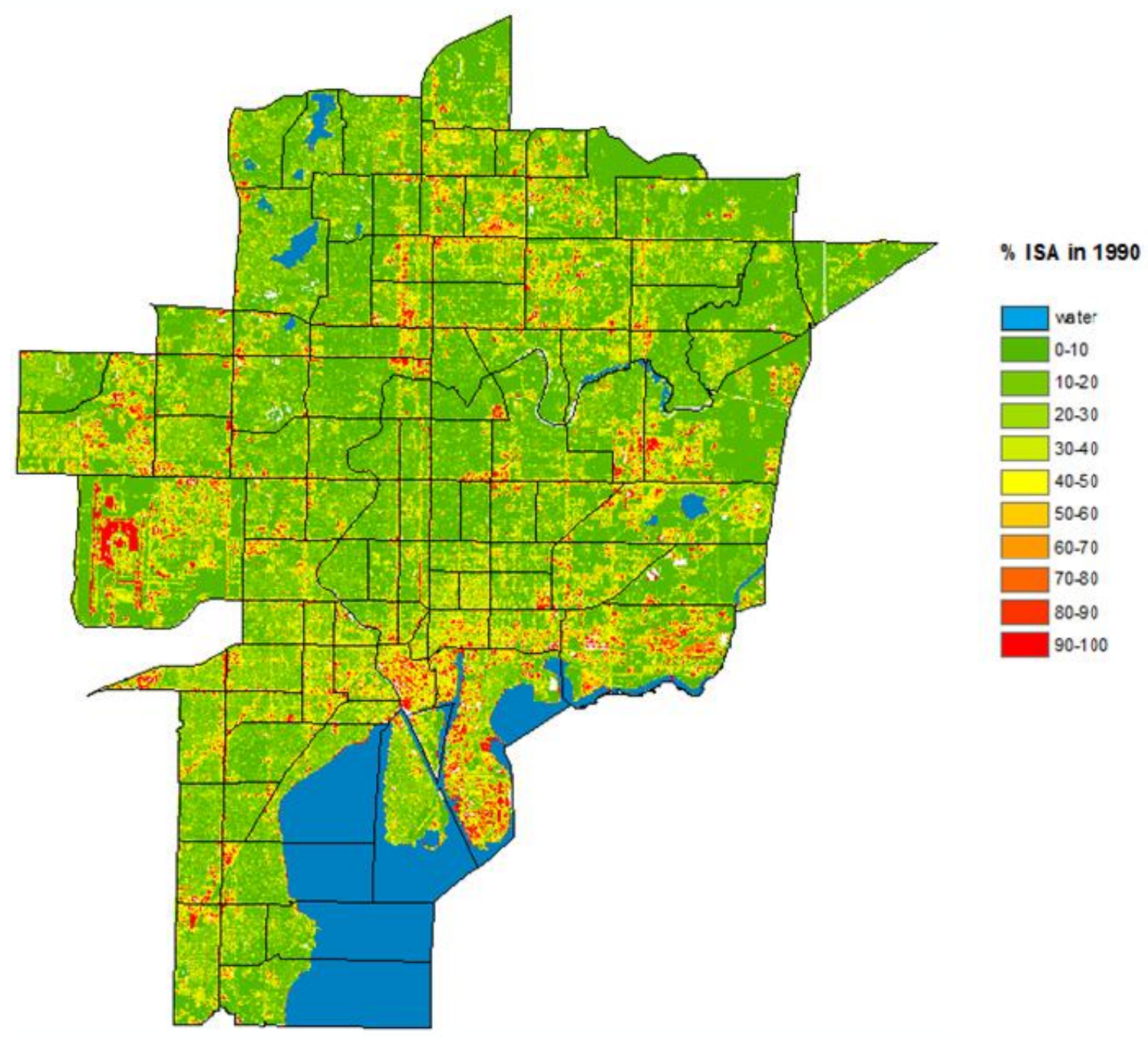

Figure A 1. \%ISA of the 94 tracts covered by the study area in the City of Tampa in 1990. 


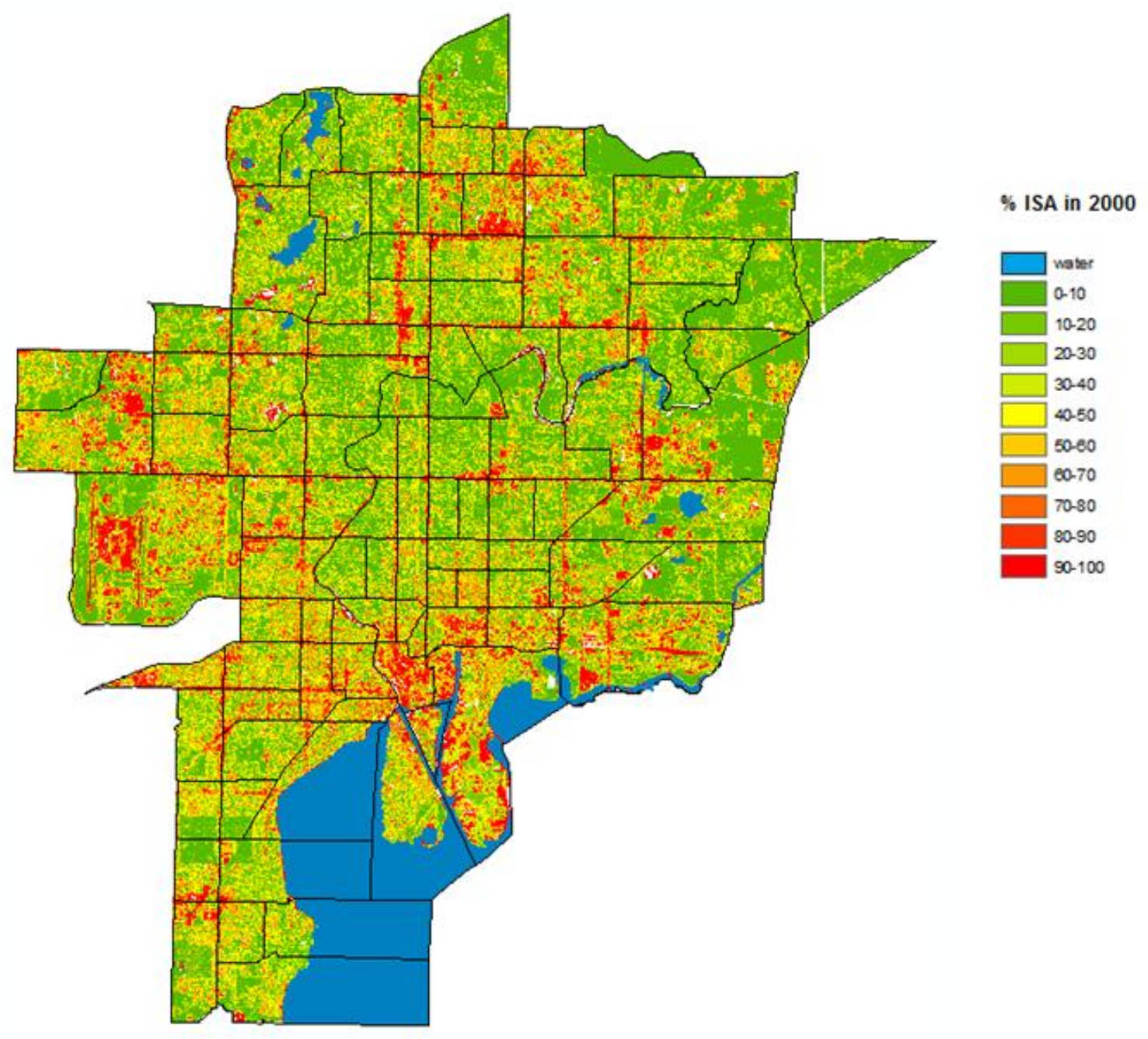

Figure A 2. \%ISA of the 94 tracts covered by the study area in the City of Tampa in 2000. 


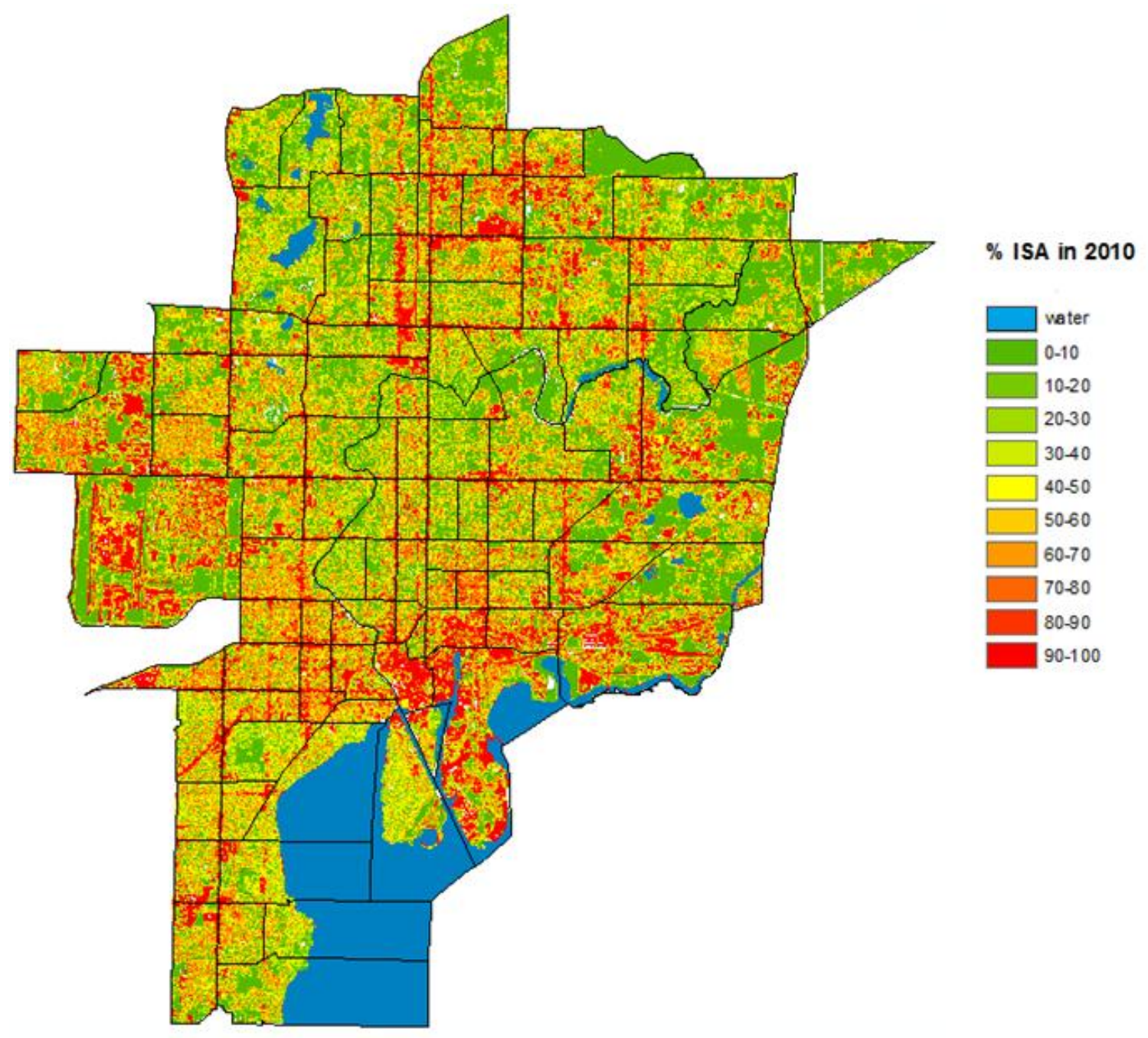

Figure A 3. \%ISA of the 94 tracts covered by the study area in the City of Tampa in 2010. 


\section{A6. Abbreviation}

DOQQ

FLAASH

ISA

LC

LSMA

LULC

MESMA

NSMA

PNMESMA

RMSE

SMA

Stdev

$\mathrm{TM}$

USGS
Digital Orthophoto Quarter Quads

Fast Line-of-Sight Atmospheric Analysis of

Spectral Hypercubes

Impervious Surface Area

Land Cover

Linear Spectral Mixture Analysis

Land Use and Land Cover

Multiple Endmember Spectral Mixture Analysis

Normalized Spectral Mixture Analysis

Pre-screened and Normalized Multiple Endmember

Spectral Mixture Analysis

Spectral Mixture Analysis

Standard Deviation

Thematic Mapper

United States Geological Survey 
A7. Location of three high percentage of impervious surface places in the study area

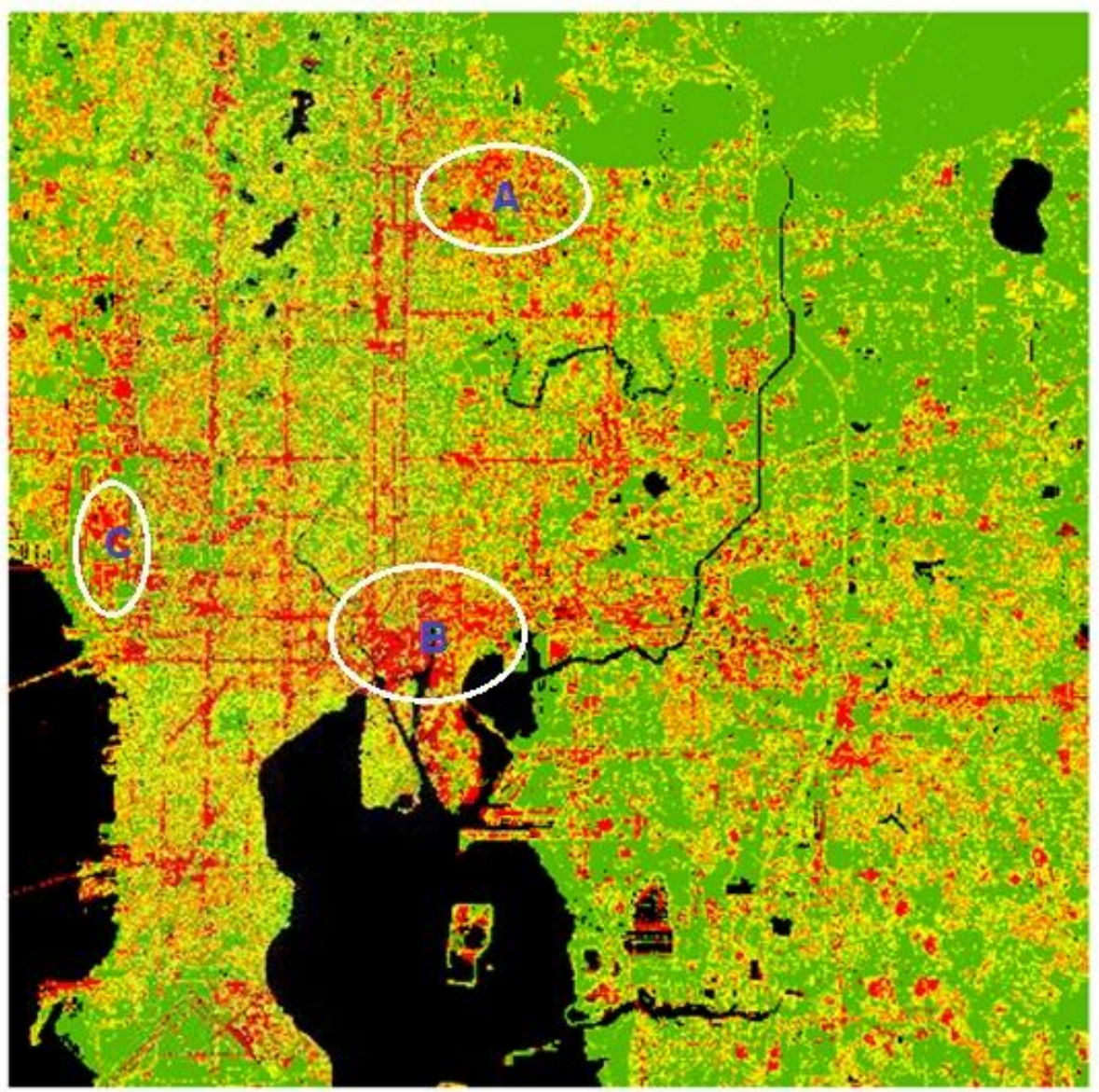

Figure A 4. Location of University Square (A), Downtown (B), and International Airport (C). 